\title{
TITLE:
}

\section{Influence of surrounding environment on subcritical crack growth in marble}

$\operatorname{AUTHOR}(\mathrm{S})$ :

Nara, Yoshitaka; Kashiwaya, Koki; Nishida, Yuki; li, Toshinori

\section{CITATION:}

Nara, Yoshitaka ... [et al]. Influence of surrounding environment on

subcritical crack growth in marble. Tectonophysics 2017, 706-707: 116128

ISSUE DATE:

2017-06-05

URL:

http://hdl.handle.net/2433/224815

\section{RIGHT:}

(c) 2017. This manuscript version is made available under the CC-BY-NC-ND 4.0 license

http://creativecommons.org/licenses/by-nc-nd/4.0/; The full-text file will be made open to the public on 5 June 2019 in accordance with publisher's 'Terms and Conditions for Self-Archiving'; この論文は出版社版でありません。引用の際に は出版社版をご確認ご利用ください。; This is not the published version. Please cite only the published version. 


\section{Highlights}

- Influence of surrounding environment on the crack velocity in marble was studied.

- Crack velocity in air increased at higher temperature and/or humidity.

- Subcritical crack growth in marble occurs in grain boundary.

- Region II behavior of subcritical crack growth was observed in marble with low porosity in air. 
1 Influence of surrounding environment on subcritical crack growth in marble

2

3 Yoshitaka Nara $^{1^{*}}$, Koki Kashiwaya ${ }^{1}$, Yuki Nishida ${ }^{1}$, Toshinori Ii $^{2}$

4

$5 \quad{ }^{1}$ Graduate School of Engineering, Kyoto University, Kyoto-Daigaku-Katsura,

$6 \quad$ Nishikyo-ku, Kyoto 615-8540, Japan.

7

$8 \quad{ }^{2}$ Department of Civil Engineering, Tottori University, 4-101 Koyama-Minami, Tottori 9 680-8552, Japan.

10

Address: Department of Civil and Earth Resources Engineering, Graduate School of Engineering, Kyoto University, Kyoto Daigaku-Katsura, Nishikyo-ku, Kyoto 615-8540, Japan. 


\section{Abstract}

Understanding subcritical crack growth in rock is essential for determining appropriate measures to ensure the long-term integrity of rock masses surrounding structures and for construction from rock material. In this study, subcritical crack growth in marble was investigated experimentally, focusing on the influence of the surrounding environment on the relationship between the crack velocity and stress intensity factor.

The crack velocity increased with increasing temperature and/or relative humidity. In all cases, the crack velocity increased with increasing stress intensity factor. However, for Carrara marble $(\mathrm{CM})$ in air, we observed a region in which the crack velocity still increased with temperature, but the increase in the crack velocity with increasing stress intensity factor was not significant. This is similar to Region II of subcritical crack growth observed in glass in air. Region II in glass is controlled by mass transport to the crack tip. In the case of rock, the transport of water to the crack tip is important. In general, Region II is not observed for subcritical crack growth in rock materials, because rocks contain water. Because the porosity of CM is very low, the amount of water contained in the marble is also very small. Therefore, our results imply that we observed Region II in CM.

Because the crack velocity increased in both water and air with increasing temperature and humidity, we concluded that dry conditions at low temperature are desirable for the long-term integrity of a carbonate rock mass. Additionally, mass transport to the crack tip is an important process for subcritical crack growth in rock with low porosity. 
41 Keywords: subcritical crack growth, marble, relative humidity, temperature, water,

porosity 


\section{Introduction}

The long-term stability of rock masses surrounding structures, such as underground repositories of radioactive waste, caverns to store liquid natural gas and liquid petroleum gas, and underground power plants, is crucial. In addition, it is important to ensure the stability of rock slopes in open-pit mines for safety. Various studies have examined time-dependent fracturing in rock to determine the time-dependency of rock stability (Atkinson, 1984; Swanson, 1984; Meredith and Atkinson, 1985; Sano, 1988; Nara and Kaneko, 2005, 2006). In particular, studies of time-dependent fracturing in rock have been conducted to examine the natural hazards related to failure in rock, such as the increase in seismicity seen prior to earthquake rupture, fault formation, growth, sliding, and volcanic eruption (Kilburn and Voight, 1998; Ciccotti et al., 2000a, 2001; Heap et al., 2011; Brantut et al., 2013, 2014a; Violay et al., 2013). Additionally, several studies have evaluated the long-term strength and time-to-failure based on the measurement of time-dependent fracturing (Schmidtke and Lajtai, 1986; Jeong et al., 2007; Nara et al., 2013; Nara, 2015).

Although classical fracture mechanics postulates that crack propagation occurs when the value of the stress intensity factor reaches that of the fracture toughness, the crack can propagate even at a stress intensity factor lower than the fracture toughness. This is known as subcritical crack growth, which is considered to be one of the main mechanisms responsible for the time-dependent behavior of rock in the brittle regime (Atkinson, 1984). Most studies of subcritical crack growth in rock have been conducted on silicate rocks, such as igneous rocks (Sano and Kudo, 1992; Nara et al., 2009, 2010), sandstones (Holder et al., 2001; Ponson, 2009; Nara et al., 2011, 2014), and novaculite (Atkinson, 1980). 
68 Only a few studies have examined subcritical crack growth in carbonate minerals and 69 rocks. Henry et al. (1977) reported that for micrite the crack velocity in water is higher than that in air. Røyne et al. (2011) suggested that some plastic processes might affect subcritical crack growth in calcite. Rostom et al. (2012) reported that the fluid salinity influences the crack velocity in calcite in a $\mathrm{NaCl}$ solution; specifically, they showed that the stress intensity factor decreased when the concentration of $\mathrm{NaCl}$ is $<0.8 \mathrm{~mol} / \mathrm{L}$. Bergsaker et al. (2016) examined the impact of the fluid composition on subcritical crack growth in calcite single crystal, and concluded that a $\mathrm{pH}$ in the range of $5-7.5$ has a negligible influences. However, subcritical crack growth in carbonate rocks under different temperature and humidity conditions is poorly understood.

In this study, we investigated subcritical crack growth in marble experimentally in both air and water. We focussed on examining the influence of the surrounding environment on the relationship between the crack velocity and stress intensity factor by conducting all measurements under controlled temperature and relative humidity. 


\section{Rock samples}

83

We used examined two types of marble: Carrara marble (CM) quarried in Italy, and a marble quarried in Skopje in Macedonia (MM).

Figure 1 shows photomicrographs of CM and MM observed with thin sections of $0.03 \mathrm{~mm}$ thickness. As shown in the photomicrograph, the grain size is around $0.2 \mathrm{~mm}$ and $0.3 \mathrm{~mm}$ for $\mathrm{CM}$, and MM, respectively. Figure 2 shows the results of X-ray diffraction analysis of the marbles. Remarkable peaks can be seen for calcite $\left(\mathrm{CaCO}_{3}\right)$ in $\mathrm{CM}$ and dolomite $\left(\mathrm{CaMg}\left(\mathrm{CO}_{3}\right)_{2}\right)$ in MM. Small peaks of illite are also seen in MM.

For $\mathrm{CM}$, the porosity determined by water saturation was $0.19 \%$. The P-wave velocities in three orthogonal directions were $6.04,5.98$, and $5.90 \mathrm{~km} / \mathrm{s}$ under dry conditions. $\mathrm{CM}$ is considered to be isotropic. The Brazilian tensile strength was 6.9 MPa.

The uniaxial compressive strength, Young's modulus, and Poisson's ratio were 77.8 $\mathrm{MPa}, 51.0 \mathrm{GPa}$, and 0.32 , respectively, which were determined from uniaxial compression tests with the loading rate at $10^{-5} \mathrm{strain} / \mathrm{s}$.

For MM, the porosity measured by water saturation was $0.6 \%$. The $\mathrm{P}$-wave velocities in three orthogonal directions were $4.15,4.06$, and $3.74 \mathrm{~km} / \mathrm{s}$. We named these three orthogonal directions Axes 1, 2, and 3 in order of decreasing P-wave velocity. Furthermore, we named the planes normal to these axes Planes 1, 2, and 3, respectively. Slight anisotropy was observed in the P-wave velocity. Since investigation of anisotropic properties was beyond the scope of this study, we treated the marble sample as an isotropic material. The Brazilian tensile strength was $6.2 \mathrm{MPa}$ when the fracturing was parallel to Plane 3. The uniaxial compressive strength, Young's modulus, and Poisson's ratio were $190 \mathrm{MPa}, 80.2 \mathrm{GPa}$, and 0.46, respectively, which were determined from uniaxial compression tests with the loading rate at $10^{-5} \mathrm{strain} / \mathrm{s}$. 


\section{Methodology}

108

3.1 Outline of double torsion method

In this study, the double torsion (DT) method was used. The DT method is a fracture mechanics testing method used commonly to study subcritical crack growth. The loading configuration of the DT method is shown in Figure 3. Three different types of test can be performed using the DT arrangement, each using different loading conditions: the constant load method (Kies and Clark, 1969), the constant displacement rate method (Evans, 1972), and the load relaxation (RLX) method (Evans, 1972; Williams and Evans, 1973). Using the RLX method, we can obtain a large amount of data on the relationship between the stress intensity factor, $K_{\mathrm{I}}$, and the crack velocity, $\mathrm{d} a / \mathrm{d} t$ (the $K_{\mathrm{I}}-\mathrm{d} a / \mathrm{d} t$ relation), which, in general, ranges from $10^{-2}$ to $10^{-9} \mathrm{~m} / \mathrm{s}$, using only a single experimental run. Therefore, we used the RLX method to determine the

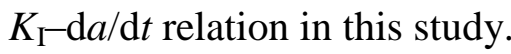

122 In the RLX method, the displacement of the loading points must be kept constant 123 during the experiment while the temporally decreasing load (load relaxation) due to the 124 crack growth is measured. The stress intensity factor and the crack velocity are 125 expressed as follows (Williams and Evans, 1973):

$126 \quad K_{\mathrm{I}}=P w_{\mathrm{m}} \sqrt{\frac{3(1+v)}{W d^{3} d_{\mathrm{n}}}}$

$$
\frac{\mathrm{d} a}{\mathrm{~d} t}=-\varphi_{\mathrm{c}} \times \frac{W d^{3} G}{3 w_{\mathrm{m}}{ }^{2}} \frac{S_{\mathrm{i}} P_{\mathrm{i}}}{P^{2}} \frac{\mathrm{d} P}{\mathrm{~d} t}
$$
where $P$ is the applied load, $w_{\mathrm{m}}$ is the moment arm (18 $\mathrm{mm}$ in this study), $v$ is Poisson's ratio, $W$ is the width of the specimen, $d$ is the thickness of the specimen, $d_{\mathrm{n}}$ is the 
reduced thickness of the specimen, $P_{\mathrm{i}}$ is the initial value of the applied load, $S_{\mathrm{i}}$ is the compliance of the specimen at the initial crack length, $\mathrm{d} P / \mathrm{d} t$ is the load relaxation rate, and $G$ is the shear modulus. $\varphi_{\mathrm{c}}$ is a constant that is dependent on the shape of the crack front. We set the value of $\varphi_{\mathrm{c}}$ as 0.4 from observation of the crack front following Sano (1988). Evans (1972, 1973), Williams and Evans (1973), and Meredith (1983)

concluded that the Mode-I stress intensity factor is evaluated from the DT test based on their experimental results using polycrystalline materials including rocks. As shown in Eq. (1), the stress intensity factor is independent of the crack length in the DT test. Because it is impossible to detect the crack tip in rock specimens, various researchers have employed DT tests to investigate subcritical crack growth (Atkinson, 1984; Atkinson and Meredith, 1987). For similar reasons, we employed the DT test in this study.

The size of the DT specimen must satisfy the following condition (Atkinson, 1979; Pletka et al., 1979):

$12 d \leq W \leq L / 2$

where $L$ is the length of the specimen. Ciccotti et al. (2000b) performed a finite element analysis to demonstrate the option of using specimens thicker than those recommended by Atkinson (1979). Previous studies (Shyam and Lara-Curzio, 2006; Madjoubi et al., 2007) recommended that the length of the specimen should be greater than twice the width.

Taking the above studies into consideration, we set the width $W$, length $L$, and thickness $d$ to be 45, 140, and $3 \mathrm{~mm}$, respectively. The width and depth of the guide groove were both $1 \mathrm{~mm}$.

\subsection{Experimental apparatus and conditions}


156 The experimental apparatus used in this study was the same as that used by Nara and

157 Kaneko $(2005,2006)$ in air, and Nara et al. (2009) in water. The apparatus was set in a room where the temperature and relative humidity could be controlled over ranges of 278-353 K, and 40-90\%, respectively.

160 The subcritical crack growth in air was measured under different temperatures at

161 fixed relative humidity and vice-versa to investigate the influences of temperature and 162 relative humidity separately. We performed experiments under low temperature (293 K, $16347-50 \%)$, intermediate temperature (323-324 K, 50\%), and high temperature (351 K, $50 \%$ ) conditions to investigate the influence of temperature; and under low humidity (323 K, 5-7\%), intermediate humidity (323-324 K, 50\%), and high humidity (323-324 K, 89-92\%) conditions to investigate the influence of relative humidity. We could only control the temperature of the air in the apparatus. Therefore, the measurements in water were made at slightly different temperatures than those in air. The subcritical crack growth was measured at low temperature (290-291 K), and at intermediate temperature $(313-319 \mathrm{~K})$ in water.

3.3 Experimental procedure

Initially, precracking was performed. We applied a displacement of $4 \mu \mathrm{m}$ at the loading point, and then maintained the displacement at this distance to observe the surface of the specimen, with a digital microscope set under the specimen to determine the crack length. We continued these operations until the crack length reached $25 \mathrm{~mm}$, which is the minimum length required so that the stress intensity factor is independent of the crack length for a DT specimen (Trantina, 1977). 
180 After precracking, the specimen was exposed to the experimental environment at a

181 constant temperature and relative humidity for more than 20 hours. Then, measurements

182 following the RLX method were made.

183 For rock, hysteresis in the $K_{\mathrm{I}}-\mathrm{d} a / \mathrm{d} t$ relation has been reported during measurements

184 using the RLX method several times with a single specimen. Sano (1988) suggested that

185 the source of this hysteresis was friction and locking on the crack surfaces, because no

186 hysteresis was observed on soda-lime glass. When measurements using the RLX

187 method are performed, it is essential to minimise the influence of friction and locking.

188 Hence, it is important to open the crack as much as possible, not to repeat opening and

189 closing of the crack, and to perform only a single experimental run with one specimen

190 to avoid the significant influence of friction and locking.

191 Based on the above considerations, after applying a preload of 14-15 N (27-30\% of

192 the maximum load) to avoid hitting the specimen, we applied displacements of 0.300

$193 \mathrm{~mm}$ and $0.332 \mathrm{~mm}$ at the loading points of CM and MM specimens, respectively,

194 because the DT specimens completely broke if we increased the displacement.

195 For the measurements in water, we used the distilled water in which the marble

196 samples had been stored for more than 1 month. The $\mathrm{pH}$ of the water was measured just

197 after measuring the subcritical crack growth. Figure 4 shows a photo of the

198 experimental apparatus and a $\mathrm{pH}$ measurement. 
199

200

201

202

203

204

205

206

$207 \quad \frac{\mathrm{d} a}{\mathrm{~d} t}=A K_{\mathrm{I}}^{n}$

$208 \quad \frac{\mathrm{d} a}{\mathrm{~d} t}=v_{0} \exp \left(\frac{-E^{\dagger}+b K_{\mathrm{I}}}{R T}\right)$

209

210

211

212

213

214

$$
\left.\begin{array}{l}
\ln \left(\frac{\mathrm{d} a}{\mathrm{~d} t}\right)=\alpha+\frac{b}{R T} K_{\mathrm{I}} \\
\because \alpha=\ln v_{0}-\frac{E^{\ddagger}}{R T}
\end{array}\right\}
$$

The $K_{\mathrm{I}}-\mathrm{d} a / \mathrm{d} t$ relation for $\mathrm{CM}$ and $\mathrm{MM}$ at constant temperature in air with different relative humidities, and in water, are shown in Figure 6. The crack velocity increased with increasing relative humidity in air. In addition, the crack velocity in water was significantly higher than that in air. For CM in air, the slope was smaller when the crack velocity was $>10^{-4} \mathrm{~m} / \mathrm{s}$. 
for $\mathrm{CM}$ and $\mathrm{MM}$ in air and water under different relative humidities, respectively. The stress intensity factor for $\mathrm{d} a / \mathrm{d} t=10^{-5}[\mathrm{~m} / \mathrm{s}], K_{\mathrm{I}}\left(10^{-5}\right)$, is listed to quantitatively compare the values because the range in the crack velocity is $10^{-2}-10^{-8} \mathrm{~m} / \mathrm{s}$. Table 1 lists the values of the crack velocity at $K_{\mathrm{I}}=1.0\left[\mathrm{MN} / \mathrm{m}^{3 / 2}\right], \mathrm{d} a / \mathrm{d} t(1.0)$. In the case of CM in air, the crack velocity values $<10^{-4} \mathrm{~m} / \mathrm{s}$ were analyzed. The values of the average and standard deviation were estimated from several experimental results performed under the same conditions. The crack velocity in air increases as the relative humidity increases. Additionally, the crack velocity in water is significantly higher than that in air. Figure 7 shows the $K_{\mathrm{I}}-\mathrm{d} a / \mathrm{d} t$ relation at different temperatures in air at a constant relative humidity, and in water for $\mathrm{CM}$ and $\mathrm{MM}$. The crack velocity increases with increasing temperature. In Figure $7 \mathrm{a}$, the slope is small when the crack velocity is $>10^{-4}$ $\mathrm{m} / \mathrm{s}$ for CM in air. This decrease in the slope is remarkable, which implies Region II subcritical crack growth (Lawn, 1974, 1993).

Tables 3 and 4 show the subcritical crack growth measurements for CM and MM, respectively, at different temperatures, in air under a constant relative humidity and in water. In the case of $\mathrm{CM}$ in air, the values of crack velocity $<10^{-4} \mathrm{~m} / \mathrm{s}$ were analyzed. As the temperature increases, the crack velocity increases, while the stress intensity factor decreases in both air and water. The crack velocity in water is higher than that in air. 


\section{Discussion}

Water significantly affects subcritical crack growth in marble. Specifically, the increase in the crack velocity in water is remarkable.

If the fracture toughness of marble is obtained, we can verify the range of the stress intensity factor where subcritical crack growth occurs. Therefore, determining fracture toughness is important. Several researchers have measured the fracture toughness using DT tests (Atkinson, 1979; Meredith, 1983; Meredith and Atkinson, 1985; Nara, 2015; Nara et al., 2012). Since fracture toughness depends on the environmental conditions such as temperature (Meredith and Atkinson, 1985; Funatsu et al., 2004, 2014), relative humidity (Nara et al., 2012), water vapor pressure (Kataoka et al., 2015), and water (Vavro and Souček, 2013), it is necessary to conduct fracture toughness measurements under controlled environmental conditions. Consequently, we measured the fracture toughness of marble under controlled temperatures and relative humidities $\#$ using the constant displacement rate method of DT test (Evans, 1972) with the same methodology as Nara et al. (2012) (see Appendix).

Table 5 summarizes the results of the fracture toughness measurements in the marble samples in air while controlling the temperature and relative humidity. For MM, the fracture toughness was measured in air at different temperatures with the same relative humidity. The fracture toughness of MM decreases as the temperature increases. This tendency agrees well with that for the Mode-I fracture toughness of Kimachi sandstone reported by Funatsu et al. (2004, 2014).

Table 5 also summarizes the results of the fracture toughness measurements for CM in air $(293 \mathrm{~K}, 47 \%)$. The results of $\mathrm{CM}$ and $\mathrm{MM}$ were used to check the range of the 
relationships between the crack velocity and the stress intensity factor normalized by the fracture toughness determined under the same environmental conditions. The subcritical crack growth of marble occurs in the same range as the normalized stress intensity factor, which is higher than $74 \%$ of the fracture toughness in this study. If the values of the subcritical crack growth index $n$ (in Eq. (4)) and constant $b$ (in Eq. (5)) increase, the range of the stress intensity factor causing subcritical crack growth decreases. This can contribute to the long-term stability of rock (Nara et al., 2013).

It is important to compare the results in this study to previous studies. Henry et al. (1977) showed that the crack velocity in micrite in water is higher than that in air, and the slope (the value of subcritical crack growth index) in water is lower than that in air. These tendencies agree well with the results in this study. On the other hand, according to the result of calcite crystal by Bergsaker et al. (2016), the difference between the crack velocity in distilled water and that in air is unclear. It is considered that the extent of the influence of water on subcritical crack growth in rock completely differs from a single crystal. Røyne et al. (2011) showed the results of subcritical crack growth measurement on calcite single crystals. They reported that the variation in the crack velocity at a given energy release rate might be caused by the plastic process or other unclarified process.

Figure 9 depicts the relationships between the crack velocity and the stress intensity factor for CM, MM, and calcite crystal (Røyne et al., 2011; Rostom et al., 2012). Since the measured values of the stress intensity factor differ significantly between the marbles in this study and the calcite crystals (Røyne et al., 2011; Rostom et al., 2012), the stress intensity factors in Figure 9 are normalized by the fracture toughness. For CM and MM, the values obtained in air at the same temperature are used (see Table 5). The fracture toughness of the calcite crystal is $0.22 \mathrm{MN} / \mathrm{m}^{3 / 2}$ (Chen et al., 2001; Shushakova 
et al., 2013). The shape of the relationship for the calcite crystal is nonlinear, although the shape for marbles is linear. The nonlinearity for the calcite crystal can be recognized in different environmental conditions (Røyne et al., 2011; Rostom et al., 2012;

Bergsaker et al., 2016). It is considered that the mechanism controlling subcritical crack growth in marble differs from that in calcite crystal. To understand why the mechanism controlling subcritical crack growth differs, the crack path must be observed.

Figure 10 shows images of the crack paths in CM (Figure 10a) and MM (Figure 10b) from thin sections $(0.03 \mathrm{~mm}$ thickness $)$ observed using an optical microscope under an open nicol, because this allowed the most clear crack path to be observed. On the other hand, the crack path could not be observed clearly under crossed nicols. To prepare a thin section, first an epoxy resin was permeated into the cracks. Then thin sections were prepared to observe the tension plane (the lower plane in Figure 3). In Figure 10, green, which corresponds to the epoxy resin, indicates the crack path. The crack path is mainly inter-granular, and trans-granular crack paths are quite rare. Sano (1981) suggested that microcracking occurs ahead of the crack tip in DT specimens of granite using the source location of the acoustic emission. Swanson (1984) suggested that the fracture process zone is generated ahead of the crack tip in DT specimen of rock. Nasseri et al. (2007) suggested that the fracture process zone was generates ahead of the crack tip and the crack grows by connecting smaller microcracks in the fracture process zone in granite. the inter-granular crack path is dominant for marble, microcracking in the fracture process zone occurs at the boundary of mineral grains mainly. Thus, the crack growth in the grain boundary is more important in marble than the crack growth within a mineral grain. In particular, it is suggested that fracturing in cement materials at a grain boundary is important for subcritical crack growth in marble. 
The crack path in marble is not perfectly planer (Figure 10). Previous studies did not observe planer crack paths for subcritical crack growth in rocks (Meredith and Atkinson, 1983; Swanson, 1985, 1987; Kudo et al., 1992; Nara and Kaneko, 2005; Nara et al., 2006, 2011). In this study, a rectangular guide groove is put on the specimen (Figure 3), generating a zigzag path. Nara and Kaneko (2005) tried to constrain the crack path to a straight line by preparing a semi-circular guide groove and a tri-angular guide groove on the DT specimen; they demonstrated that straight crack paths are not generated.

Consequently, the larger scattering is obtained due to the crack propagation away from the bottom of the semi-circular and triangular grooves, where the crack thickness is not constant. Considering this result, the rectangular guide groove has been used to measure subcritical crack growth (e.g., Nara and Kaneko, 2006; Nara et al., 2011, 2013) and fracture toughness (e.g., Nara et al., 2012).

The results in this study are also compared to the results in a previous study of subcritical crack growth in igneous rocks shown in Nara et al. (2013). In igneous rocks, the crack velocity in distilled water was higher than that in air at 50\% relative humidity by two to four orders of magnitude (Nara et al., 2013). The increase in the crack velocity in marble was greater than that recorded in igneous rock. As shown in Figure 2, MM contained illite. Francisca et al. (2005) reported that the strength of sediment containing illite decreased with increasing water content. Nara et al. (2011) showed that the crack velocity increased in rock containing illite with increasing water content. The results of these two studies agreed with those of this study. Thus, the presence of clay in rock increases the crack velocity in water.

337 Temperature affected the increase in the crack velocity in marble. Weakening processes, i.e. stress corrosion, can occur at the crack tip under tension (Anderson and 
340 siloxane bonds via chemical reaction with water occurs at the crack tip under tension

341 (Michalske and Freiman, 1982). However, alternative mechanisms should also be considered for carbonate rocks.

Additionally, other chemical reactions between a carbonate mineral and water should be considered. Various researchers have studied the dissolution kinetics of calcite (e.g., Garrels and Christ, 1965; Sjöberg and Rickard, 1984; MacInnis and Brantley, 1992; Liang et al., 1996; Shiraki et al., 2000). The solubility of many carbonate minerals in water decreases as the temperature increases (Garrels and Christ, 1965). This property may suppress subcritical crack growth in carbonate materials. However, Nara et al. (2010) suggested that the electric double layer formed around the crack tip affects the acceleration of subcritical crack growth. Since the aperture of the crack close to the crack tip is very small, it is possible that the water vapor turns to liquid water by capillary condensation in this zone. Consequently, the crack path close to the crack tip is immersed in liquid water (Thomson, 1871; Nara et al., 2010; Nakao et al., 2016). In this case, an electric double layer is formed in the condensed water around the crack tip and a repulsive force acts between the crack planes. The electric double layer increases as the temperature increases (Shaw, 1980), causing the repulsive force in the crack tip to increase, which can decrease the activation energy of subcritical crack growth. This effect can reduce the stress intensity factor applied at the crack tip at a given crack velocity.

Variations in the slope of the $K_{\mathrm{I}}-\mathrm{d} a / \mathrm{d} t$ relation for $\mathrm{CM}$ in air were observed. A similar trend has been observed in soda-lime glass (Wiederhorn, 1967), and in aluminia (Evans, 1972) in air. Subcritical crack growth is divided into three key regions based on the mechanisms that control the crack velocity. In Region I, the crack velocity is controlled by the rate of stress corrosion. In Region II, the crack velocity is controlled by the rate 
of transport of the reactive agent to the crack tip (Lawn, 1974, 1993). In Region III, the crack propagation is insensitive to the chemical environment and occurs mechanically (Wiederhorn et al., 1974). This is the classic tri-modal behaviour of the $K_{\mathrm{I}}$ - $\mathrm{d} a / \mathrm{d} t$ relation for subcritical crack growth. Figure 11 shows schematic illustrations of the tri-modal behaviour of the $K_{\mathrm{I}}-\mathrm{d} a / \mathrm{d} t$ relation (Figure 11a) and that obtained for silica glass (Figure 11b). The change in the slope can be seen clearly for glass in air.

$$
\text { For } \mathrm{CM} \text { in air, the region with a low slope can be seen clearly. This is likely to }
$$
represent Region II of subcritical crack growth, in which the mass-transport rate of the reactive agent (in this case, water) controls the crack velocity. Since water is included within the rock materials, Region II is not usually observed in rock in air. According to Nakao et al. (2016), rock materials contain water in cracks and pores of tiny aperture because of the capillary condensation of water vapour. In the case of $\mathrm{CM}$, the porosity is very low $(0.19 \%)$, and the water content is also very low, so that the transport rate of the water to the crack tip largely depends on the surrounding environmental conditions, similar to glass and alumina. For this reason, we were able to observe the region in which the transport of the reactive agent (water) controlled the crack velocity for subcritical crack growth in $\mathrm{CM}$ in air. In contrast, the porosity of $\mathrm{MM}$ is $0.6 \%$, which is higher than that of CM, and Region II crack growth was not observed, even in air.

The subcritical crack growth index $n$ in water was lower than that in air for both types of marble. This tendency was similar to that previously observed in igneous rocks (Nara et al., 2013). Lower subcritical crack growth index results in lower long-term strength and shorter time-to-failure (Nara et al., 2013). This implies that long-term integrity will be realized under dry condition if structures are constructed in marble rock masses. The results of this study provide insight on time-dependent fracturing under tension. Therefore, data under confining pressures is necessary to consider the long-term 
390 stability in a rock mass in the underground. According to Brantut et al. (2014b),

391 pressure solution can occur in calcite under compression. In addition, data under higher 392 temperature is required. De Bresser et al. (2005) reported that the compressive strength

393 of Carrara marble at a confining pressure of $300 \mathrm{MPa}$ decreases as the temperature

394 increases up to $1000{ }^{\circ} \mathrm{C}$. Even in a compressive stress field such as underground, tensile

395 stress can occur locally. Thus, the information and knowledge under tension as well as

396 those under compression are important to ensure the long-term stability of rock masses. 


\section{Conclusion}

398

399 Subcritical crack growth in marble was investigated experimentally in both air and

400 water. Specifically, the influence of the surrounding environment on the relationship

401 between the crack velocity and the stress intensity factor was investigated by conducting

402 all measurements under controlled temperature and relative humidity.

403 The crack velocity in water was significantly higher than that in air. The crack

404 velocity increased with increasing relative humidity in air, and with increasing

405 temperature in both air and water. For CM in air, Region II crack growth was observed, 406 which was due to the low porosity of CM.

407 The increasing crack velocity with increasing temperature and humidity implies that 408 dry conditions at low temperature are desirable for the long-term integrity of carbonate rock masses. Additionally, mass transport to the crack tip represents a key process for subcritical crack growth in rock with low porosity. 
Appendix - Fracture toughness measurement using double torsion test

413

414

415

416

The constant displacement rate method of the DT test (DT-CDR test) was used for the measurement of the fracture toughness in this study. In the DT-CDR test, the displacement rate of the loading points has to be kept constant during the experiment. When this method is used for the fracture toughness measurement, the displacement rate of the loading points should be large (Shyam and Lara-Curzio, 2006); this is especially important for applying this particular method to the calculation of fracture toughness. Selçuk and Atkinson (2000) reported an influence of measured stress intensity factor with loading rate when employing the DT-CDR method, with the use of a high displacement rates (above approximately $0.07 \mathrm{~mm} / \mathrm{s}$ ) mitigating this effect.

In the DT-CDR test as a fracture toughness measurement, the maximum value of applied load at failure is used to calculate fracture toughness via the following equation:

$$
K_{\mathrm{Ic}}=P_{\max } w_{\mathrm{m}} \sqrt{\frac{3(1+v)}{W d^{3} d_{\mathrm{n}}}}
$$

where $K_{\mathrm{Ic}}$ is Mode-I fracture toughness, and $P_{\max }$ is the maximum value of the applied load.

Atkinson (1979), Meredith (1983) and Meredith and Atkinson (1985) applied the DT-CDR method using displacement rates of approximately $20 \mathrm{~mm} / \mathrm{min}$ (around 0.33 mm/s) (Atkinson, 1979; Meredith, 1983) and $10 \mathrm{~mm} / \mathrm{min}$ (around $0.17 \mathrm{~mm} / \mathrm{s}$ ) (Meredith, 1983; Meredith and Atkinson, 1985), respectively. These displacement rates are higher than that mentioned by Selçuk and Atkinson (2000). Meredith (1983) reported that the fracture toughness values obtained by DT-CDR method agreed well with those obtained by the short-rod method which is the standard method for Mode-I fracture toughness measurement of rock (International Society for Rock Mechanics, 1988). Based on these 
considerations, DT-CDR test in this study was performed using by applying a load at a displacement rate of $0.23 \mathrm{~mm} / \mathrm{s}$, which is the maximum rate of our apparatus and higher than the rate suggested by Selçuk and Atkinson (2000). pre-cracked in order to introduce a small starting crack as described in Section 3.3. Then the apparatus and specimen were exposed to the environmental condition of interest with the same temperature and relative humidity for approximately 20 hours. Following this period, a fracture toughness measurement with DT-CDR method was performed using by applying a load at a displacement rate of $0.23 \mathrm{~mm} / \mathrm{s}$, after applying a small amount of pre-load around $10 \mathrm{~N}$.

446 A photo of the apparatus used in this study is shown in Figure A-1. This apparatus consists of a speed-control (stepping) motor that drives the loading axis moving perpendicular to the DT specimen. This apparatus is housed in a temperature and humidity controlled room.

In Figure A-2, a photo of the DT specimen of MM used in the fracture toughness measurement is shown. All DT specimens were completely broken in the fracture toughness measurement. In Figure A-3, examples of the raw data from CM and MM are

453 presented in the form of load vs. time plots. Using the maximum value of the applied 454 load, the fracture toughness can be estimated. 
456

457

458

459

460

461

462

463

464

465

466

467

468

469

470

471

472

473

\section{References}

Anderson, O.L., Grew, P.C., 1977. Stress corrosion theory of crack propagation with applications to geophysics. Rev. Geophys. Space Phys. 15, 77-104.

Atkinson, B.K., 1979. Fracture toughness of Tennessee sandstone and Carrara marble using the double torsion testing method. Int. J. Rock Mech. Min. Sci. \& Geomech. Abstr. 16, 49-53.

Atkinson, B.K., 1980. Stress corrosion and the rate-dependent tensile failure of a fine-grained quartz rock. Techtonophysics, 65, 281-290.

Atkinson, B.K., 1984. Subcritical crack growth in geological materials. J. Geophys. Res. 89, 4077-4114.

Atkinson, B.K. and Meredith, P.G., 1987. Experimental fracture mechanics data for rocks and minerals. Fracture Mechanics of Rock (ed. B.K. Atkinson) pp. 477-525.

Bergsaker, A.S., Røyne, A., Ougier-Simonin, A., Aubry, J., Renard, F., 2016. The effect of fluid composition, salinity, and acidity on subcritical crack growth in calcite crystals. J. Geophys. Res. Solid Earth, 121, 1631-1651.

Brantut, N., Heap, M.J., Meredith, P.G. and Baud, P., 2013. Time-dependent cracking and brittle creep in crustal rocks: A review, J. Struct. Geol., 52, 17-43.

Brantut, N., Heap, M.J., Baud, P. and Meredith, P.G., 2014a. Rate- and strain-dependent brittle deformation of rocks, J. Geophys. Res. Solid Earth 119, 1818-1836.

Brantut, N., Heap, M.J., Baud, P. and Meredith, P.G., 2014b. Mechanisms of time-dependent deformation in porous limestone. J. Geophys. Res. Solid Earth 119, 5444-5463.

Charles, R.J., 1958. Static fatigue of glass II. J. Appl. Phys. 29, 1554-1560.

Chen, C., Lin, C., Liu, L., Sinogeikin, S., Bass, J., 2001. Elasticity of single-crystal 
calcite and rhodochrosite by brillouin spectroscopy. Am. Mineral. 86, 1525-1529.

482

483

484

485

486

487

488

489

490

491

492

493

494

495

496

497

498

499

500

501

502

503

504

505

Ciccotti, M., Negri, N., Sassi, L., Gonzato, G., Mulargia, F., 2000a. Elastic and fracture parameters of Etna, Stromboli, and Vulcano lava rocks. J. Volcanol. Geother. Res. 98, 209-217.

Ciccotti, M., Gonzato. G., Mulargia, F., 2000b. The double torsion loading configuration for fracture propagation: an improved methodology for load relaxation at constant displacement. Int. J. Rock Mech. Min. Sci. 37, 1103-1113.

Ciccotti, M., Negri, N., Gonzato, G., Mulargia, F., 2001. Practical application of an improved methodology for the double torsion load relaxation method. Int. J. Rock Mech. Min. Sci. 38, 569-576.

De Bresser, J.H.P., Urai, J.L. and Olgaad, D.L., 2005. Effect of water on the strength and microstructure of Carrara marble axially compressed at high temperature. J. Struct. Geol. 27, 265-281.

Evans, A.G., 1972. A method for evaluating the time-dependent failure characteristics of brittle materials - and its application to polycrystalline alumina. J. Mater. Sci. 7, $1137-1146$.

Evans, A.G., 1973. A simple method for evaluating slow crack growth in brittle materials. Int. J. Fract., 9, 267-275.

Francisca, F., Yun, T.S., Ruppel, C., Santamarina, J.C., 2005. Geophysical and geotechnical properties of near-seafloor sediments in the northern Gulf of Mexico gas hydrate province. Earth Planet. Sci. Lett. 237, 924-939.

Funatsu, T., Seto, M., Shimada, H., Matsui, K. and Kuruppu, M., 2004. Combined effects of increasing temperature and confining pressure on the fracture toughness of clay bearing rocks. Int. J. Rock Mech. Min. Sci., 41, 927-938.

Funatsu, Kuruppu, M. and Matsui, K., 2014. Effects of temperature and confining 
506

507

508

509

510

511

512

513

514

515

516

517

518

519

520

521

522

523

525

526

527

528

529

530

pressure on mixed-mode (I-II) and mode II fracture toughness of Kimachi sandstone. Int. J. Rock Mech. Min. Sci., 67, 1-8.

Garrels, R.M. and Christ, C.L., 1965, Solutions, Minerals and Equilibria, Butterworth, London, UK.

Heap, M.J., Baud, P., Meredith, P.G., Vinciguerra, S., Bell, A.F. and Main, I.G., 2011. Brittle creep in basalt and its application to time-dependent volcano deformation, Earth Planet. Sci. Lett., Vol.307, pp.71-82.

Henry, J.P., Paquet, J., Tancrez, J.P., 1977. Experimental study of crack propagation in calcite rocks. Int. J. Rock Mech. Min. Sci. \& Geomech. Abstr. 14, 85-91.

Holder, J., Olson, J.E., Philip, Z., 2001. Experimental determination of subcritical crack growth parameters in sedimentary rock. Geophys. Res. Lett. 28, 599-602.

International Society for Rock Mechanics, 1988. Suggested methods for the fracture toughness of rock. Int. J. Rock Mech. Min. Sci. 25, 71-96.

Jeong, H.S., Kang, S.S., Obara, Y., 2007. Influence of surrounding environments and strain rates on the strength of rocks subjected to uniaxial compression. Int. J. Rock Mech. Min. Sci. 44, 321-331.

Kataoka, M., Obara, Y. and Kuruppu, M., 2015. Estimation of fracture toughness of anisotropic rocks by semi-circular bend tests under water vapor pressure. Rock Mech. Rock Eng. 48, 1353-1367.

Kies, J.A., Clark, A.B.J., 1969. Fracture propagation rates and times to fail following proof stress in bulk glass. In: Platt, P.L. (Ed.), Fracture 1969, Chapman and Hall, London, pp. 483-491.

Kilburn, C.R.J., Voight, B., 1998. Slow rock fracture as eruption precursor at Soufriere Hills Volcano, Montserrat. Geophys. Res. Lett. 25, 3665-3668.

Kudo, Y., Sano, O., Murashige, N., Mizuta, Y. and Nakagawa, K., 1992. Stress-induced 
crack path in Aji granite under tensile stress. Pure Appl. Geophys., 138, 641-656.

532

533

534

535

536

537

538

539

540

541

542

543

544

545

546

547

548

549

550

551

552

553

554

555

Lawn, B.R., 1974. Diffusion-controlled subcritical crack growth in the presence of a dilute gas environment, Mater. Sci. Eng., 13, 277-283, 1974.

Lawn, B., 1993. Fracture of brittle solids - Second edition, Cambridge University Press, Cambridge.

Liang, Y., Baer, D.R., McCoy, J.M., Amonette, J.E. and LaFemina, J.P., 1996.

Dissolution kinetics at the calcite-water interface. Geochim. Cosmochim. Acta 60, 4883-4887.

MacInnis, I.N. and Brantley, S.L., 1992. The role of dislocations and surface morphology in calcite dissolution. Geochim. Cosmochim. Acta 56, 1113-1126.

Madjoubi, M.A., Hamidouche, M., Bouaouadja, N., 2007. Experimental evaluation of the double torsion analysis in soda-lime glass. J. Mater. Sci. 42, 7872-7881.

Meredith, P.G., 1983. A fracture mechanics study of experimentally deformed crustal rocks. Ph.D. Thesis, University of London.

Meredith, P.G., Atkinson, B.K., 1983. Stress corrosion and acoustic emission during tensile crack propagation in Whin Sill dolerite and other basic rocks. Geophys. J. R. Astr. Soc., 75, 1-21.

Meredith, P.G., Atkinson, B.K., 1985. Fracture toughness and subcritical crack growth during high-temperature tensile deformation of Westerly granite and Black gabbro. Phys. Earth Planet. Inter. 39, 33-51.

Michalske, T.A., Freiman, S.W., 1982. A molecular interpretation of stress corrosion in silica. Nature 295, 511-512.

Nakao, A., Nara, Y. and Kubo, T., 2016. P-wave propagation in dry rocks under controlled temperature and humidity, Int. J. Rock Mech. Min. Sci., 86, 157-165.

Nara, Y., 2015. Effect of anisotropy on the long-term strength of granite, Rock Mech. 
556

557

558

559

560

561

562

563

564

565

566

567

568

569

570

571

572

573

574

575

576

577

578

579

580

Rock Eng., 48, 959-969.

Nara, Y., Kaneko, K., 2005. Study of subcritical crack growth in andesite using the Double Torsion test. Int. J. Rock Mech. Min. Sci. 42, 521-530.

Nara, Y., Kaneko, K., 2006. Sub-critical crack growth in anisotropic rock. Int. J. Rock Mech. Min. Sci. 43, 437-453.

Nara, Y., Koike, K., Yoneda, T. and Kaneko, K., 2006. Relation between subcritical crack growth behavior and crack paths in granite. Int. J. Rock Mech. Min. Sci. 43, $1256-1261$.

Nara, Y., Takada, M., Igarashi, T., Hiroyoshi, N., Kaneko, K., 2009. Subcritical crack growth in rocks in an aqueous environment. Explor. Geophys. 40, 163-171.

Nara, Y., Hiroyoshi, N., Yoneda, T., Kaneko, K., 2010. Effect of temperature and relative humidity on subcritical crack growth in igneous rock. Int. J. Rock Mech. Min. Sci. 47, 640-646.

Nara, Y., Morimoto, K., Yoneda, T., Hiroyoshi, N. and Kaneko, K., 2011. Effects of humidity and temperature on subcritical crack growth in sandstone, Int. J. Solids Struct., 48, 1130-1140.

Nara, Y., Morimoto, K., Hiroyoshi, N., Yoneda, T., Kaneko, K., Benson, P.M., 2012. Influence of relative humidity on fracture toughness of rock: implications for subcritical crack growth. Int. J. Solids Struct., 49, 2471-2481.

Nara, Y., Yamanaka, H., Oe, Y. and Kaneko, K., 2013. Influence of temperature and water on subcritical crack growth parameters and long-term strength for igneous rocks, Geophys. J. Int., 193, 47-60.

Nara, Y., Nakabayashi, R., Maruyama, M., Hiroyoshi, N., Yoneda, T. and Kaneko, K., 2014. Influences of electrolyte concentration on subcritical crack growth in sandstone in water, Eng. Geol., 179, 41-49. 
581 Nasseri, M.H.B., Schubnel, A., Young, R.P., 2007. Coupled evolutions of fracture

582 toughness and elastic wave velocities at high crack density in thermally treated

583 Westerly granite, Int. J. Rock Mech. Min. Sci., 44, 601-616.

584

585

586

587

588

589

590

591

592

593

594

595

596

597

598

599

600

601

602

603

604

605

Pletka, B.J., Fuller, E.R. Jr., Koepke, B.G., 1979. An evaluation of double-torsion testing - Experimental. ASTM STP 678, 19-37.

Ponson, L., 2009. Depinning transition in the failure of inhomogeneous brittle materials. Phys. Rev. Lett. 103, 055501.

Rostom, F., Røyne, A., Dysthe, D.K., and Renard, F., 2012. Effect of fluid salinity on subcritical crack propagation in calcite, Tectonophysics, 583, 68-75.

Røyne, A., Bisschop, J., Dysthe, D.K., 2011. Experimental investigation of surface energy and subcritical crack growth in calcite. J. Geophys. Res., 116, B04204. DOI: 10.1029/2010JB008033.

Sano, O., 1981. A note on the sources of acoustic emissions associated with subcritical crack growth, Int. J. Rock Mech. Min. Sci. \& Geomech. Abstr. 18, 259-263.

Sano, O., 1988. A revision of the double-torsion technique for brittle materials. J. Mater. Sci. 23, 2505-2511.

Sano, O., Kudo, Y., 1992. Relation of fracture resistance to fabric for granitic rocks. Pure Appl. Geophys. 138, 657-677.

Schmidtke, R.H., Lajtai, E.Z., 1986. The long-term strength of Lac du Bonnet granite. Int. J. Rock Mech. Min. Sci. \& Geomech. Abstr. 22, 461-465.

Selçuk, A., Atkinson, A., 2000. Strength and toughness of tape-cast yttria-stabilized zirconia. J. Am. Ceram Soc. 83, 2029-2035.

Shaw, D.J., 1980, Introduction to Colloid and Surface Chemistry, New York, USA.

Shiraki, R., Rock, P.A. and Casey, W.H., 2000. Dissolution kinetics of calcite in $0.1 \mathrm{M}$ $\mathrm{NaCl}$ solution at room temperature: an atomic force microscope (AFM) study. 
606

607

608

609

610

611

612

613

614

615

616

617

618

619

620

621

622

623

624

625

626

627

628

629

630

Aquat. Geochem., 6, 87-108.

Shushakova, V., Fuller Jr., E.R., Siegesmund, S., 2013. Microcracking in calcite and dolomite marble: microstructural influences and effects on properties. Environ. Earth Sci., 69, 1263-1279.

Shyam, A., Lara-Curzio, E., 2006. The double-torsion testing technique for determination of fracture toughness and slow crack growth behaviour of materials: a review. J. Mater. Sci. 41, 4093-4104.

Sjöberg, E.L and Rickard, D.T., 1984. Temperature dependence of calcite dissolution kinetics between 1 and $62^{\circ} \mathrm{C}$ at $\mathrm{pH} 2.7$ to 8.4 in aqueous solutions. Geochim. Cosmochim. Acta 48, 485-493.

Swanson, P.L., 1984. Subcritical crack growth and time-and environment-dependent behaviour in crustal rocks. J. Geophys. Res. 89, 4173-4152.

Swanson, P.L., 1985. Subcritical fracture propagation in rocks: an examination using the methods of fracture mechanics and non-destructive testing. Ph.D. thesis, University of Colorado, Boulder, USA.

Swanson, P.L., 1987. Tensile fracture resistance mechanisms in brittle polycrystals: an ultrasonics and in situ microscopy investigation. J. Geophys. Res., 92, 8015-8036.

Thomson, W., 1871. On equilibrium of vapour at a curved surface of liquid. Philos.

$$
\text { Mag., 42, 448-452. }
$$

Trantina, G.G., 1977. Stress analysis of the double-torsion specimen. J. Am. Ceram. Soc. 60, 338-341.

Vavro, L. and Souček, K., 2013. Study of the effect of moisture content and bending rate on the fracture toughness of rocks. Acta Geodyn. Geomater. 10, 247-253.

Violay, M., Nielsen, S., Spagnuolo, E., Cinti, D., Di Toro, G. and Di Stefano, G., 2013. Pore fluid in experimental calcite-bearing faults: Abrupt weakening and 
631 geochemical signature of co-seismic processes, Earth Planet. Sci. Lett., 361, 74-84. 632 Wiederhorn, S.M., 1967. Influence of water vapor on crack propagation in soda-lime 633 glass. J. Am Ceram. Soc. 50, 407-414.

634 Wiederhorn, S.M., Bolz, L.H., 1970. Stress Corrosion and Static Fatigue of Glass. J. Am. $635 \quad$ Ceram. Soc. 53, 543-548.

636 Wiederhorn, S.M., Johnson, H., Diness, A.M. and Heuer, A.H., 1974, Fracture of glass 637 in vacuum, J. Am. Ceram. Soc., 57, 336-341.

638 Williams, D.P., Evans, A.G., 1973. A simple method for studying slow crack growth. J. 639 Test. Eval. 1, 264-270.

640 


\section{$641 \quad$ Figures}

642

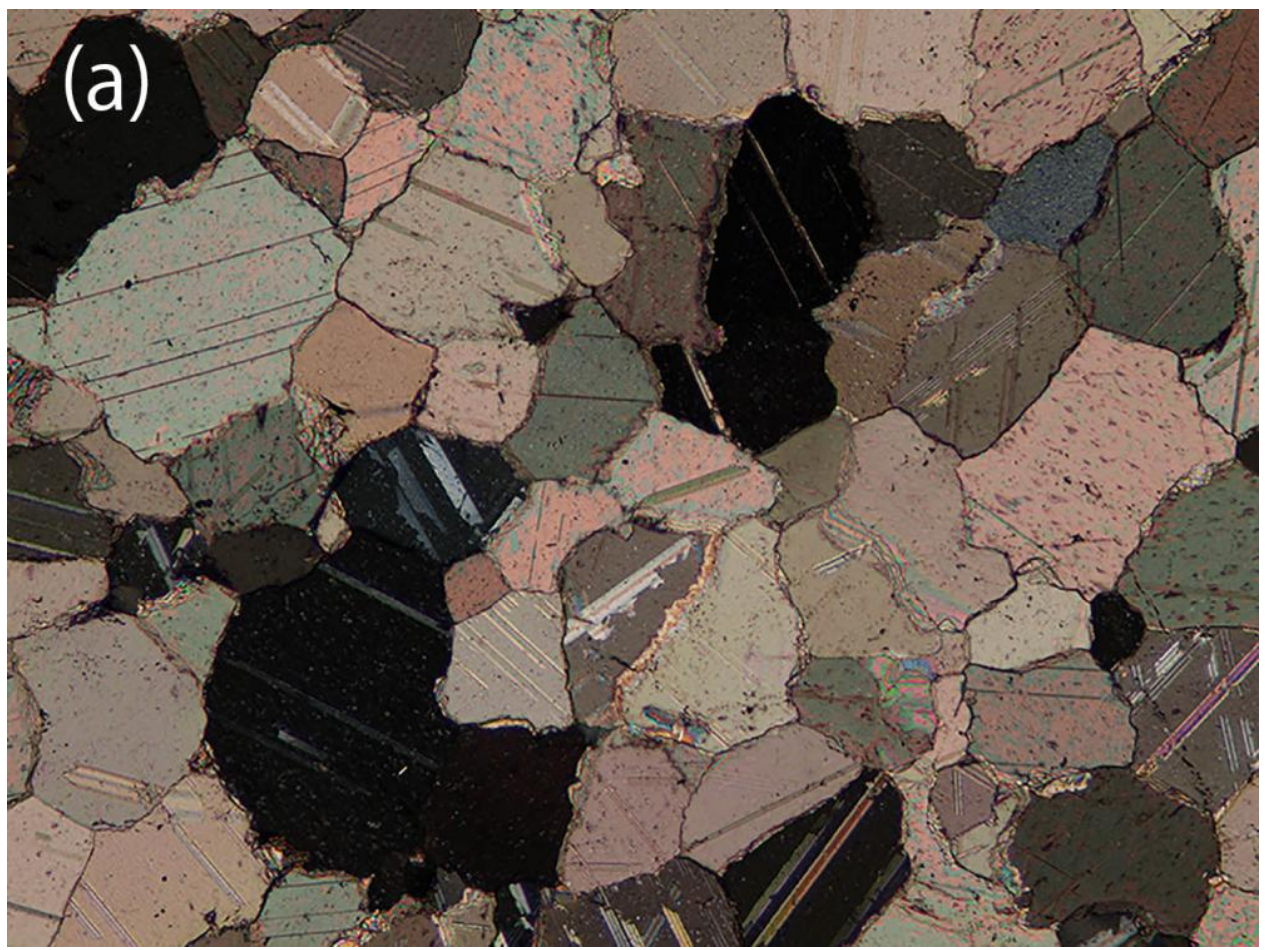

644 Figure 1. Photomicrographs of (a) Carrara marble (CM) and (b) Macedonian marble

645 (MM) observed with a thin section under crossed nicols. The width and height of the

646 sections are $1.5 \mathrm{~mm}$ and $1.1 \mathrm{~mm}$, respectively. 


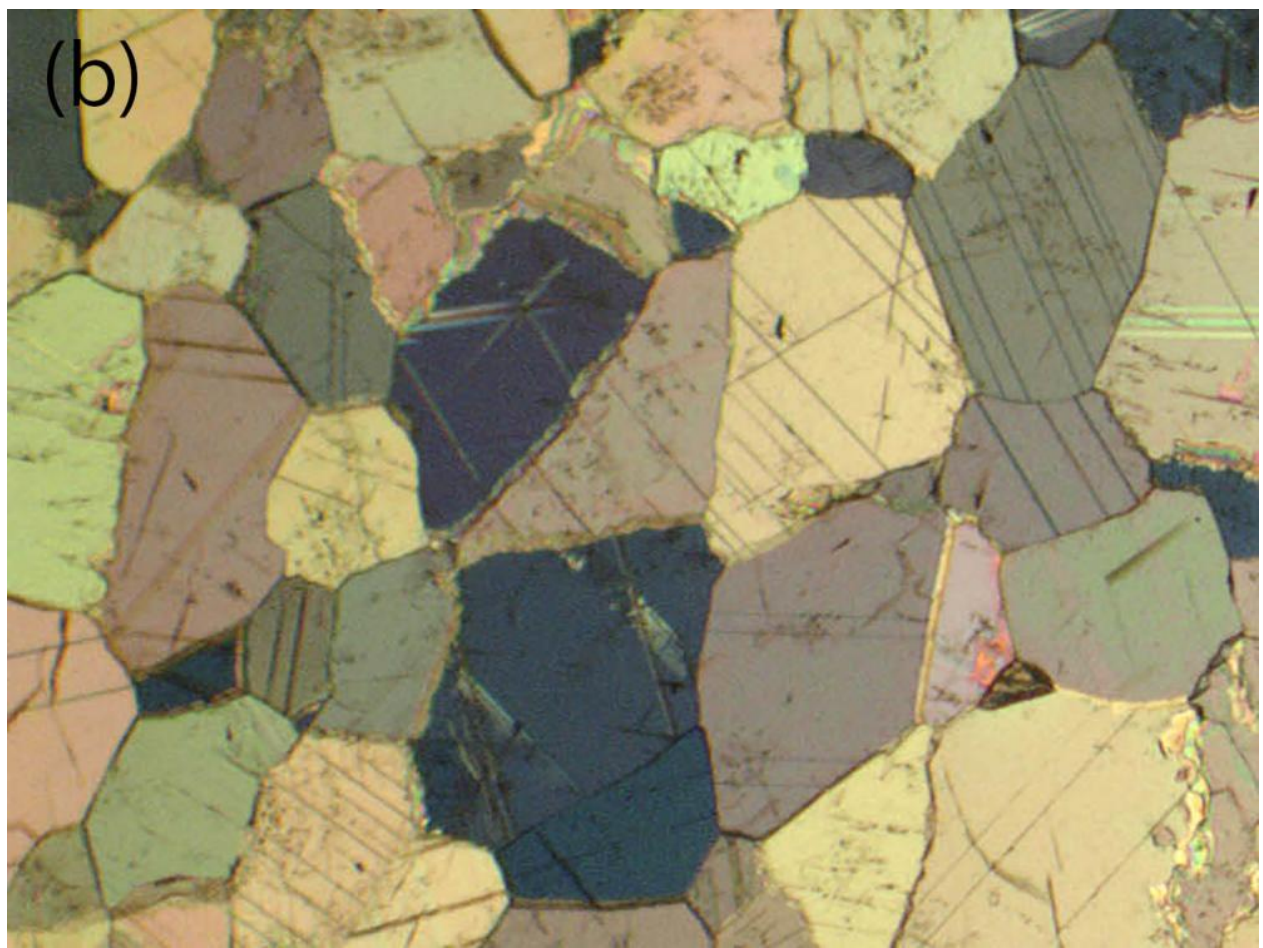

649 Figure 1. Photomicrographs of (a) Carrara marble (CM) and (b) Macedonian marble 650 (MM) observed with a thin section under crossed nicols. The width and height of the $651 \quad$ sections are $1.5 \mathrm{~mm}$ and $1.1 \mathrm{~mm}$, respectively.

652

653

654 
655

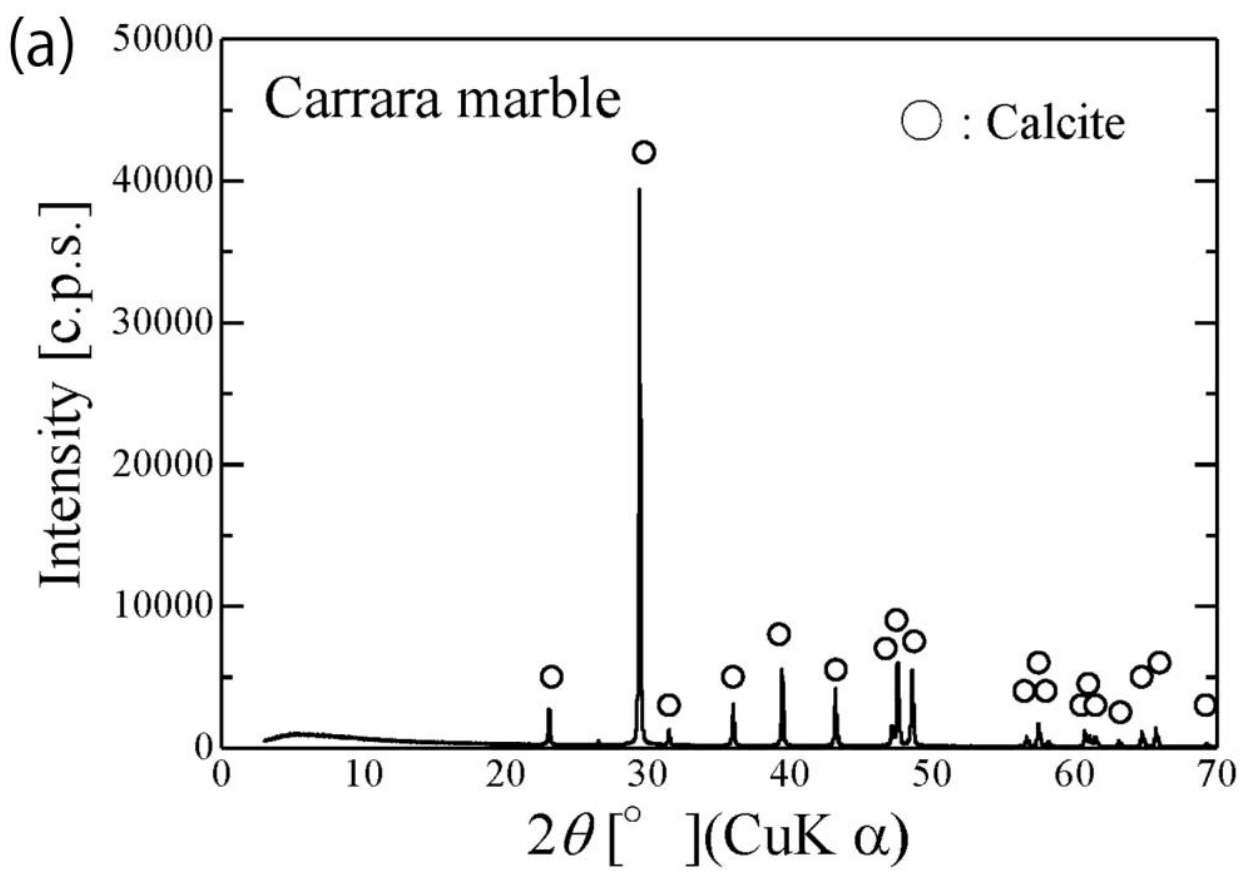

656 Figure 2. X-ray diffraction patterns for (a) CM and (b) MM.

657

658

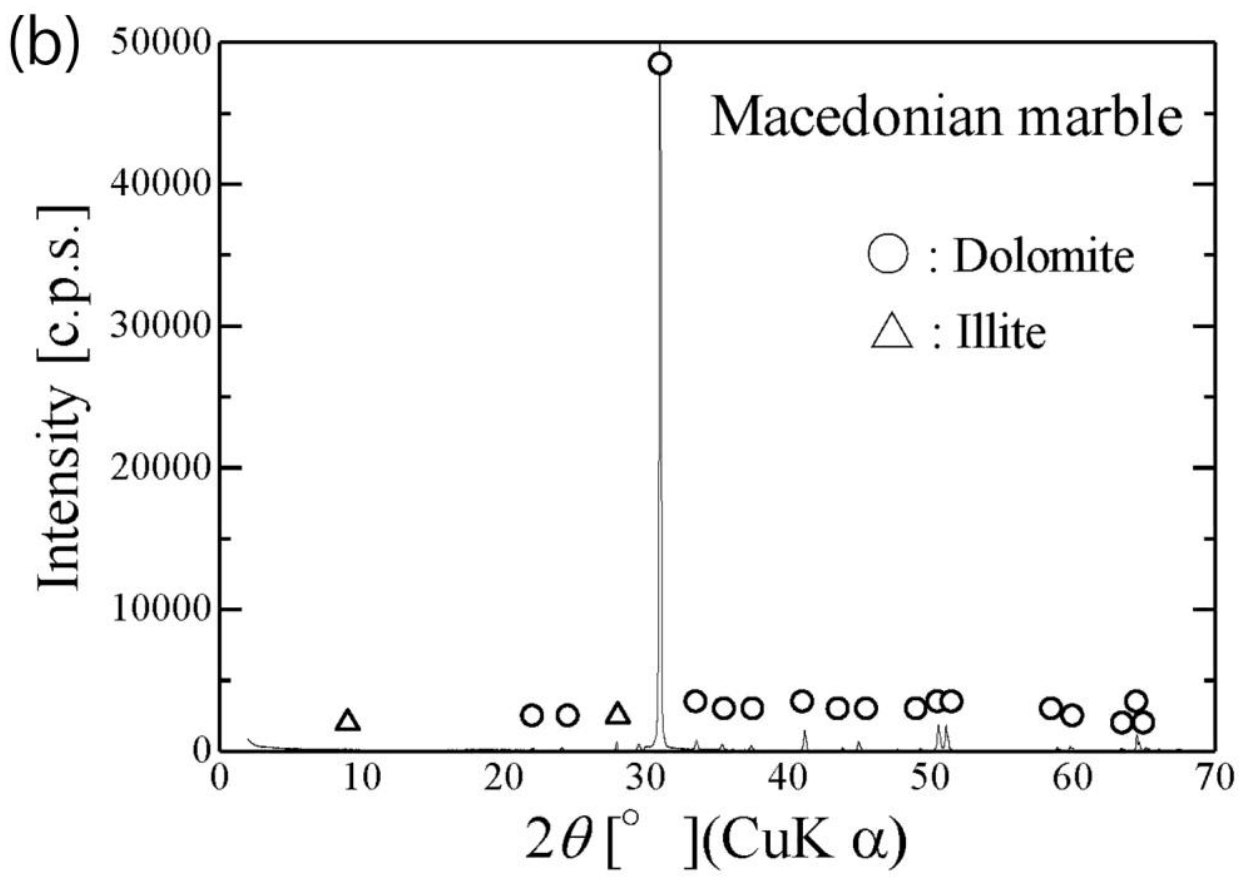

659 Figure 2. X-ray diffraction patterns for (a) CM and (b) MM. 
661

662

663

664

665

666

667

668

669

670

671

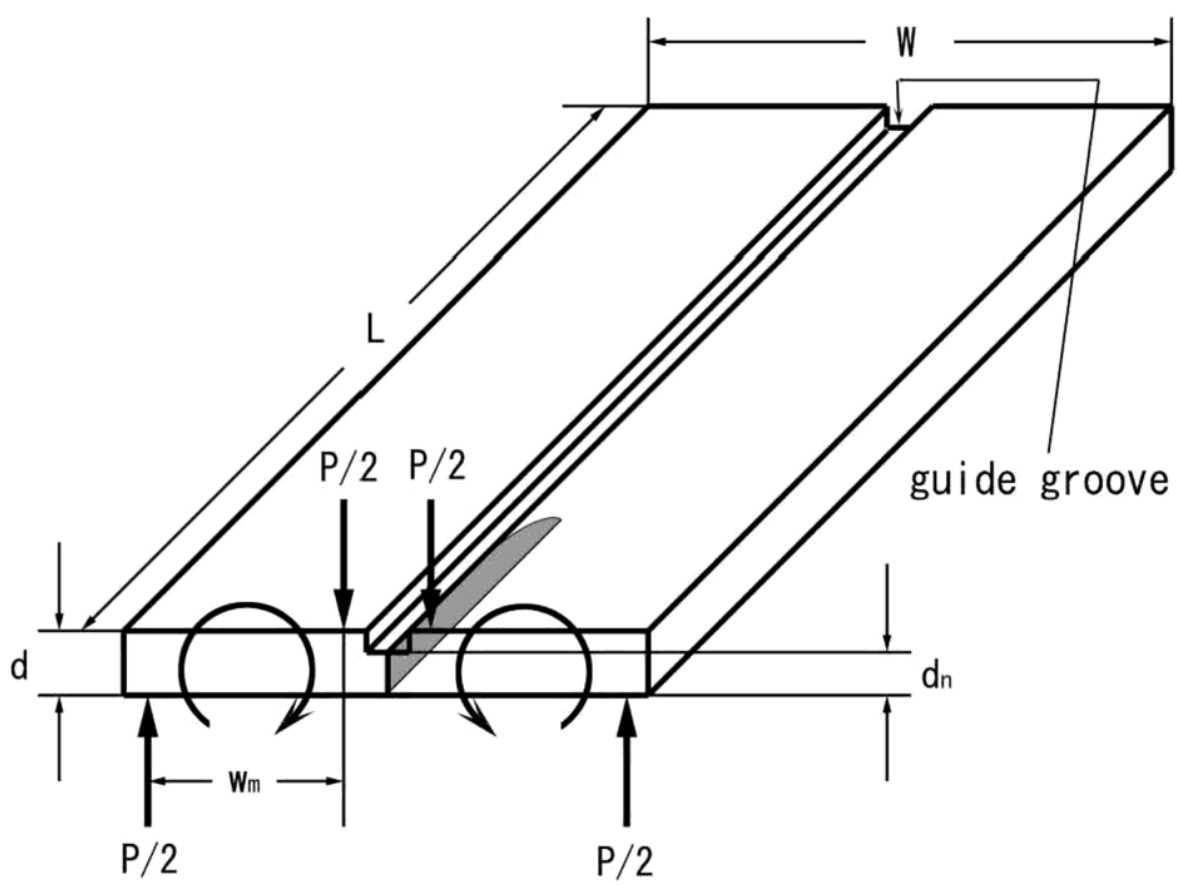

Figure 3. Schematic illustration of double torsion specimen and loading configuration.

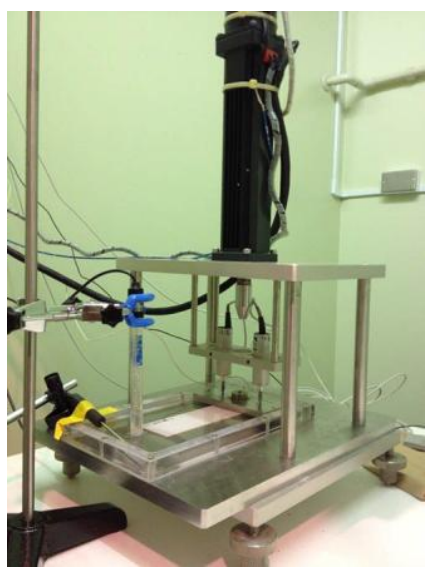

Figure 4. Photo of experimental apparatus of DT-RLX test with $\mathrm{pH}$ measurement. 

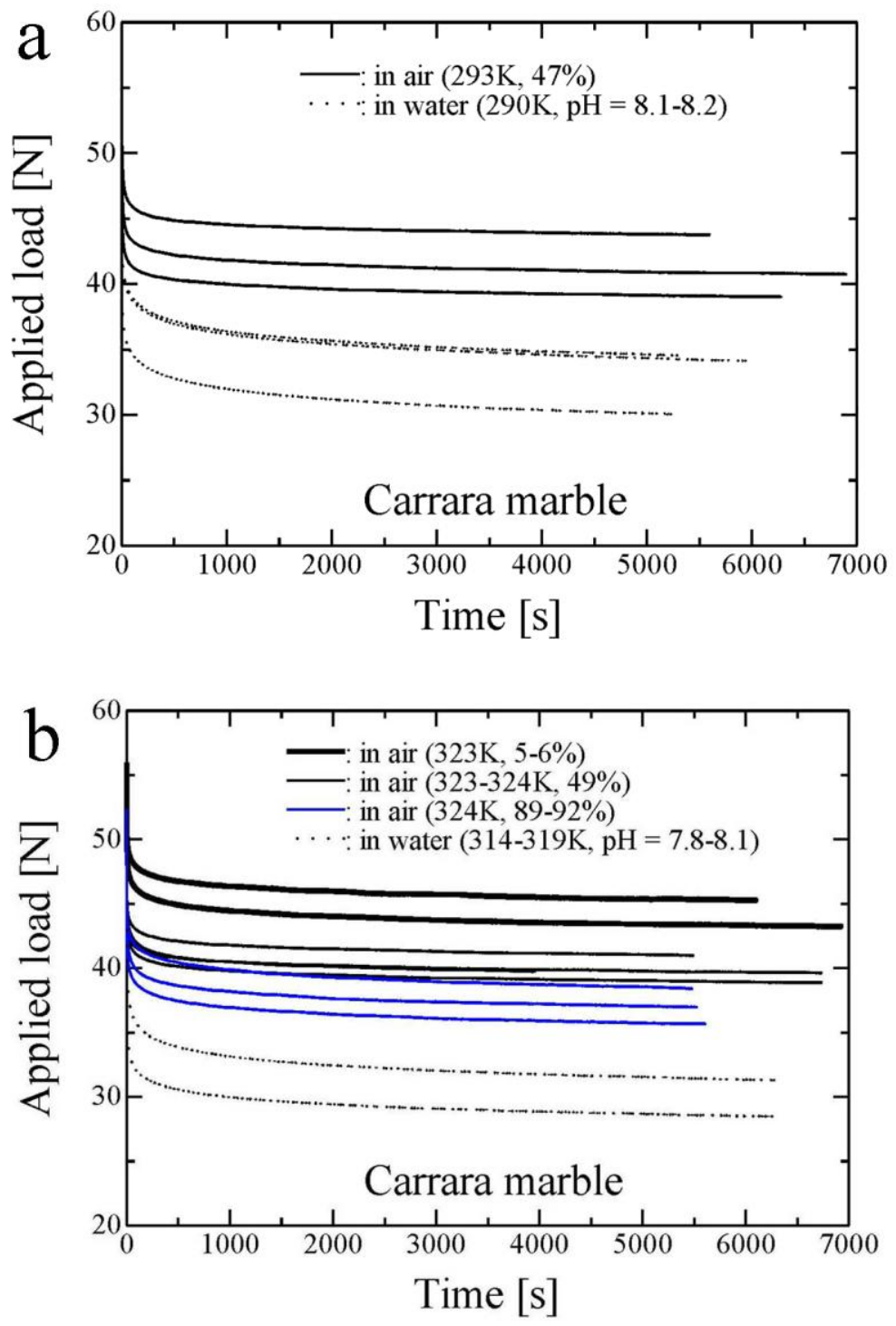

673

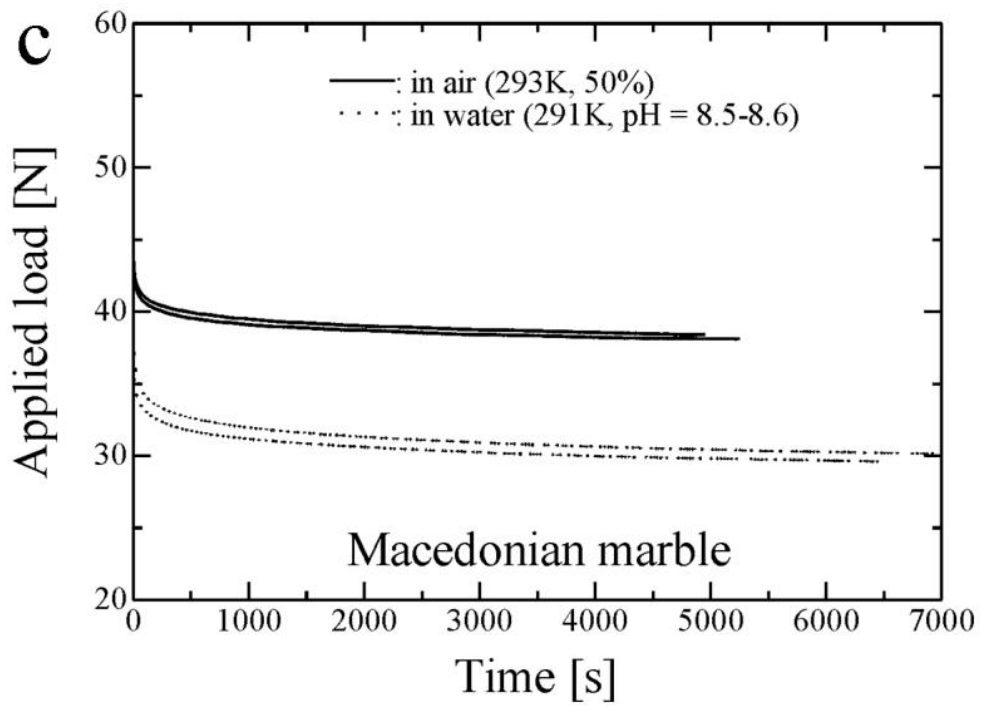



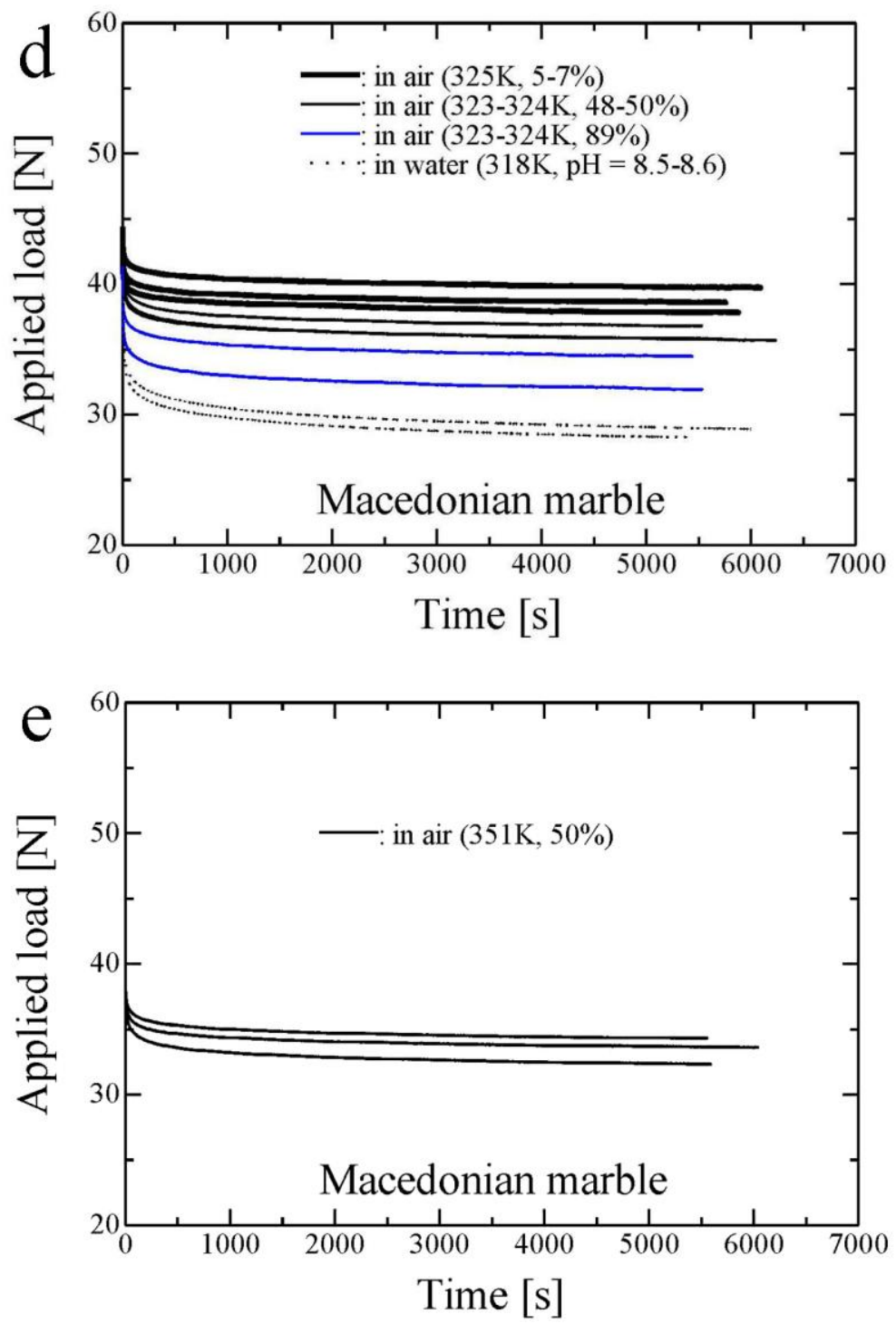

676

677 Figure 5. Load-relaxation curves for marbles. (a): CM at 290-293K, and (b): CM at 
686

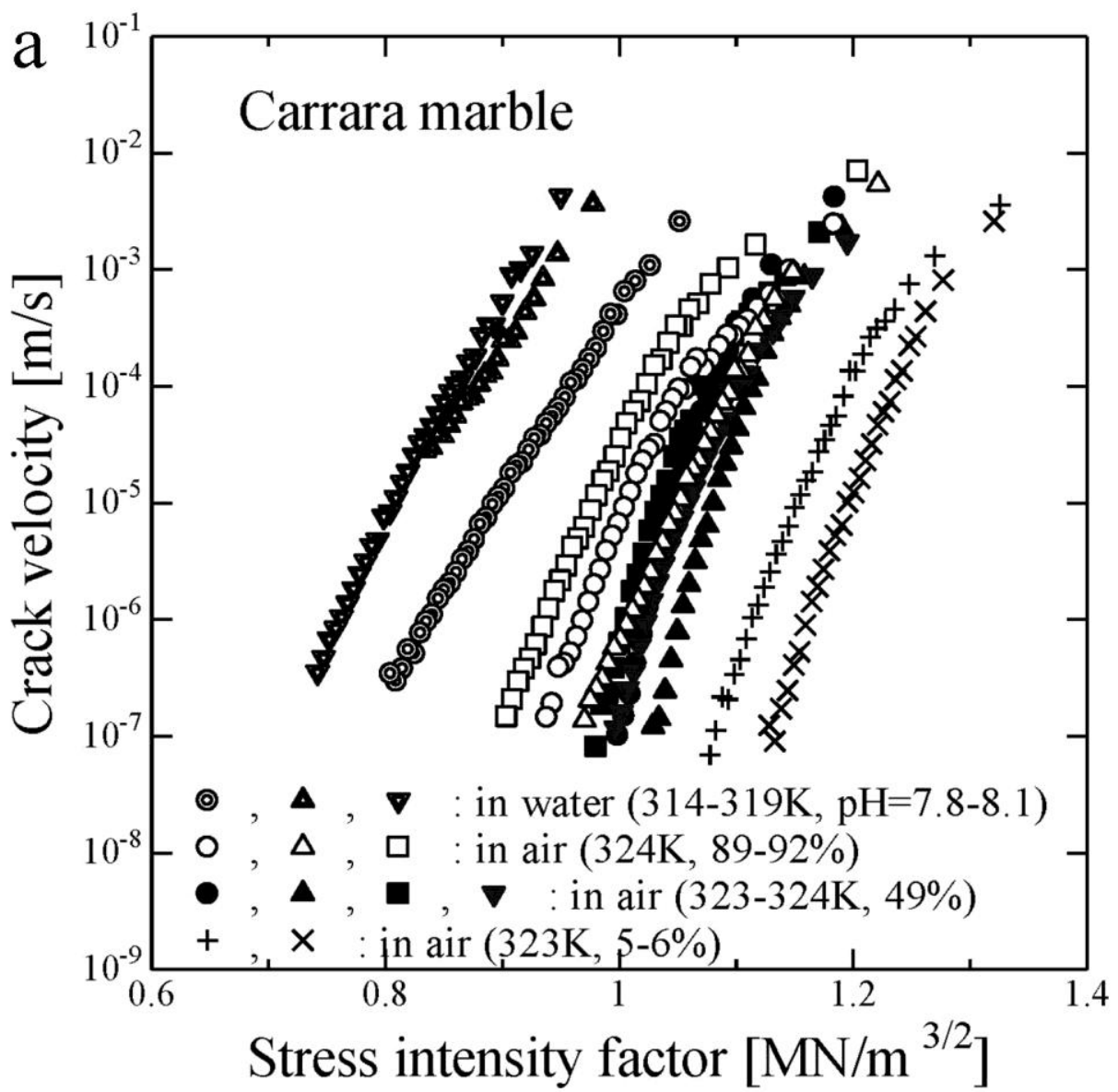

687 Figure 6. Relationship between crack velocity and stress intensity factor for (a) CM and (b) MM in air with different relative humidities, and in water. 
690

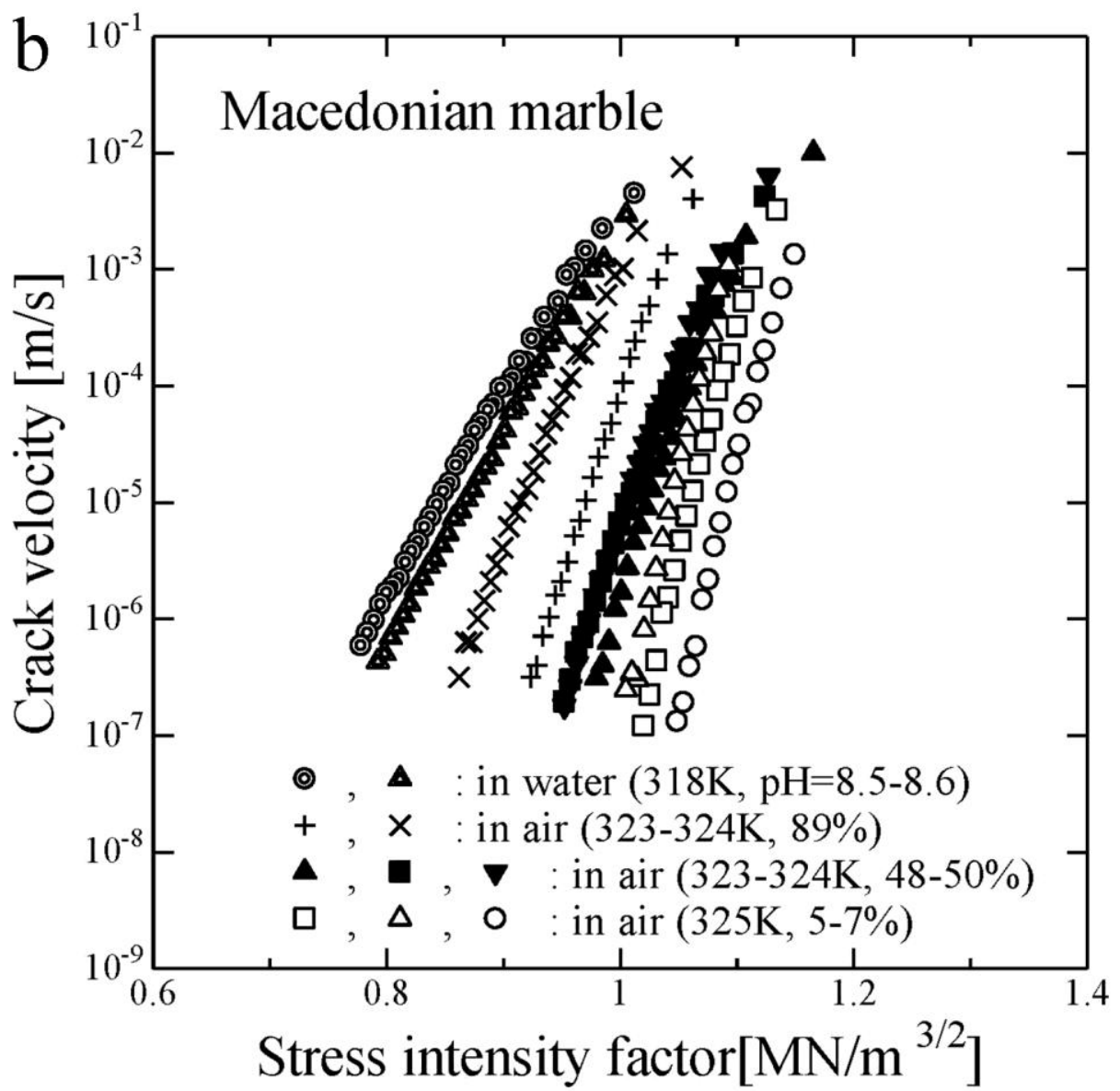

691 Figure 6. Relationship between crack velocity and stress intensity factor for (a) CM and (b) MM in air with different relative humidities, and in water.

693

694

695

696

697

698

699

700 


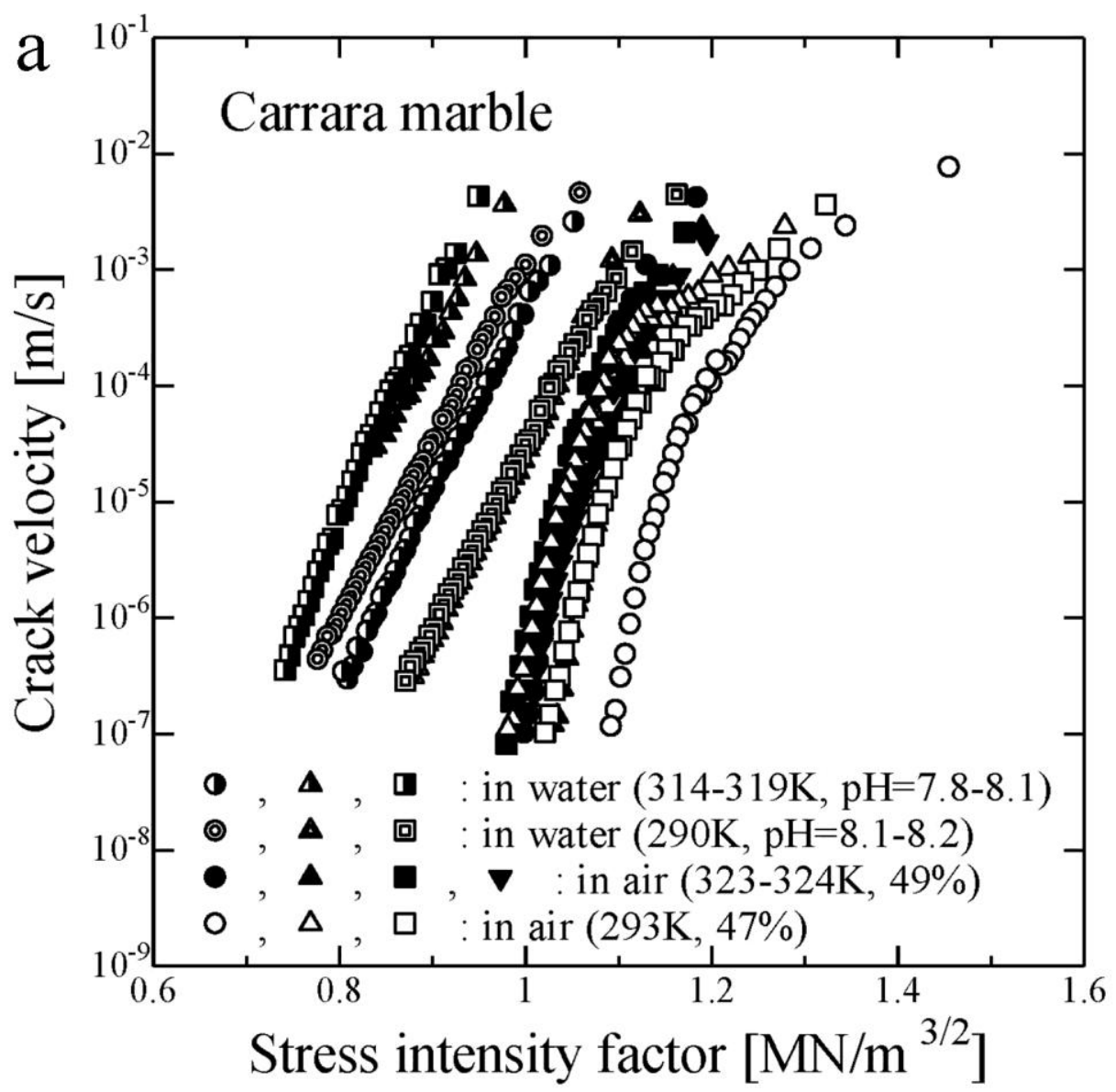

703 Figure 7. Relationship between crack velocity and stress intensity factor for (a) CM and (b) MM in air and water at different temperatures. 


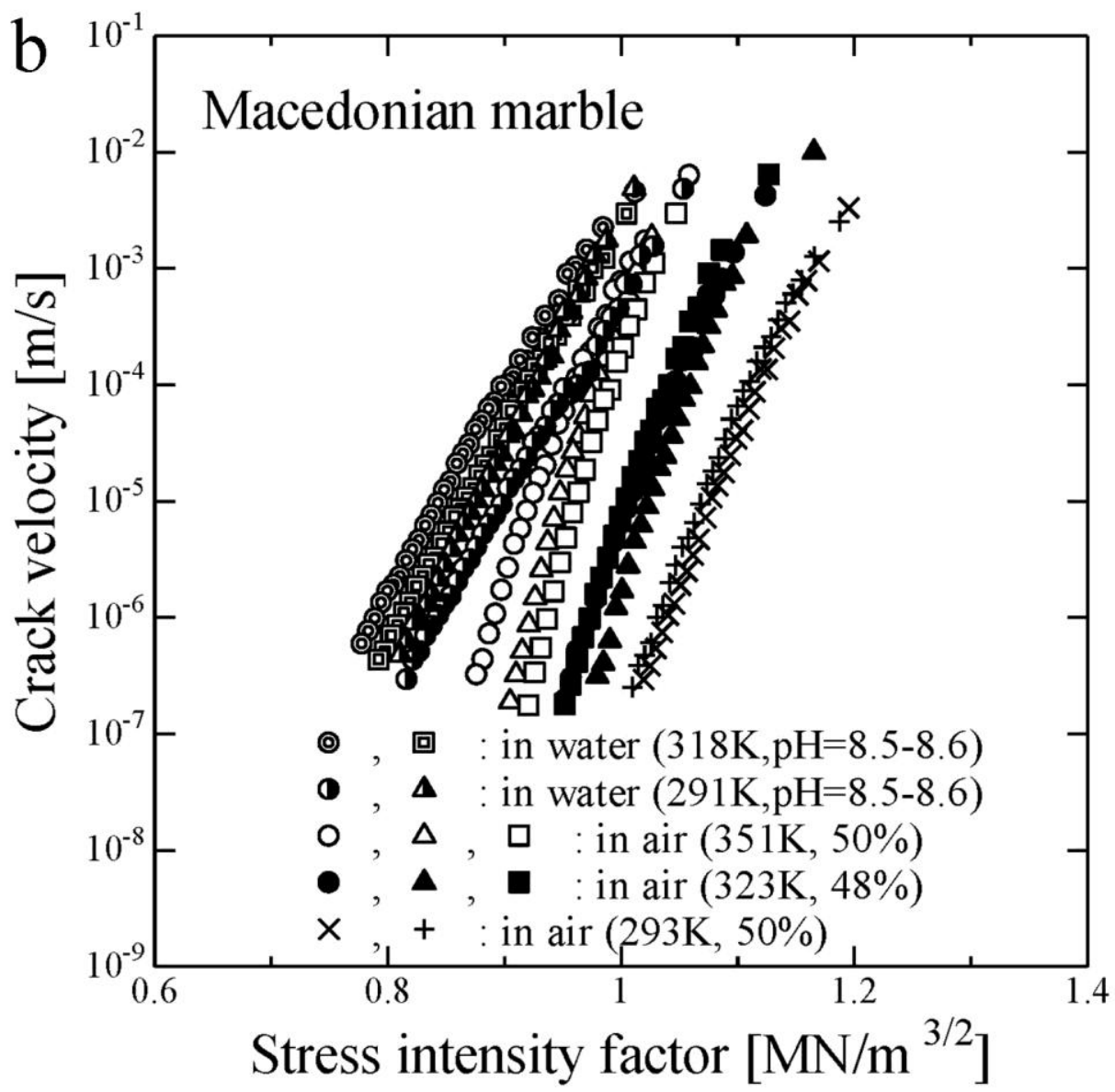

707 Figure 7. Relationship between crack velocity and stress intensity factor for (a) CM and (b) MM in air and water at different temperatures. 


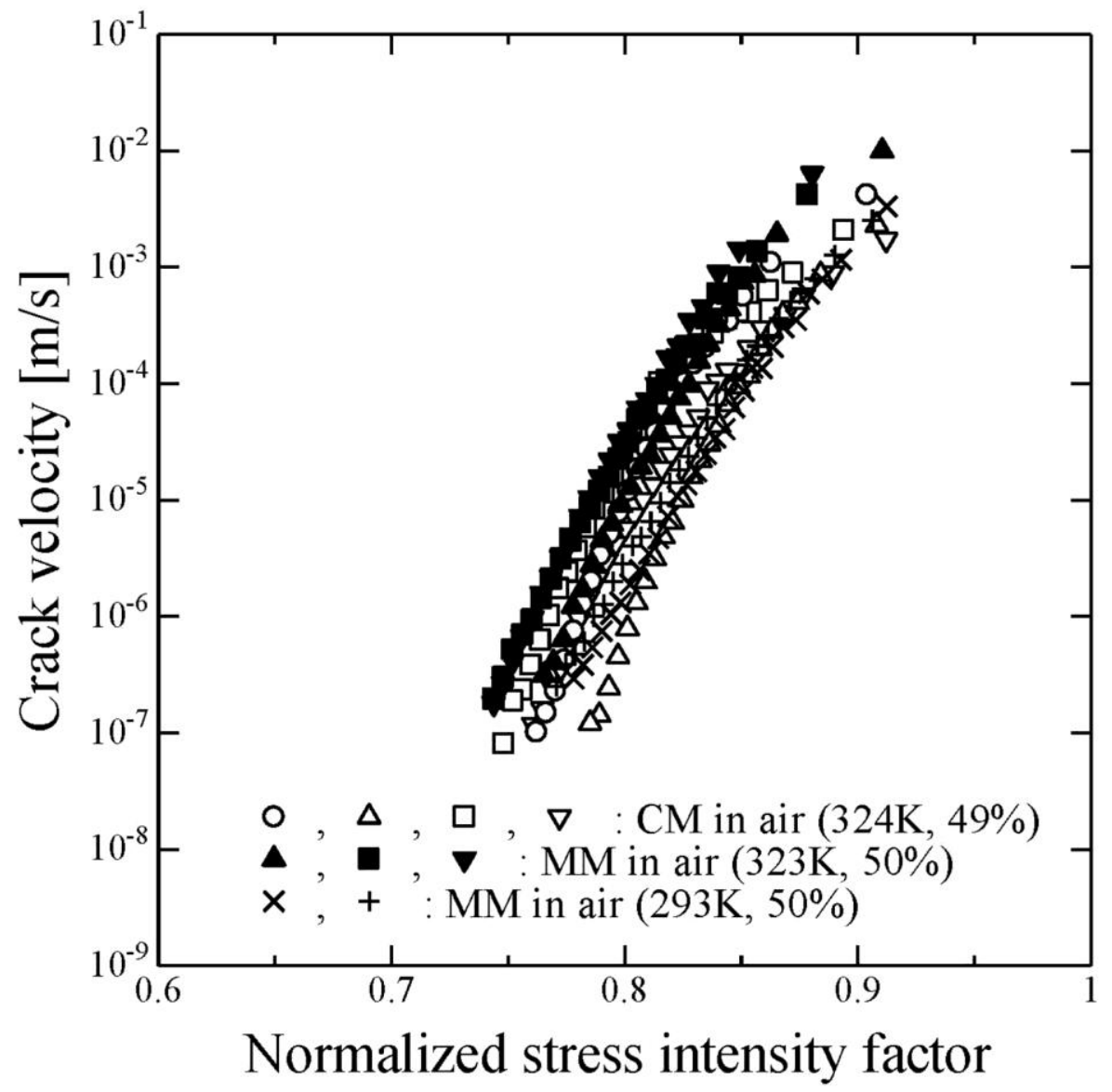

712 Figure 8. Relationship between crack velocity and stress intensity factor normalized by fracture toughness for marble in air. 


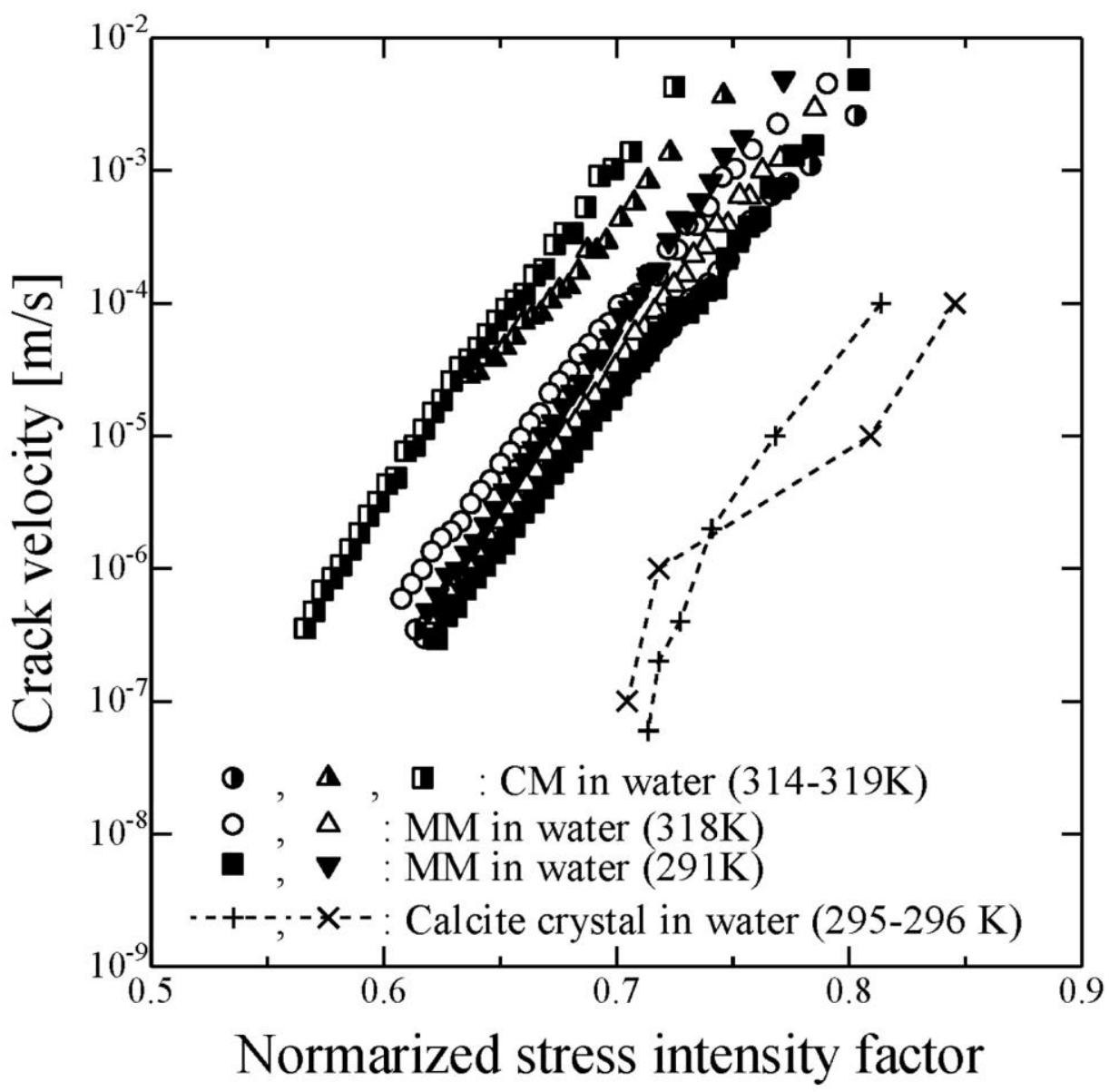

716 Figure 9. Relationship between crack velocity and stress intensity factor normalized by fracture toughness for marble and calcite crystal. " $x "$ and "+" are the relationships obtained by Røyne et al. (2011) and Rostom et al. (2012),

719 respectively.

720

721

722 


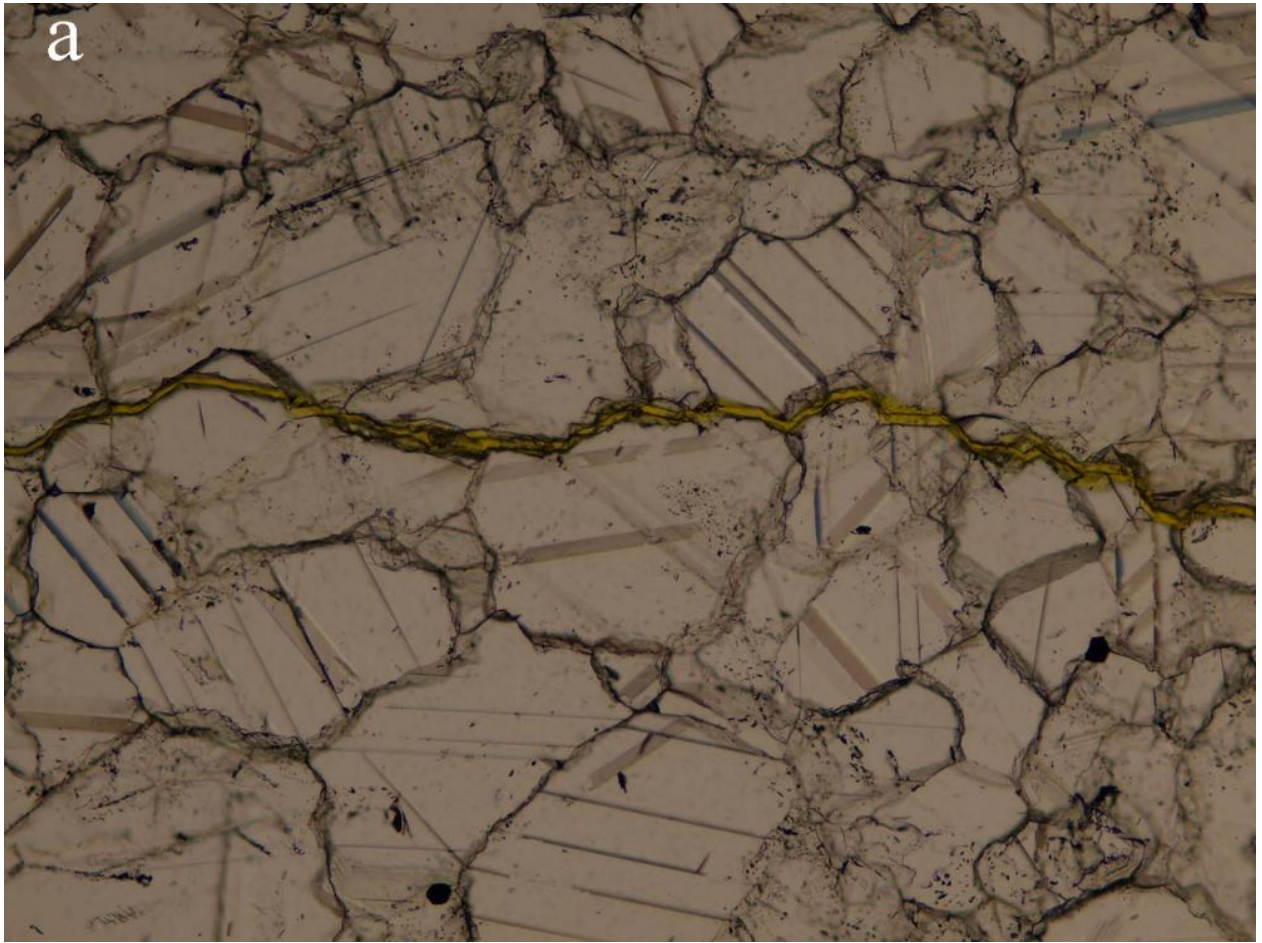

724

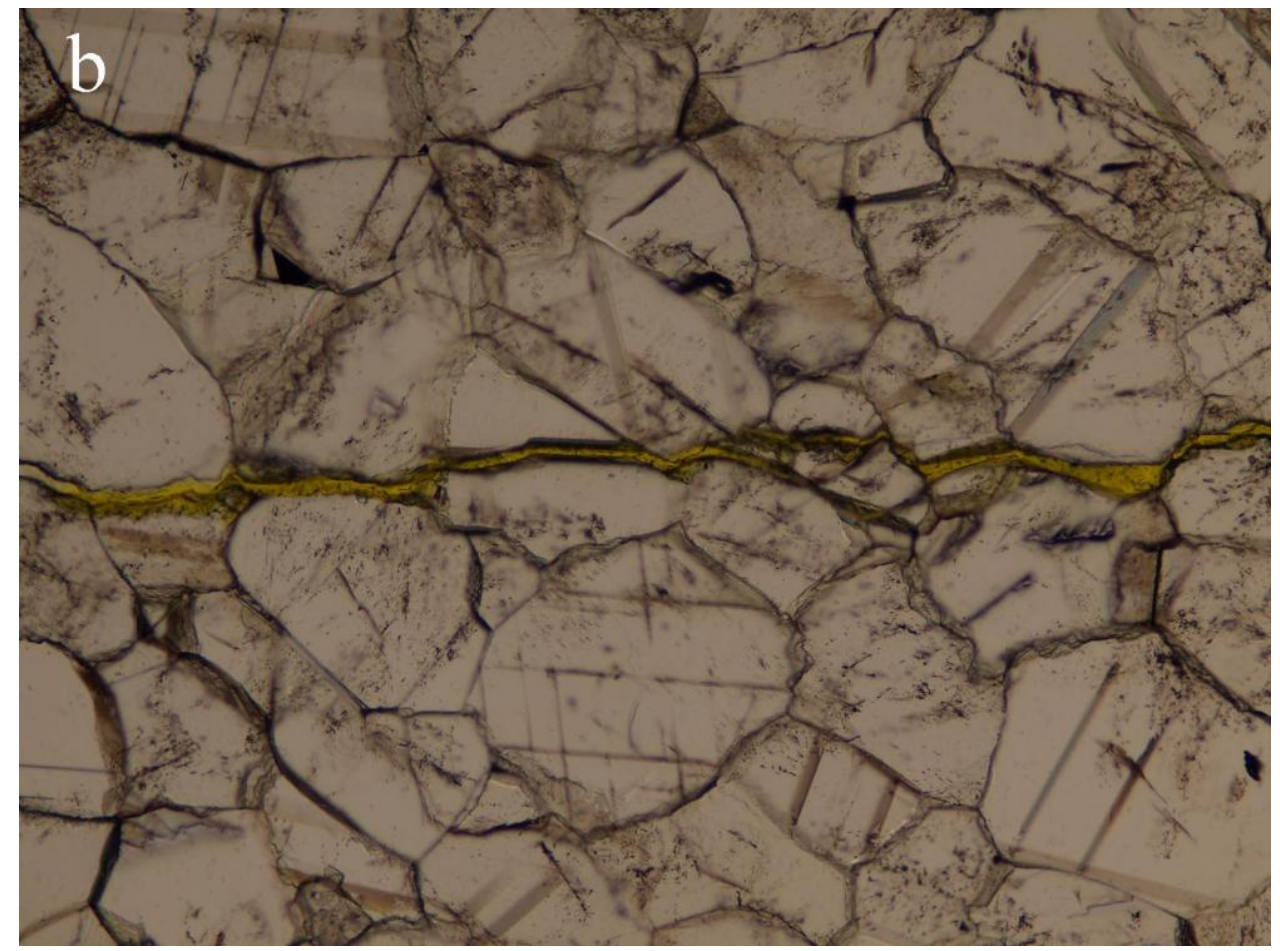

Figure 10. Images of crack path observed for (a) CM and (b) MM. The width and height of the images are $1.5 \mathrm{~mm}$ and $1.1 \mathrm{~mm}$, respectively. 


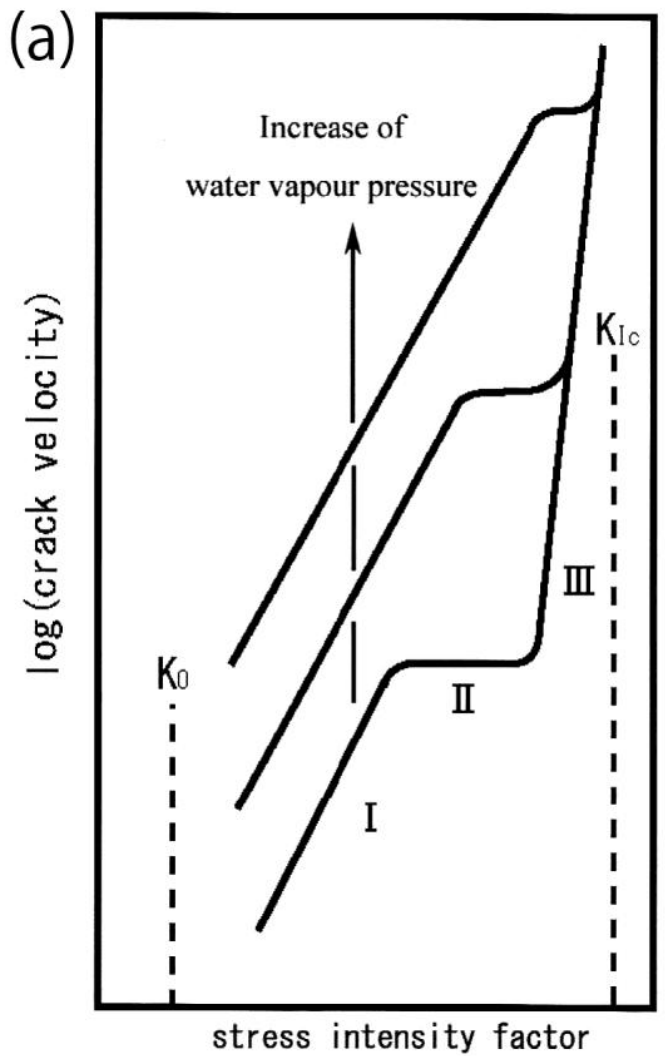

731 Figure 11. Tri-modal behaviour of relationship between crack velocity and stress intensity factor for subcritical crack growth. (a): Schematic illustration, (b): Relationship in silica glass in air. 


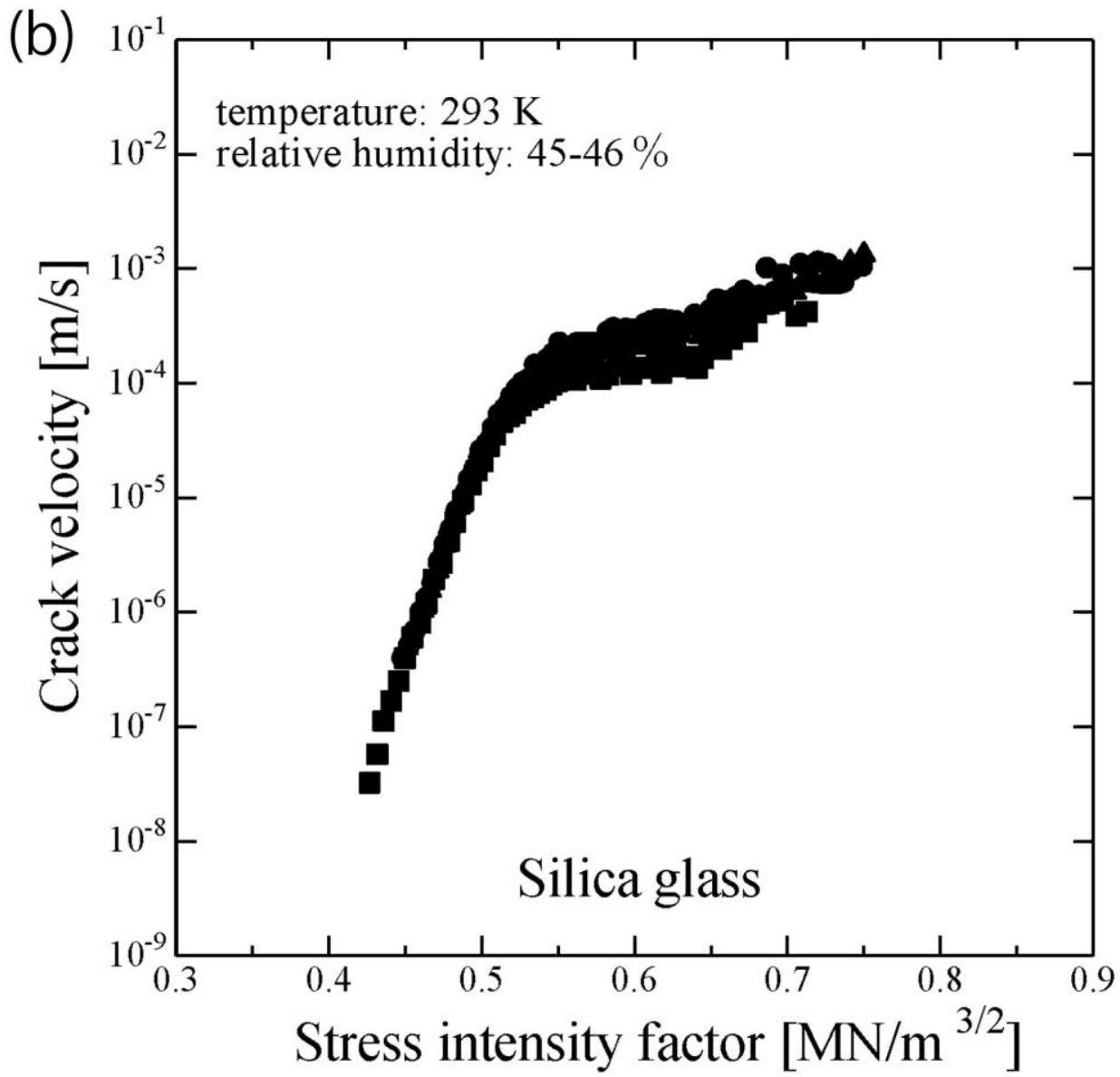

737 Figure 11. Tri-modal behaviour of relationship between crack velocity and stress

738 intensity factor for subcritical crack growth. (a): Schematic illustration, (b):

Relationship in silica glass in air.

740

741

742

743 


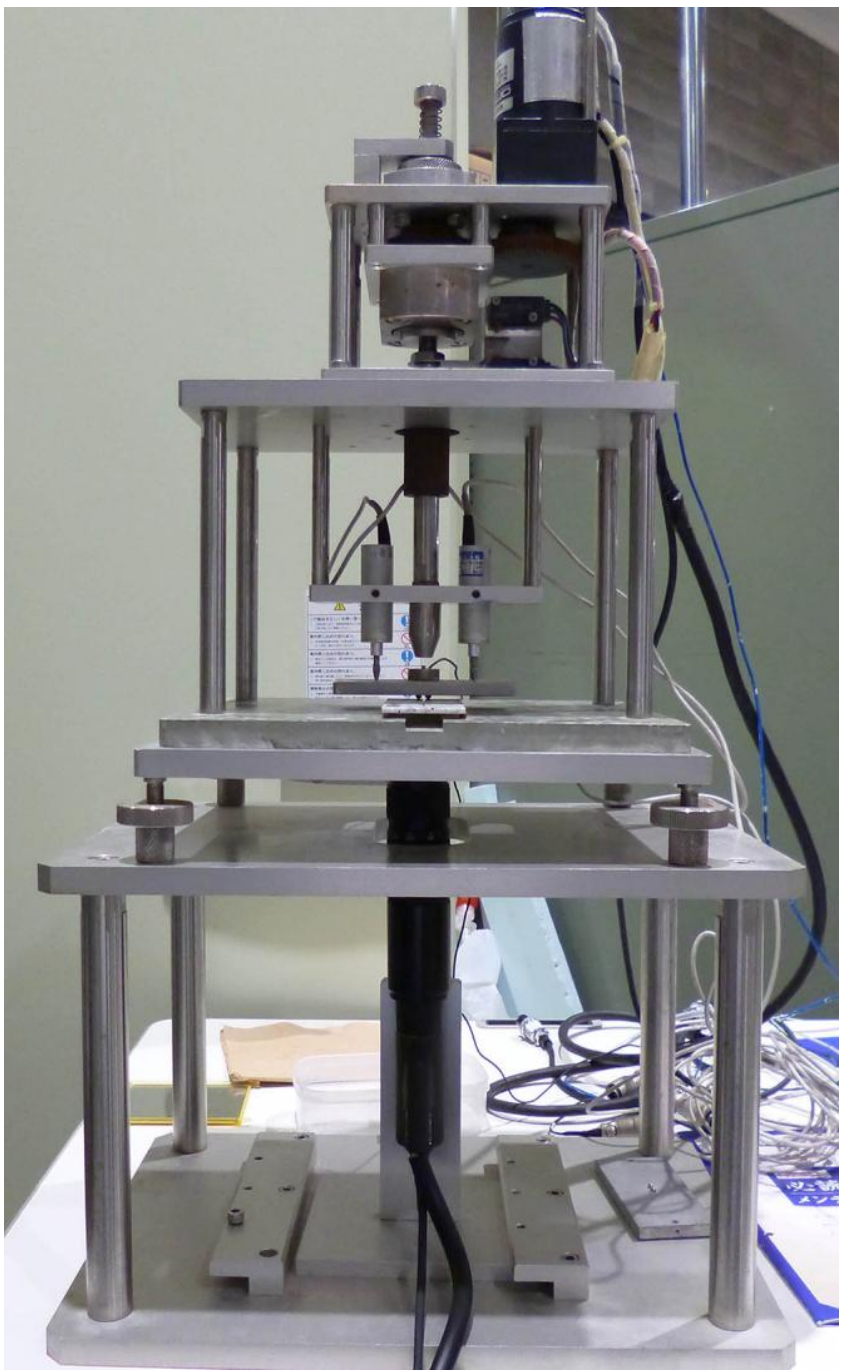

745 Figure A-1. Photo of apparatus of fracture toughness measurement by DT-CDR test.

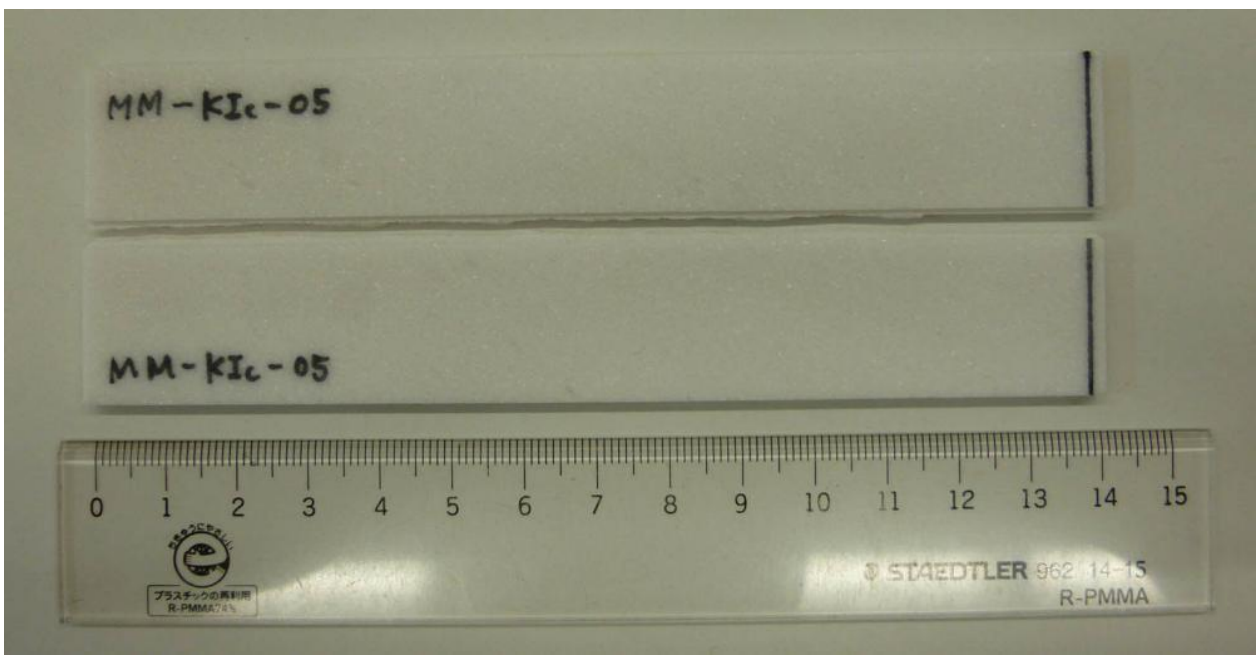

747 Figure A-2. Photo of DT specimen of Macedonian marble used in fracture toughness 

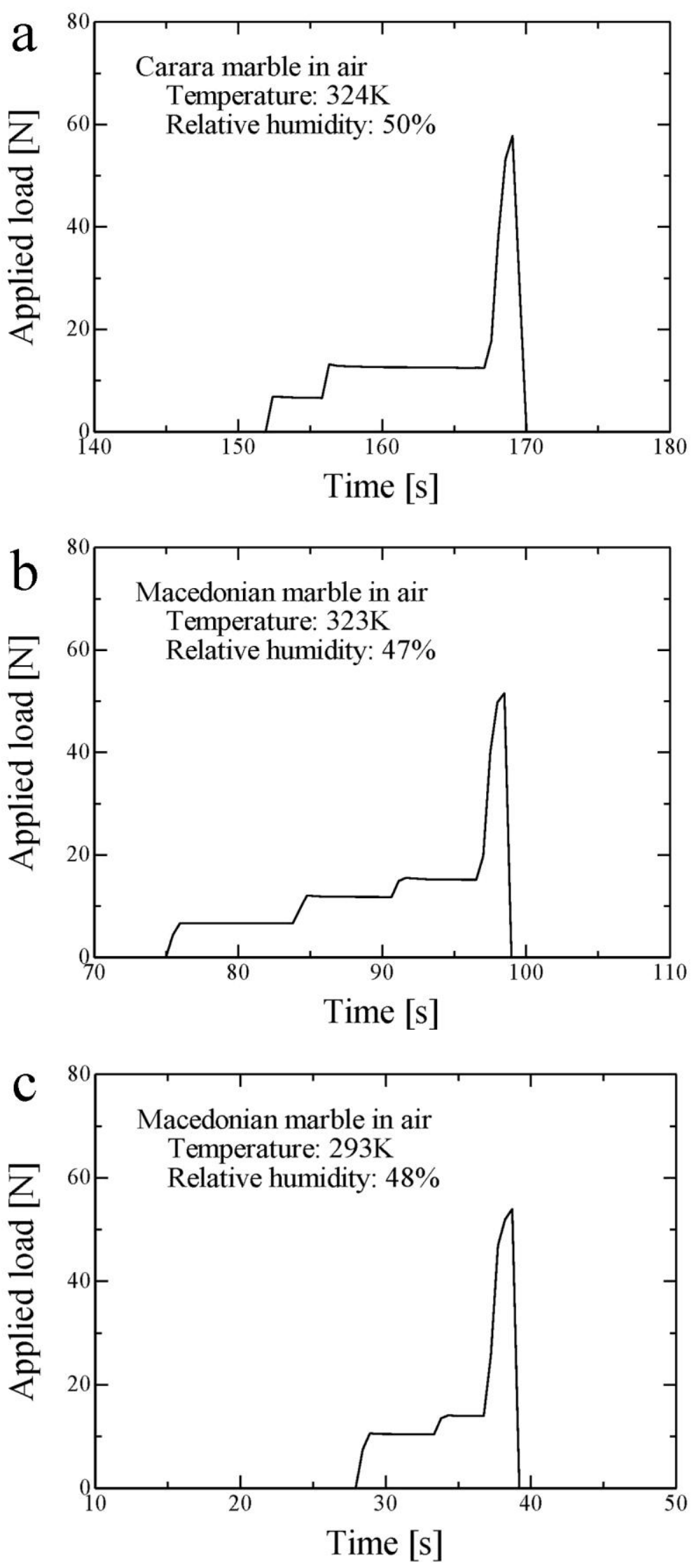

752 Figure A-3. Temporal change of applied load on DT specimen for fracture toughness 
measurement. (a): CM in air at $324 \mathrm{~K}$ with $50 \%$ relative humidity, (b) MM in air at $323 \mathrm{~K}$ with $47 \%$ relative humidity, (c): $\mathrm{MM}$ in air at $293 \mathrm{~K}$ with $48 \%$ relative

755 humidity.

756

757 


\section{$758 \quad$ Tables}

759 Table 1. Summary of subcritical crack growth measurements for Carrara marble in air with different relative humidities, and in water.

\begin{tabular}{|c|c|c|c|c|c|c|c|c|c|}
\hline \multicolumn{2}{|c|}{ Condition } & $n$ & $\log A$ & $\begin{array}{c}K_{\mathrm{I}}\left(10^{-5}\right) \\
{\left[\mathrm{MN} / \mathrm{m}^{3 / 2}\right]} \\
\text { (power law) }\end{array}$ & $\begin{array}{c}\mathrm{d} a / \mathrm{d} t(1.0) \\
{[\mathrm{m} / \mathrm{s}]} \\
\text { (power law) }\end{array}$ & $\begin{array}{c}b \\
{\left[\mathrm{~m}^{5 / 2} / \mathrm{mol}\right]}\end{array}$ & $\alpha$ & $\begin{array}{c}K_{I}\left(10^{-5}\right) \\
{\left[\mathrm{MN} / \mathrm{m}^{3 / 2}\right]} \\
\text { (exponential law) }\end{array}$ & $\begin{array}{c}\mathrm{d} a / \mathrm{d} t(1.0) \\
{[\mathrm{m} / \mathrm{s}]} \\
\text { (exponential law) }\end{array}$ \\
\hline \multirow{12}{*}{ air } & $323 \mathrm{~K}, 5 \%$ & 69 & -9.26 & 1.15 & $5.50 \times 10^{-10}$ & 0.132 & -68.3 & 1.15 & $9.08 \times 10^{-10}$ \\
\hline & $323 \mathrm{~K}, 6 \%$ & 71 & -11.15 & 1.20 & $6.31 \times 10^{-12}$ & 0.179 & -91.3 & 1.20 & $1.95 \times 10^{-11}$ \\
\hline & average & $\begin{array}{r}70 \\
\pm 1\end{array}$ & $\begin{array}{r}-10.21 \\
\pm 1.33\end{array}$ & $\begin{array}{r}1.18 \\
\pm 0.04\end{array}$ & $\begin{array}{c}\text { ave: } \\
6.17 \times 10^{-11} \\
\text { std: } 2.14 \times 10^{1} \\
\text { (in } \log \text { ) }\end{array}$ & $\begin{array}{r}0.156 \\
\pm 0.033\end{array}$ & $\begin{array}{r}-79.8 \\
\pm 16.3\end{array}$ & $\begin{array}{r}1.18 \\
\pm 0.04\end{array}$ & $\begin{array}{l}\text { ave: } 1.33 \times 10^{-10} \\
\text { std: } 1.51 \times 10^{1} \\
\text { (in } \log )\end{array}$ \\
\hline & $324 \mathrm{~K}, 49 \%$ & 92 & -6.91 & 1.05 & $1.23 \times 10^{-7}$ & 0.239 & -104.6 & 1.05 & $1.41 \times 10^{-7}$ \\
\hline & $324 \mathrm{~K}, 49 \%$ & 88 & -7.97 & 1.08 & $1.07 \times 10^{-8}$ & 0.221 & -100.1 & 1.08 & $1.48 \times 10^{-8}$ \\
\hline & $324 \mathrm{~K}, 49 \%$ & 80 & -6.23 & 1.04 & $5.89 \times 10^{-7}$ & 0.211 & -92.7 & 1.04 & $6.25 \times 10^{-7}$ \\
\hline & $323 \mathrm{~K}, 49 \%$ & 69 & -6.73 & 1.06 & $1.86 \times 10^{-7}$ & 0.177 & -81.4 & 1.06 & $1.93 \times 10^{-7}$ \\
\hline & average & $\begin{array}{r}82 \\
\pm 10\end{array}$ & $\begin{array}{r}-6.96 \\
\pm 0.73\end{array}$ & $\begin{array}{r}1.06 \\
\pm 0.02\end{array}$ & $\begin{array}{l}\text { ave: } 1.10 \times 10^{-7} \\
\text { std: } 5.37 \times 10^{0} \\
\text { (in } \log \text { ) }\end{array}$ & $\begin{array}{r}0.212 \\
\pm 0.026\end{array}$ & $\begin{array}{l}-94.7 \\
\pm 10.1\end{array}$ & $\begin{array}{r}1.06 \\
\pm 0.02\end{array}$ & $\begin{array}{l}\text { ave: } 1.26 \times 10^{-7} \\
\text { std: } 4.79 \times 10^{0} \\
\quad \text { (in } \log \text { ) }\end{array}$ \\
\hline & $324 \mathrm{~K}, 89 \%$ & 56 & -5.19 & 1.01 & $6.46 \times 10^{-6}$ & 0.152 & -68.6 & 1.01 & $6.21 \times 10^{-6}$ \\
\hline & $324 \mathrm{~K}, 92 \%$ & 54 & -6.15 & 1.05 & $7.08 \times 10^{-7}$ & 0.142 & -66.9 & 1.05 & $6.95 \times 10^{-7}$ \\
\hline & $324 \mathrm{~K}, 91 \%$ & 53 & -4.50 & 0.98 & $3.16 \times 10^{-5}$ & 0.147 & -65.1 & 0.98 & $3.20 \times 10^{-5}$ \\
\hline & average & $\begin{array}{r}54 \\
\pm 2\end{array}$ & $\begin{array}{l}-5.28 \\
\pm 0.83\end{array}$ & $\begin{array}{r}1.01 \\
\pm 0.04\end{array}$ & $\begin{array}{l}\text { ave: } 5.25 \times 10^{-6} \\
\text { std: } 6.76 \times 10^{0} \\
\text { (in log) }\end{array}$ & $\begin{array}{r}0.147 \\
\pm 0.005\end{array}$ & $\begin{array}{l}-66.9 \\
\pm 1.8\end{array}$ & $\begin{array}{r}1.01 \\
\pm 0.04\end{array}$ & $\begin{array}{l}\text { ave: } 5.13 \times 10^{-6} \\
\text { std: } 6.92 \times 10^{0} \\
\text { (in } \log \text { ) }\end{array}$ \\
\hline \multirow{4}{*}{ water } & $319 \mathrm{~K}, \mathrm{pH} 8.0$ & 34 & -3.37 & 0.89 & $4.27 \times 10^{-4}$ & 0.102 & -46.0 & 0.90 & $5.64 \times 10^{-4}$ \\
\hline & $314 \mathrm{~K}, \mathrm{pH} 7.8$ & 25 & -2.63 & 0.80 & $2.34 \times 10^{-3}$ & 0.075 & -34.5 & 0.80 & $3.20 \times 10^{-3}$ \\
\hline & 314K, pH8.1 & 39 & -1.34 & 0.81 & $4.57 \times 10^{-2}$ & 0.128 & -51.1 & 0.81 & $1.19 \times 10^{-1}$ \\
\hline & average & $\begin{array}{l}33 \\
\pm 7\end{array}$ & $\begin{array}{l}-2.45 \\
\pm 1.03\end{array}$ & $\begin{array}{r}0.83 \\
\pm 0.05\end{array}$ & $\begin{array}{l}\text { ave: } 3.57 \times 10^{-3} \\
\text { std: } 1.05 \times 10^{1} \\
\text { (in } \log \text { ) }\end{array}$ & $\begin{array}{r}0.102 \\
\pm 0.027\end{array}$ & $\begin{array}{l}-43.9 \\
\pm 8.5\end{array}$ & $\begin{array}{r}0.84 \\
\pm 0.06\end{array}$ & $\begin{array}{l}\text { ave: } 5.99 \times 10^{-3} \\
\text { std: } 1.55 \times 10^{1} \\
\text { (in } \log )\end{array}$ \\
\hline
\end{tabular}

761 ave: average, std: standard deviation 
764 Table 2. Summary of subcritical crack growth measurements for Macedonian marble

765 in air with different relative humidities, and in water.

766

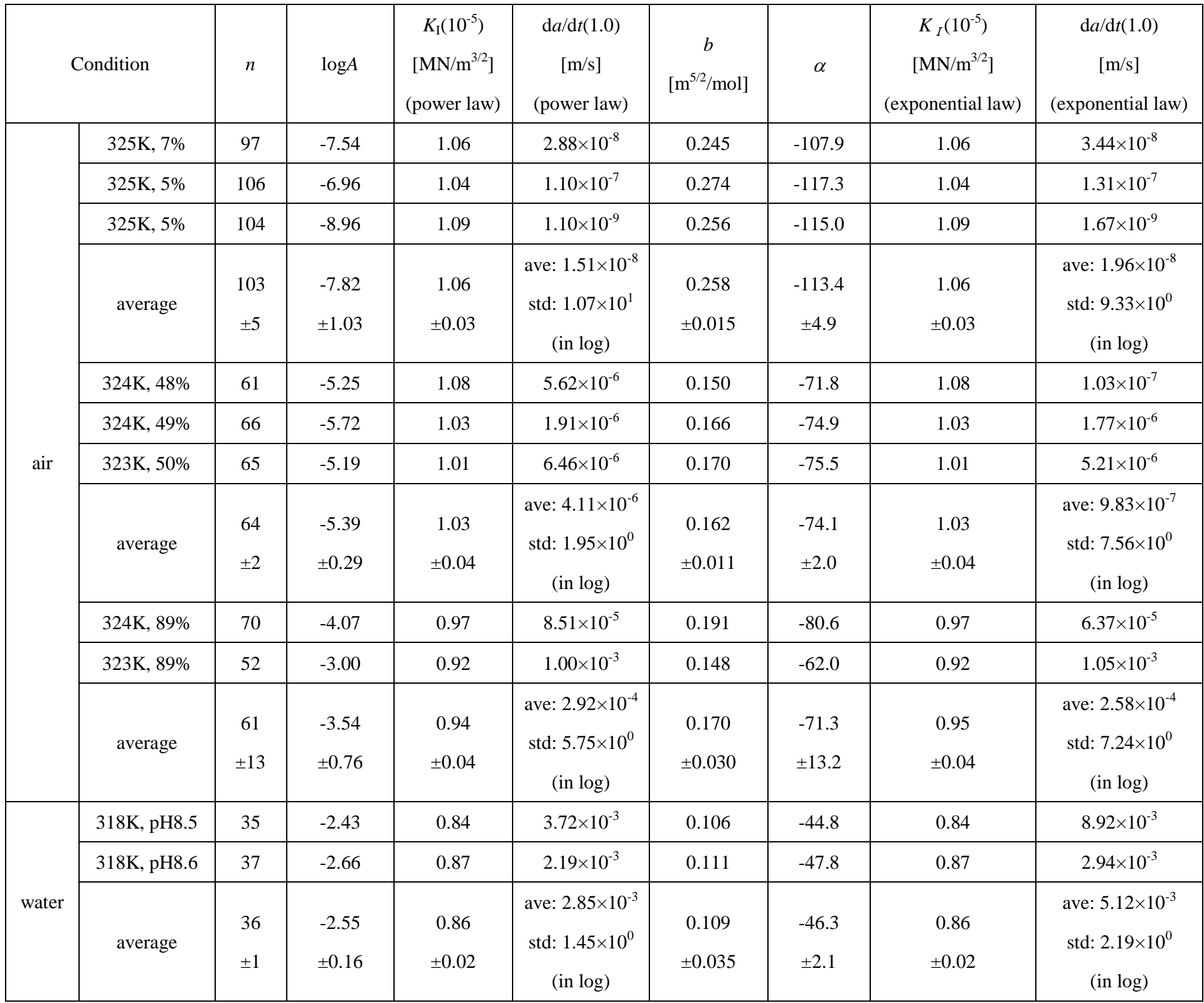

767

ave: average, std: standard deviation

768

769

770 
772 Table 3. Summary of subcritical crack growth measurements for Carrara marble in air

773 and water at different temperatures.

774

\begin{tabular}{|c|c|c|c|c|c|c|c|c|c|}
\hline \multicolumn{2}{|r|}{ Condition } & $n$ & $\log A$ & $\begin{array}{c}K_{\mathrm{I}}\left(10^{-5}\right) \\
{\left[\mathrm{MN} / \mathrm{m}^{3 / 2}\right]} \\
\text { (power law) }\end{array}$ & $\begin{array}{c}\mathrm{d} a / \mathrm{d} t(1.0) \\
{[\mathrm{m} / \mathrm{s}]} \\
\text { (power law) }\end{array}$ & $\begin{array}{c}b \\
{\left[\mathrm{~m}^{5 / 2} / \mathrm{mol}\right]}\end{array}$ & $\alpha$ & $\begin{array}{c}K_{I}\left(10^{-5}\right) \\
{\left[\mathrm{MN} / \mathrm{m}^{3 / 2}\right]} \\
\text { (exponential law) }\end{array}$ & $\begin{array}{c}\mathrm{d} a / \mathrm{d} t(1.0) \\
{[\mathrm{m} / \mathrm{s}]} \\
\text { (exponential law) }\end{array}$ \\
\hline \multirow{9}{*}{ air } & $293 \mathrm{~K}, 47 \%$ & 81 & -9.85 & 1.15 & $1.41 \times 10^{-10}$ & 0.174 & -93.5 & 1.15 & $2.70 \times 10^{-10}$ \\
\hline & $293 \mathrm{~K}, 47 \%$ & 75 & -6.31 & 1.04 & $4.90 \times 10^{-7}$ & 0.179 & -88.1 & 1.04 & $4.47 \times 10^{-7}$ \\
\hline & $293 \mathrm{~K}, 47 \%$ & 73 & -7.59 & 1.09 & $2.57 \times 10^{-8}$ & 0.165 & -85.2 & 1.09 & $2.65 \times 10^{-8}$ \\
\hline & average & $\begin{array}{l}77 \\
\pm 4\end{array}$ & $\begin{array}{r}-7.92 \\
\pm 1.79\end{array}$ & $\begin{array}{r}1.09 \\
\pm 0.06\end{array}$ & $\begin{array}{l}\text { ave: } 1.21 \times 10^{-8} \\
\text { std: } 6.17 \times 10^{1} \\
\text { (in } \log )\end{array}$ & $\begin{array}{c}0.173 \\
\pm 0.007\end{array}$ & $\begin{array}{l}-88.9 \\
\pm 4.2\end{array}$ & $\begin{array}{r}1.09 \\
\pm 0.06\end{array}$ & $\begin{array}{l}\text { ave: } 1.47 \times 10^{-8} \\
\text { std: } 4.17 \times 10^{1} \\
\text { (in } \log )\end{array}$ \\
\hline & $324 \mathrm{~K}, 49 \%$ & 92 & -6.91 & 1.05 & $1.23 \times 10^{-7}$ & 0.239 & -104.6 & 1.05 & $1.41 \times 10^{-7}$ \\
\hline & $324 \mathrm{~K}, 49 \%$ & 88 & -7.97 & 1.08 & $1.07 \times 10^{-8}$ & 0.221 & -100.1 & 1.08 & $1.48 \times 10^{-8}$ \\
\hline & $324 \mathrm{~K}, 49 \%$ & 80 & -6.23 & 1.04 & $5.89 \times 10^{-7}$ & 0.211 & -92.7 & 1.04 & $6.25 \times 10^{-7}$ \\
\hline & $323 \mathrm{~K}, 49 \%$ & 69 & -6.73 & 1.06 & $1.86 \times 10^{-7}$ & 0.177 & -81.4 & 1.06 & $1.93 \times 10^{-7}$ \\
\hline & average & $\begin{array}{c}82 \\
\pm 10\end{array}$ & $\begin{array}{l}-6.96 \\
\pm 0.73\end{array}$ & $\begin{array}{r}1.06 \\
\pm 0.02\end{array}$ & $\begin{array}{l}\text { ave: } 1.10 \times 10^{-7} \\
\text { std: } 5.37 \times 10^{0} \\
\text { (in } \log )\end{array}$ & $\begin{array}{r}0.212 \\
\pm 0.026\end{array}$ & $\begin{array}{l}-94.7 \\
\pm 10.1\end{array}$ & $\begin{array}{r}1.06 \\
\pm 0.02\end{array}$ & $\begin{array}{l}\text { ave: } 1.26 \times 10^{-7} \\
\text { std: } 4.79 \times 10^{0} \\
\text { (in } \log )\end{array}$ \\
\hline \multirow{8}{*}{ water } & $290 \mathrm{~K}, \mathrm{pH} 8.2$ & 30 & -3.14 & 0.87 & $7.24 \times 10^{-4}$ & 0.093 & -46.0 & 0.90 & $6.25 \times 10^{-4}$ \\
\hline & $290 \mathrm{~K}, \mathrm{pH} 8.1$ & 35 & -4.58 & 0.97 & $2.63 \times 10^{-5}$ & 0.088 & -47.0 & 0.97 & $2.91 \times 10^{-5}$ \\
\hline & $290 \mathrm{~K}, \mathrm{pH} 8.2$ & 35 & -4.52 & 0.97 & $3.02 \times 10^{-5}$ & 0.088 & -46.9 & 0.97 & $3.11 \times 10^{-5}$ \\
\hline & average & $\begin{array}{l}33 \\
\pm 3\end{array}$ & $\begin{array}{l}-4.08 \\
\pm 0.81\end{array}$ & $\begin{array}{r}0.94 \\
\pm 0.06\end{array}$ & $\begin{array}{l}\text { ave: } 8.32 \times 10^{-5} \\
\text { std: } 6.46 \times 10^{0} \\
\quad \text { (in } \log )\end{array}$ & $\begin{array}{r}0.090 \\
\pm 0.003\end{array}$ & $\begin{array}{l}-46.6 \\
\pm 0.6\end{array}$ & $\begin{array}{r}0.95 \\
\pm 0.04\end{array}$ & $\begin{array}{l}\text { ave: } 8.27 \times 10^{-5} \\
\text { std: } 5.75 \times 10^{0} \\
\quad \text { (in } \log \text { ) }\end{array}$ \\
\hline & $319 \mathrm{~K}, \mathrm{pH} 8.0$ & 34 & -3.37 & 0.89 & $4.27 \times 10^{-4}$ & 0.102 & -46.0 & 0.90 & $5.64 \times 10^{-4}$ \\
\hline & $314 \mathrm{~K}, \mathrm{pH} 7.8$ & 25 & -2.63 & 0.80 & $2.34 \times 10^{-3}$ & 0.075 & -34.5 & 0.80 & $3.20 \times 10^{-3}$ \\
\hline & 314K, pH8.1 & 39 & -1.34 & 0.81 & $4.57 \times 10^{-2}$ & 0.128 & -51.1 & 0.81 & $1.19 \times 10^{-1}$ \\
\hline & average & $\begin{array}{l}33 \\
\pm 7\end{array}$ & $\begin{array}{r}-2.45 \\
\pm 1.03\end{array}$ & $\begin{array}{c}0.83 \\
\pm 0.05\end{array}$ & $\begin{array}{l}\text { ave: } 3.57 \times 10^{-3} \\
\text { std: } 1.05 \times 10^{1} \\
\quad(\text { in } \log )\end{array}$ & $\begin{array}{c}0.102 \\
\pm 0.027\end{array}$ & $\begin{array}{l}-43.9 \\
\pm 8.5\end{array}$ & $\begin{array}{r}0.84 \\
\pm 0.06\end{array}$ & $\begin{array}{l}\text { ave: } 5.99 \times 10^{-3} \\
\text { std: } 1.55 \times 10^{1} \\
\text { (in } \log \text { ) }\end{array}$ \\
\hline
\end{tabular}

775 ave: average, std: standard deviation 
778

Table 4. Summary of subcritical crack growth measurements for Macedonian marble

779 in air and water at different temperatures.

780

\begin{tabular}{|c|c|c|c|c|c|c|c|c|c|}
\hline \multicolumn{2}{|c|}{ Condition } & $n$ & $\log A$ & $\begin{array}{c}K_{\mathrm{I}}\left(10^{-5}\right) \\
{\left[\mathrm{MN} / \mathrm{m}^{3 / 2}\right]} \\
\text { (power law) }\end{array}$ & $\begin{array}{c}\mathrm{d} a / \mathrm{d} t(1.0) \\
{[\mathrm{m} / \mathrm{s}]} \\
\text { (power law) }\end{array}$ & $\begin{array}{c}b \\
{\left[\mathrm{~m}^{5 / 2} / \mathrm{mol}\right]}\end{array}$ & $\alpha$ & $\begin{array}{c}K_{I}\left(10^{-5}\right) \\
{\left[\mathrm{MN} / \mathrm{m}^{3 / 2}\right]} \\
\text { (exponential law) }\end{array}$ & $\begin{array}{c}\mathrm{d} a / \mathrm{d} t(1.0) \\
{[\mathrm{m} / \mathrm{s}]} \\
\text { (exponential law) }\end{array}$ \\
\hline \multirow{8}{*}{ air } & $293 \mathrm{~K}, 50 \%$ & 61 & -7.02 & 1.08 & $9.55 \times 10^{-8}$ & 0.136 & -71.8 & 1.08 & $1.19 \times 10^{-7}$ \\
\hline & $293 \mathrm{~K}, 50 \%$ & 60 & -6.75 & 1.07 & $1.78 \times 10^{-7}$ & 0.133 & -70.0 & 1.07 & $2.10 \times 10^{-7}$ \\
\hline & $324 \mathrm{~K}, 48 \%$ & 61 & -5.25 & 1.08 & $5.62 \times 10^{-6}$ & 0.150 & -71.8 & 1.08 & $1.03 \times 10^{-7}$ \\
\hline & $324 \mathrm{~K}, 49 \%$ & 66 & -5.72 & 1.03 & $1.91 \times 10^{-6}$ & 0.166 & -74.9 & 1.03 & $1.77 \times 10^{-6}$ \\
\hline & $351 \mathrm{~K}, 50 \%$ & 55 & -3.14 & 0.93 & $7.24 \times 10^{-4}$ & 0.167 & -64.7 & 0.93 & $5.84 \times 10^{-4}$ \\
\hline & $351 \mathrm{~K}, 50 \%$ & 74 & -3.34 & 0.95 & $4.57 \times 10^{-4}$ & 0.224 & -84.4 & 0.95 & $4.99 \times 10^{-4}$ \\
\hline & $351 \mathrm{~K}, 50 \%$ & 77 & -3.79 & 0.96 & $1.62 \times 10^{-4}$ & 0.228 & -87.0 & 0.96 & $1.46 \times 10^{-4}$ \\
\hline & average & $\begin{array}{r}69 \\
\pm 12\end{array}$ & $\begin{array}{l}-3.42 \\
\pm 0.33\end{array}$ & $\begin{array}{r}0.95 \\
\pm 0.02\end{array}$ & $\begin{array}{l}\text { ave: } 4.55 \times 10^{-4} \\
\text { std: } 2.14 \times 10^{0} \\
\text { (in } \log )\end{array}$ & $\begin{array}{r}0.206 \\
\pm 0.034\end{array}$ & $\begin{array}{r}-78.7 \\
\pm 12.2\end{array}$ & $\begin{array}{c}0.95 \\
\pm 0.02\end{array}$ & $\begin{array}{l}\text { ave: } 3.49 \times 10^{-5} \\
\text { std: } 2.14 \times 10^{0} \\
\text { (in } \log )\end{array}$ \\
\hline \multirow{3}{*}{ water } & $318 \mathrm{~K}, \mathrm{pH} 8.5$ & 35 & -2.43 & 0.84 & $3.72 \times 10^{-3}$ & 0.106 & -44.8 & 0.84 & $8.92 \times 10^{-3}$ \\
\hline & $318 \mathrm{~K}, \mathrm{pH} 8.6$ & 37 & -2.66 & 0.87 & $2.19 \times 10^{-3}$ & 0.111 & -47.8 & 0.87 & $2.94 \times 10^{-3}$ \\
\hline & average & $\begin{array}{l}36 \\
\pm 1\end{array}$ & $\begin{array}{l}-2.55 \\
\pm 0.16\end{array}$ & $\begin{array}{r}0.86 \\
\pm 0.02\end{array}$ & $\begin{array}{l}\text { ave: } 2.85 \times 10^{-3} \\
\text { std: } 1.45 \times 10^{0} \\
\quad \text { (in } \log )\end{array}$ & $\begin{array}{r}0.109 \\
\pm 0.035\end{array}$ & $\begin{array}{l}-46.3 \\
\pm 2.1\end{array}$ & $\begin{array}{r}0.86 \\
\pm 0.02\end{array}$ & $\begin{array}{l}\text { ave: } 5.12 \times 10^{-3} \\
\text { std: } 2.19 \times 10^{0} \\
\text { (in } \log \text { ) }\end{array}$ \\
\hline
\end{tabular}

781 ave: average, std: standard deviation 
783 Table 5. Summary of fracture toughness measurement for marble in air.

\begin{tabular}{|c|c|c|}
\hline \multirow{2}{*}{ Rock } & Condition & Fracture toughness $\left[\mathrm{MN} / \mathrm{m}^{3 / 2}\right]$ \\
\hline \multirow{4}{*}{ CM } & $323 \mathrm{~K}, 50 \%$ & 1.36 \\
\cline { 2 - 3 } & $323 \mathrm{~K}, 50 \%$ & 1.32 \\
\cline { 2 - 3 } & $323 \mathrm{~K}, 50 \%$ & 1.26 \\
\cline { 2 - 3 } & average & $1.31 \pm 0.05$ \\
\hline \multirow{5}{*}{ MM } & $293 \mathrm{~K}, 47 \%$ & 1.32 \\
\cline { 2 - 3 } & $293 \mathrm{~K}, 48 \%$ & 1.30 \\
\cline { 2 - 3 } & average & $1.31 \pm 0.01$ \\
\cline { 2 - 3 } & $323 \mathrm{~K}, 45 \%$ & 1.33 \\
\cline { 2 - 3 } & $323 \mathrm{~K}, 48 \%$ & 1.27 \\
\cline { 2 - 3 } & 323K, 47\% & 1.25 \\
\cline { 2 - 3 } & average & $1.28 \pm 0.04$ \\
\hline
\end{tabular}

784

785

786

787

788 The English in this document has been checked by at least two professional editors, both

789 native speakers of English, from an English editing service company:

790 https://www.zenis.co.jp/eng/index.html 
Figure1a
Click here to download high resolution image

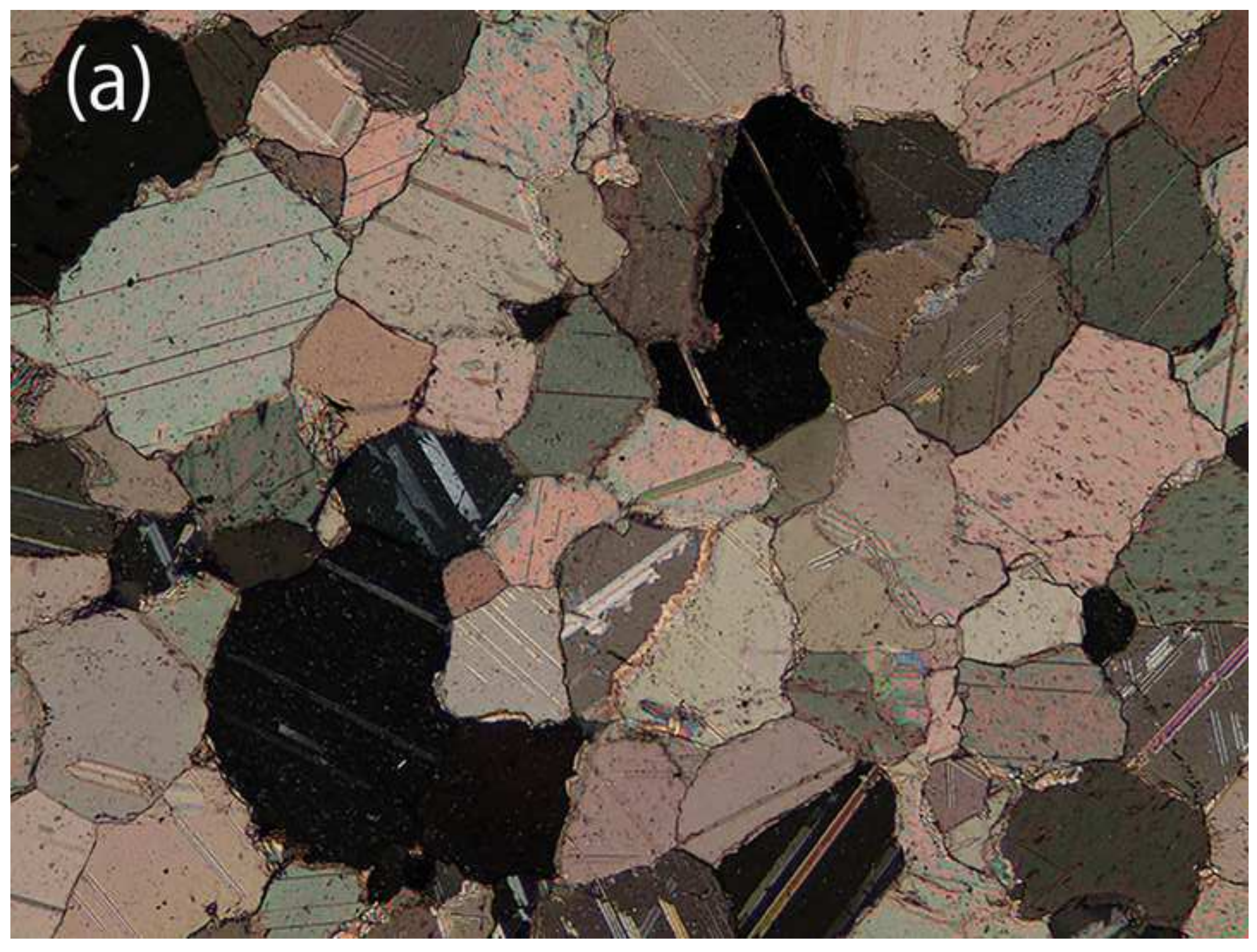


Click here to download high resolution image

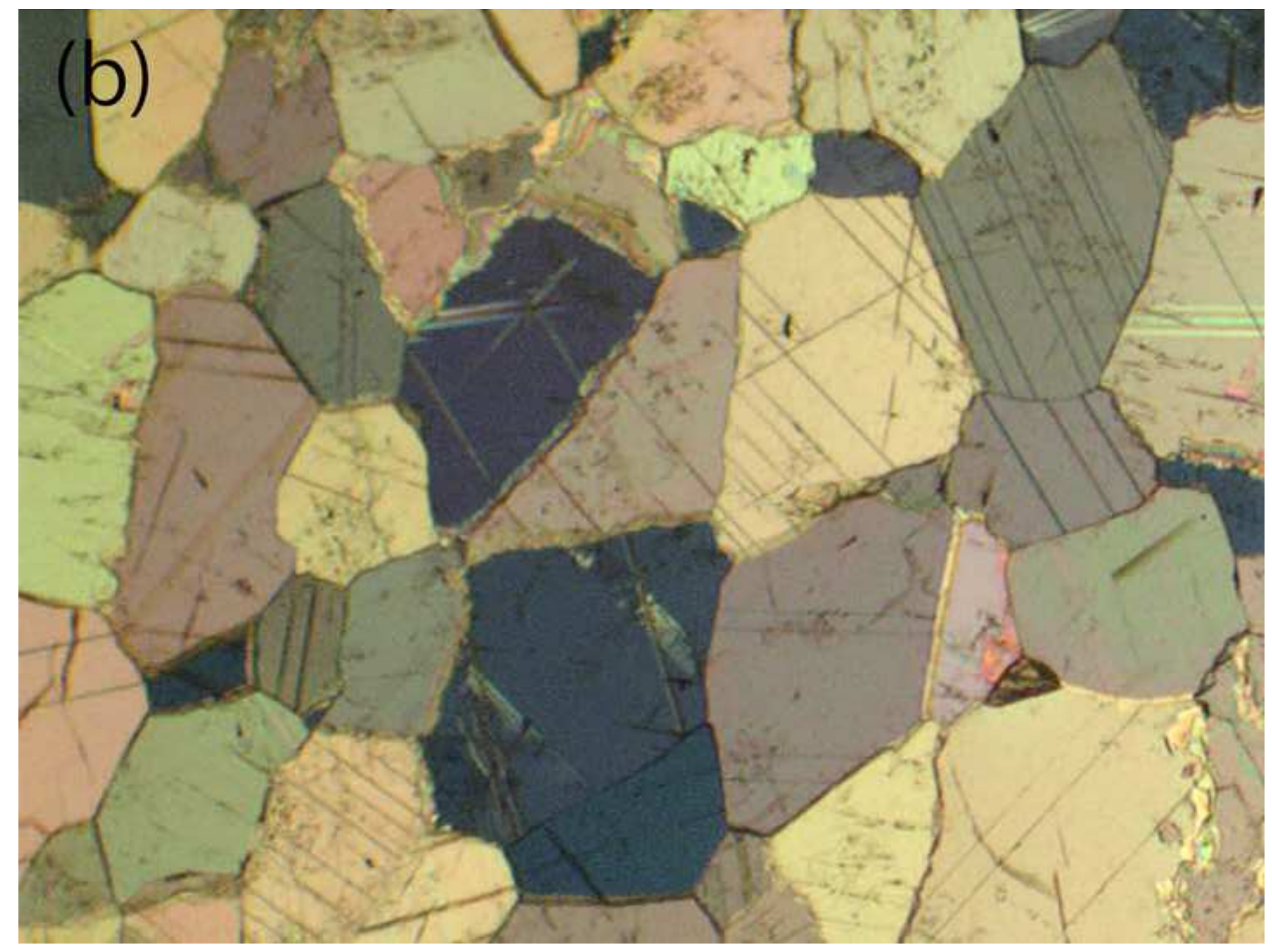




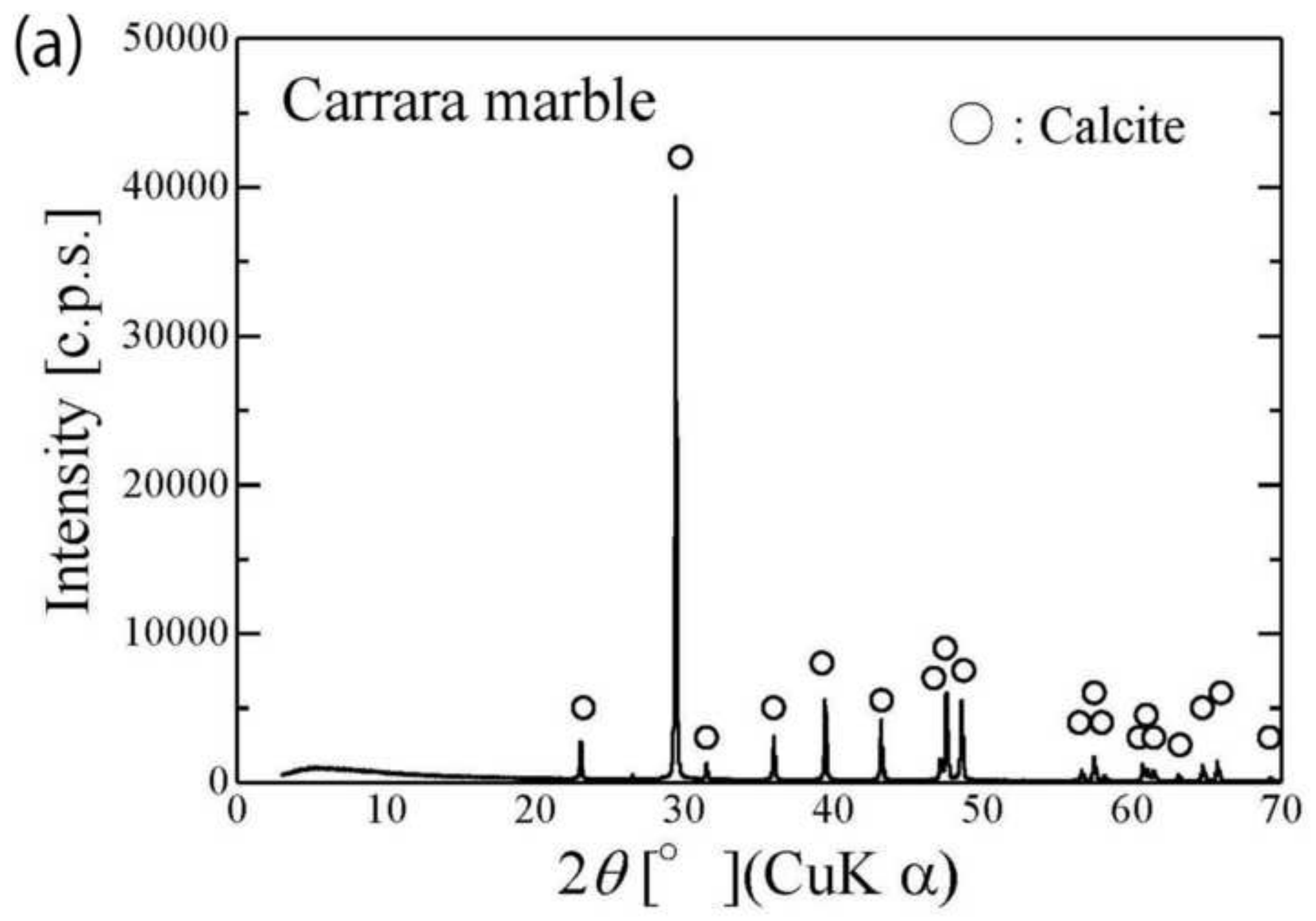




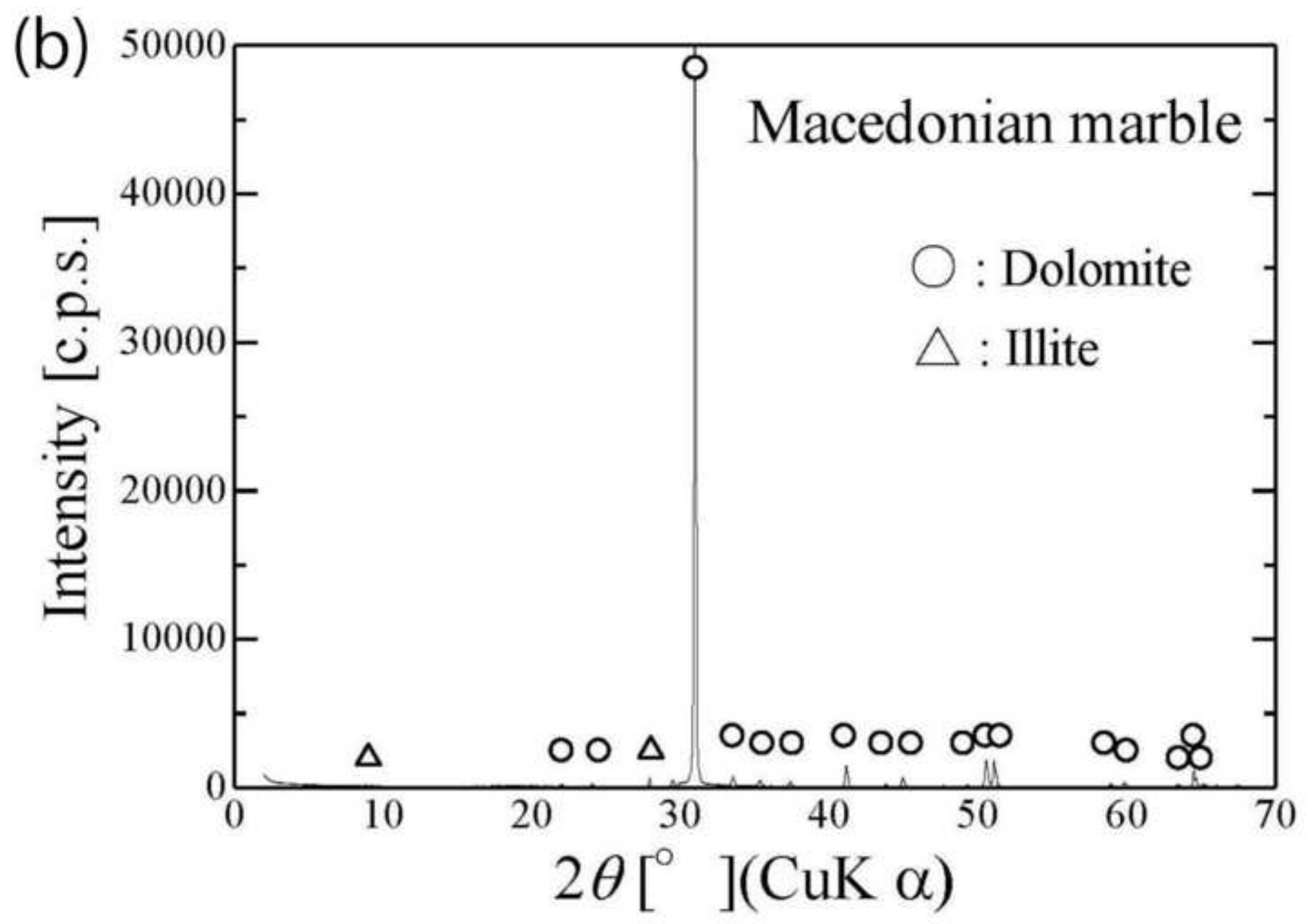




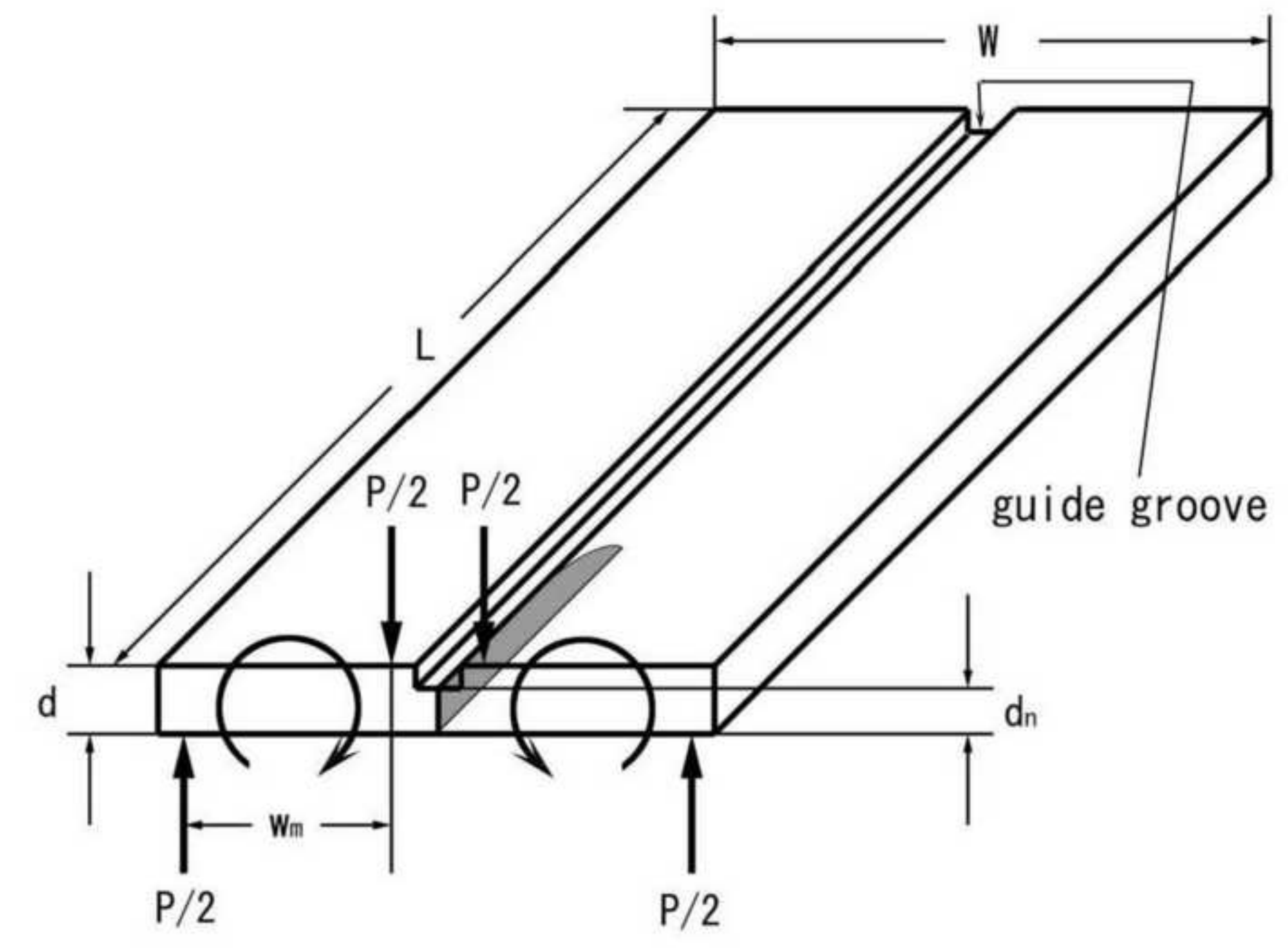




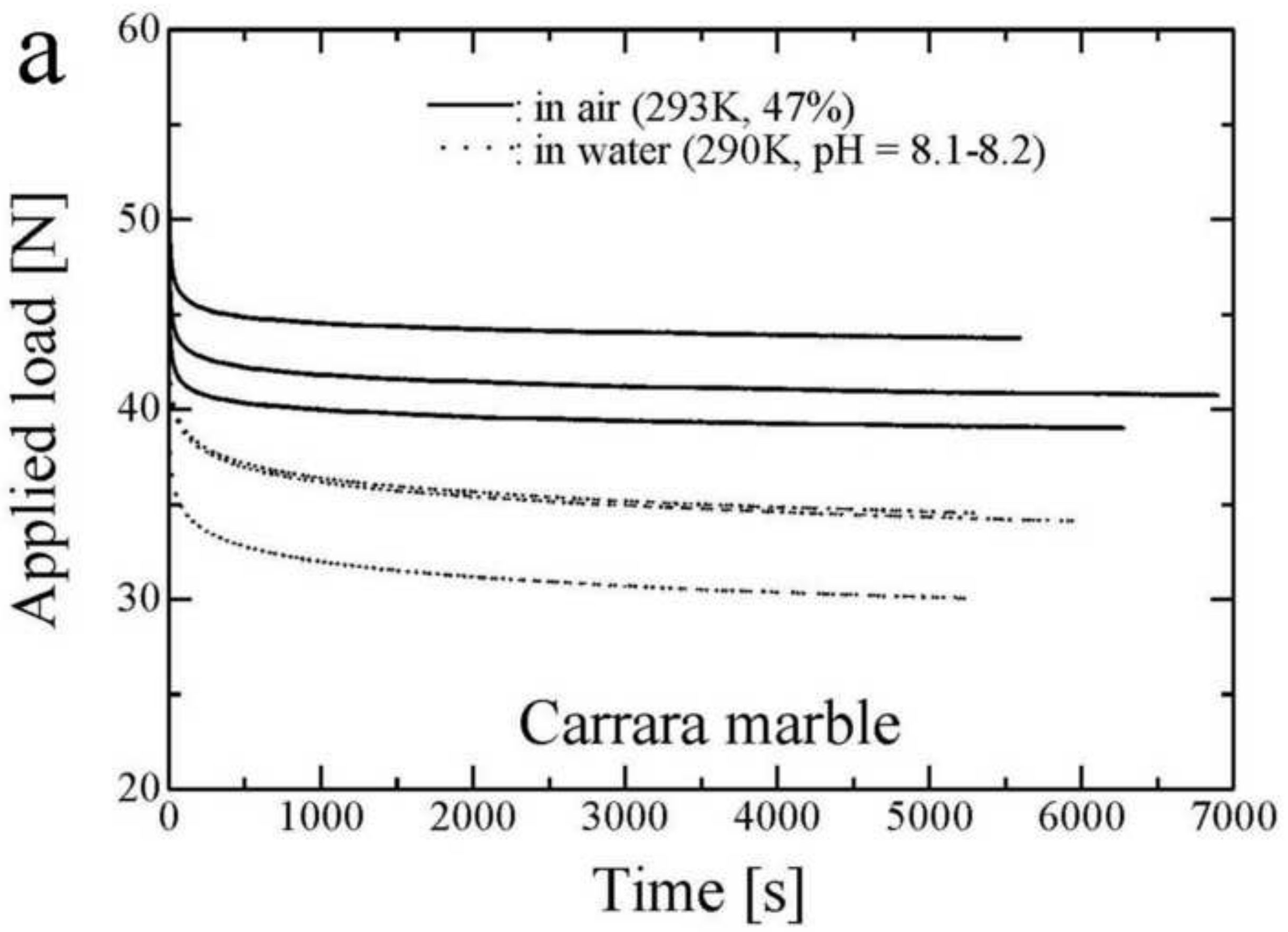




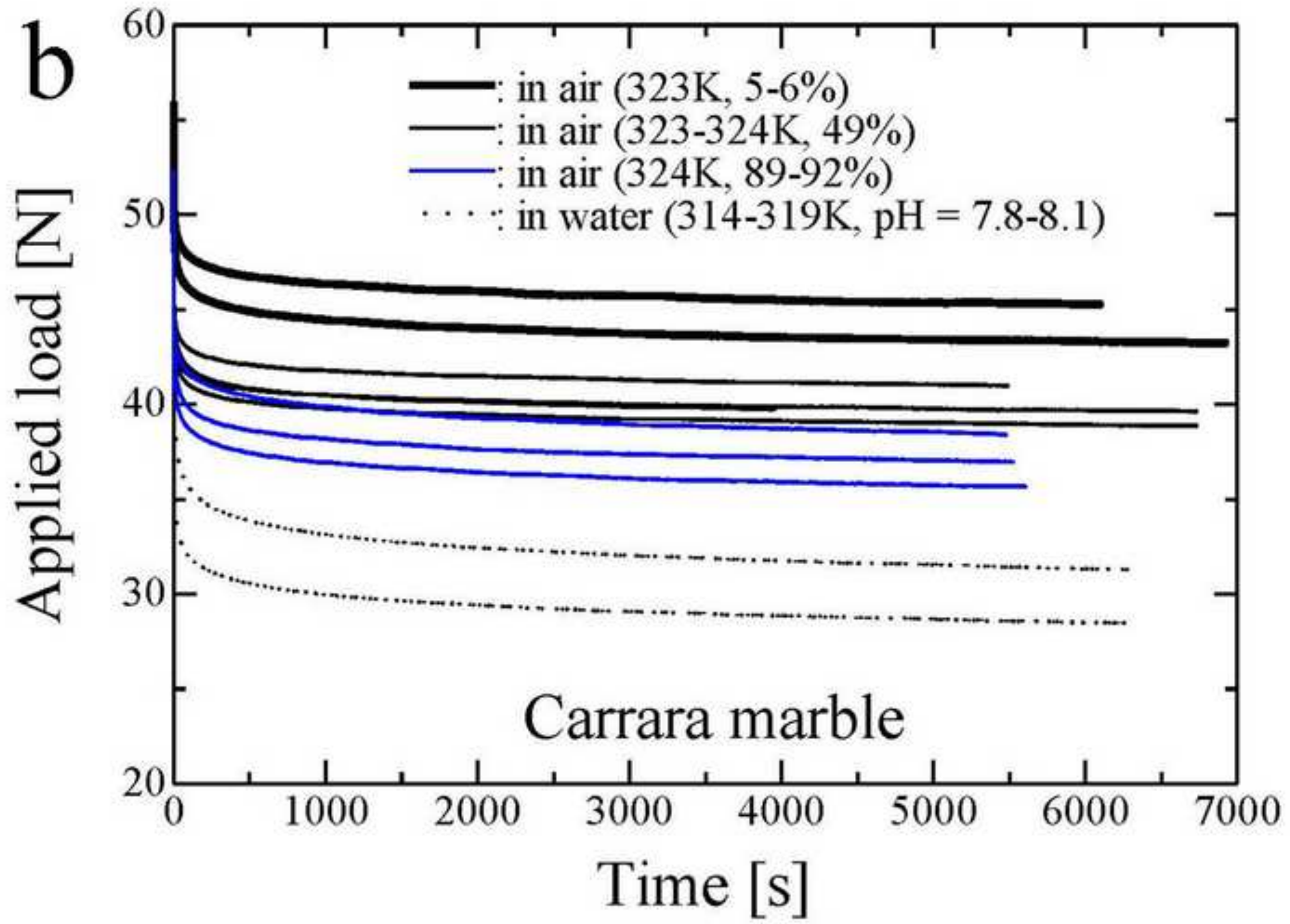




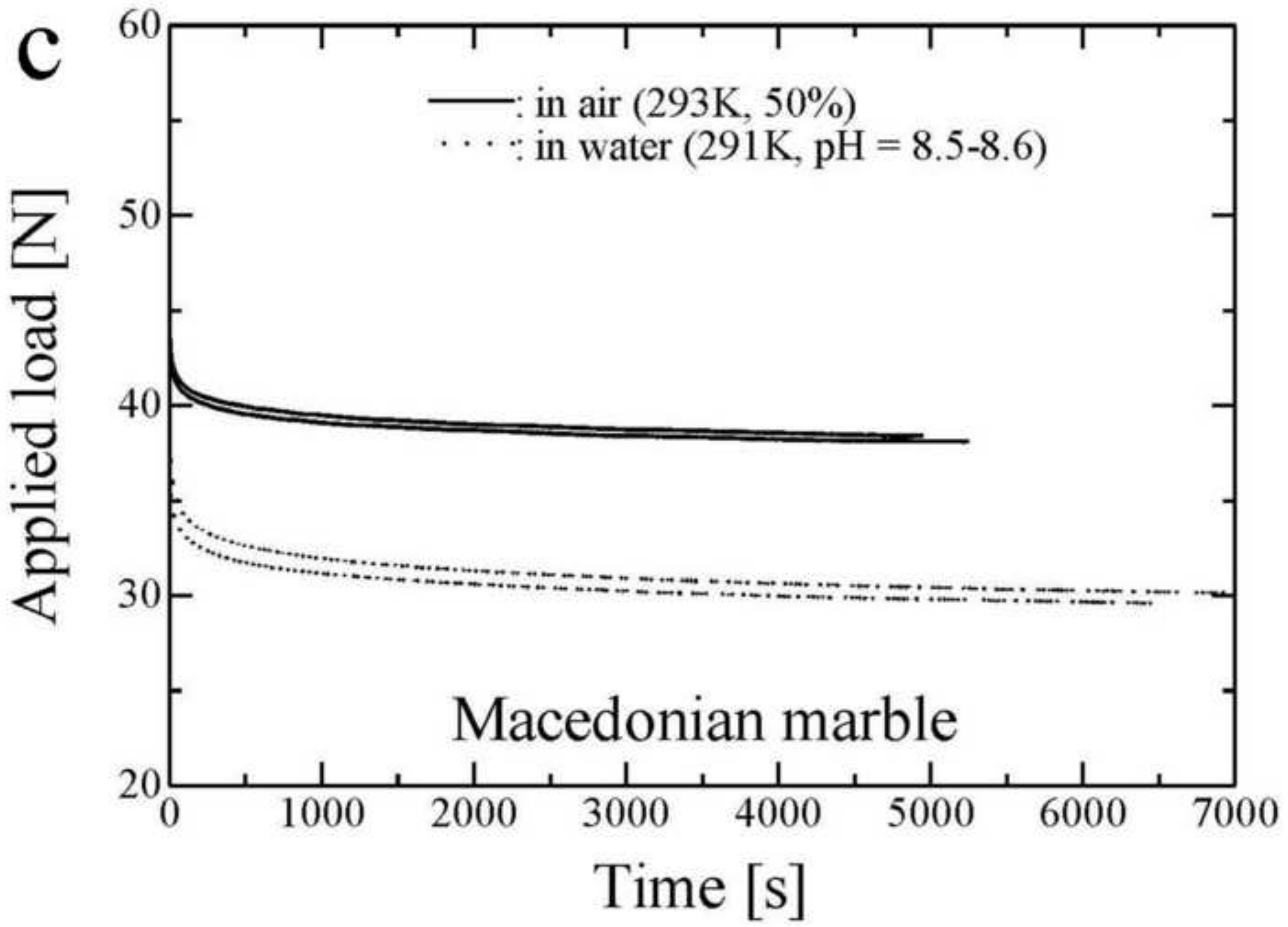




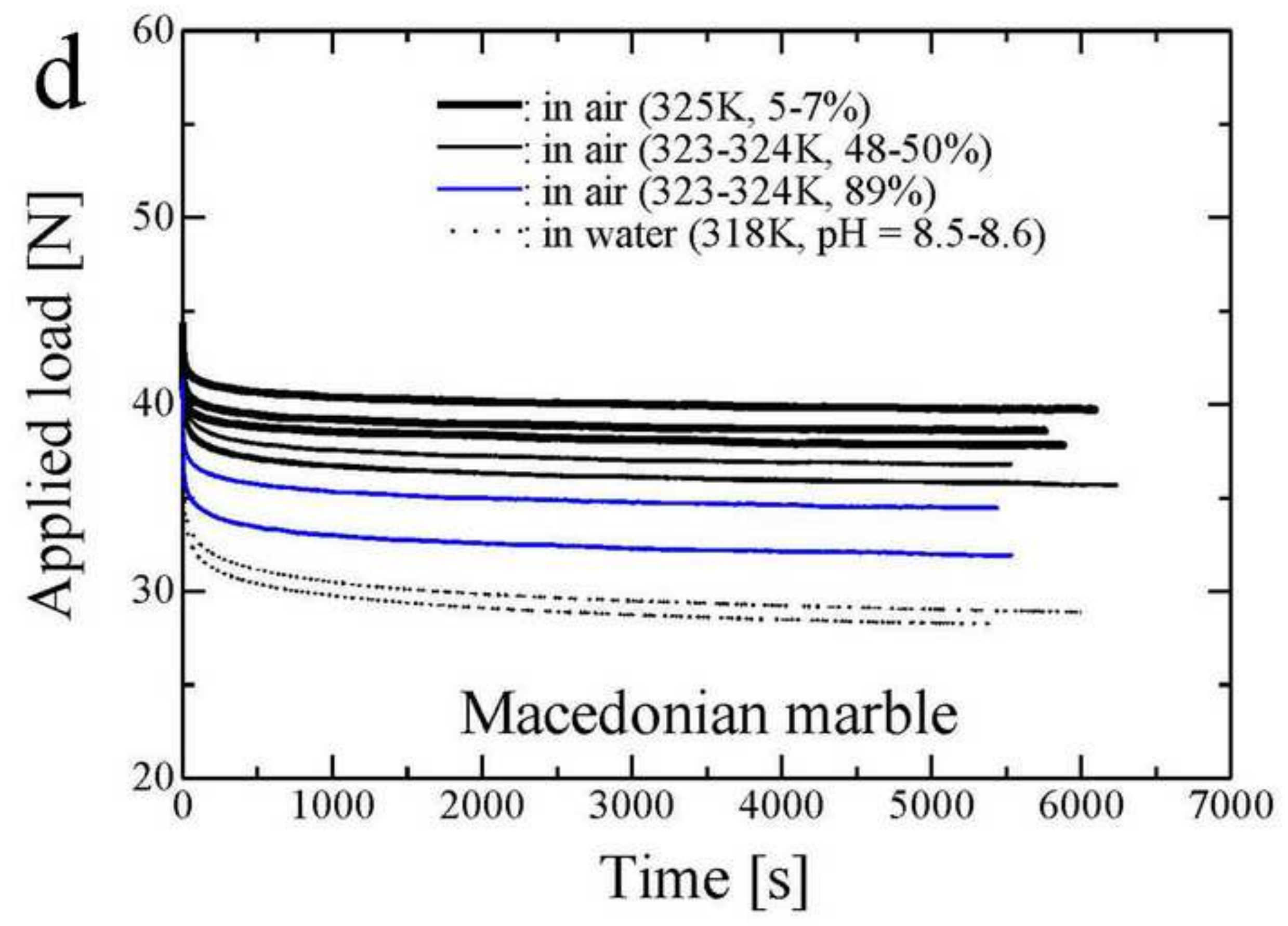




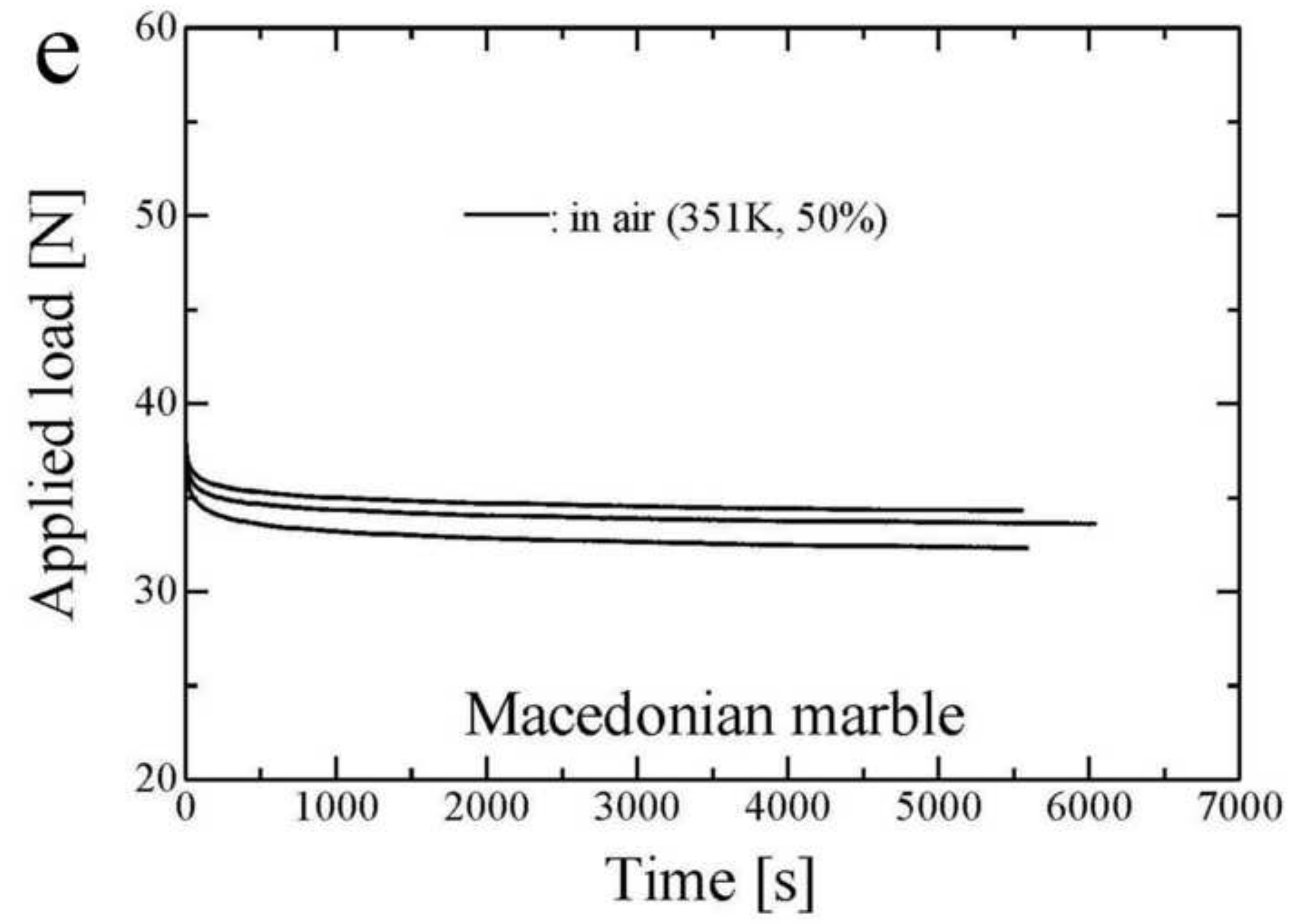

Click here to download high resolution image 


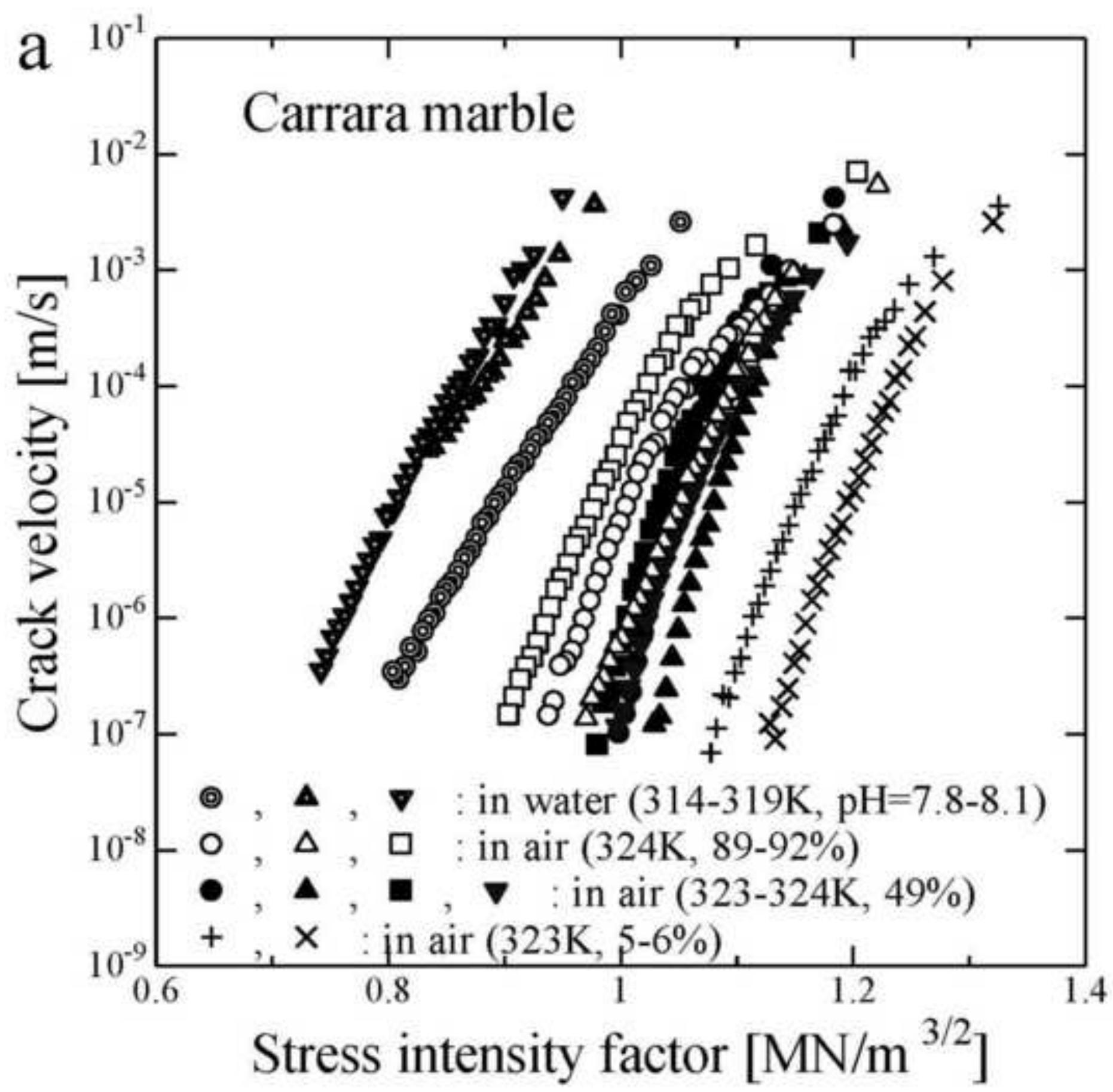




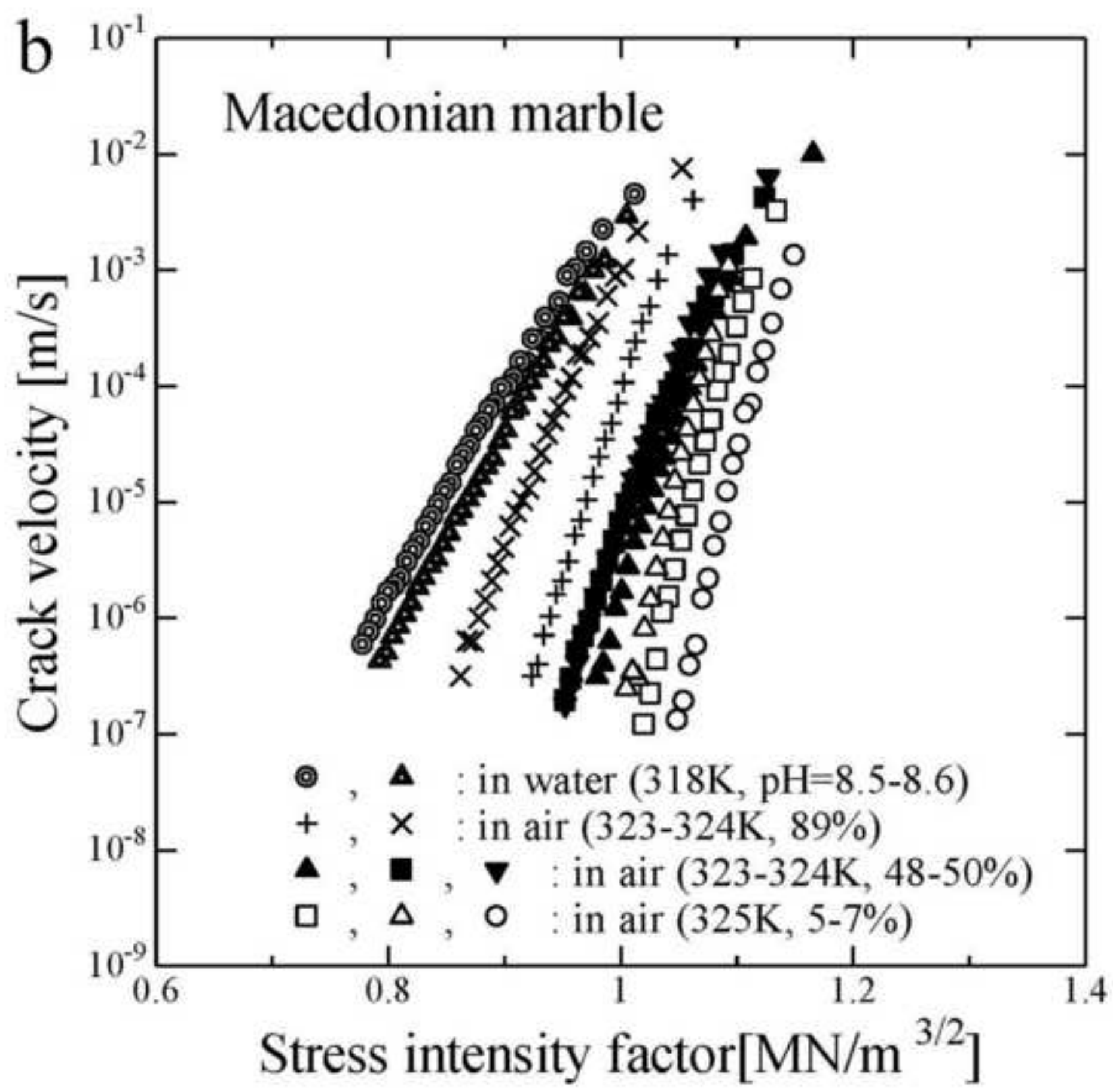




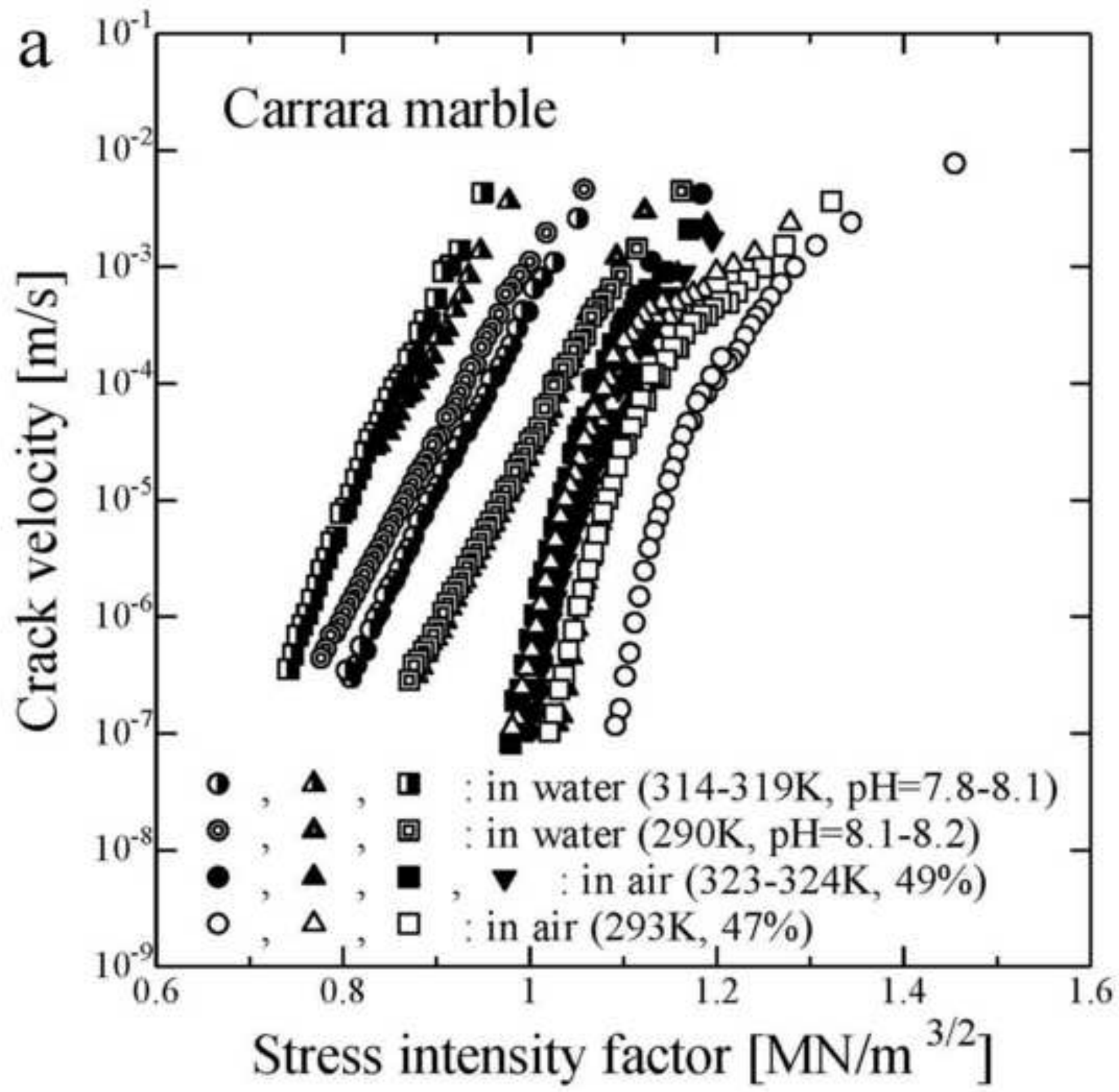




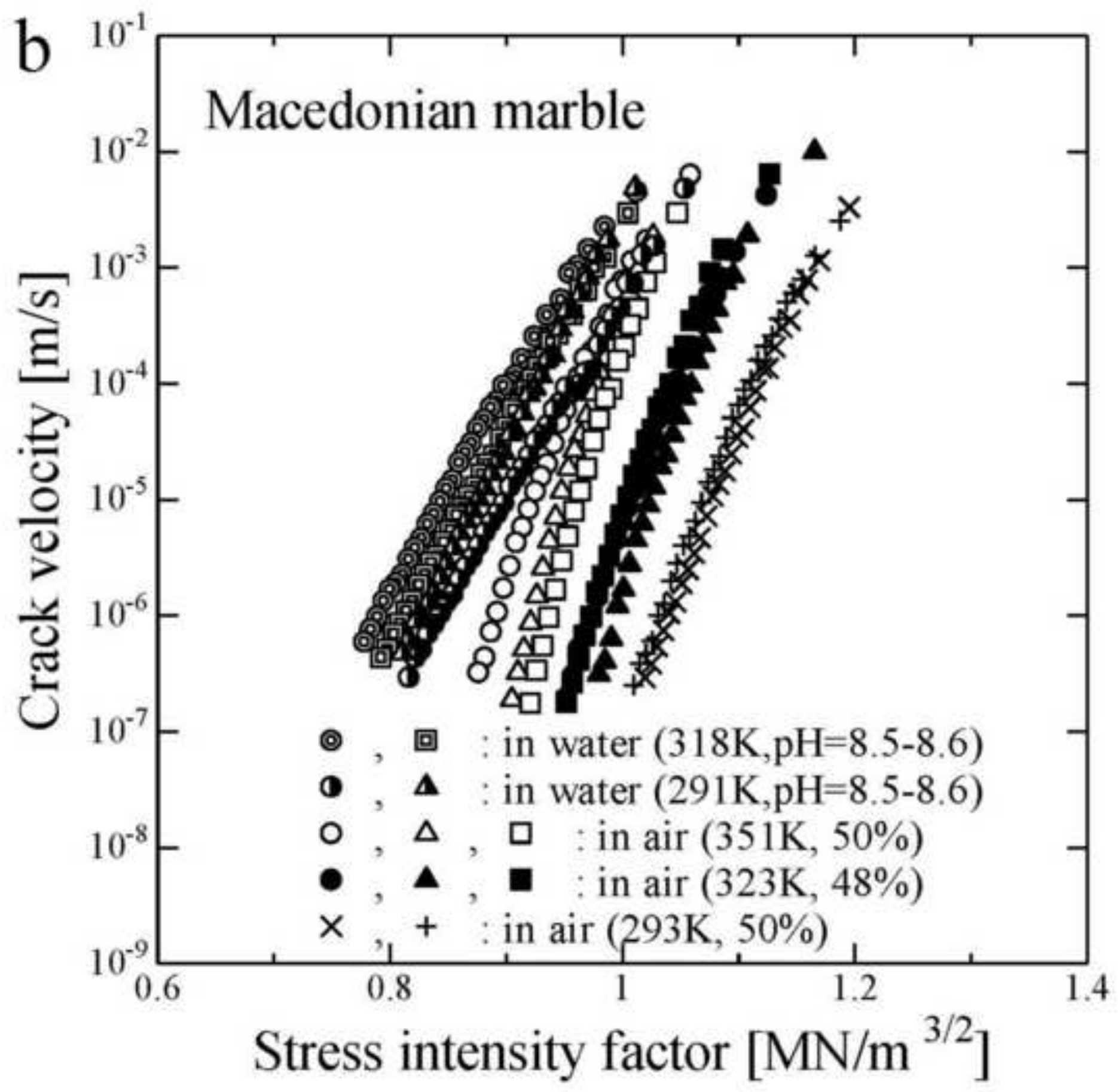




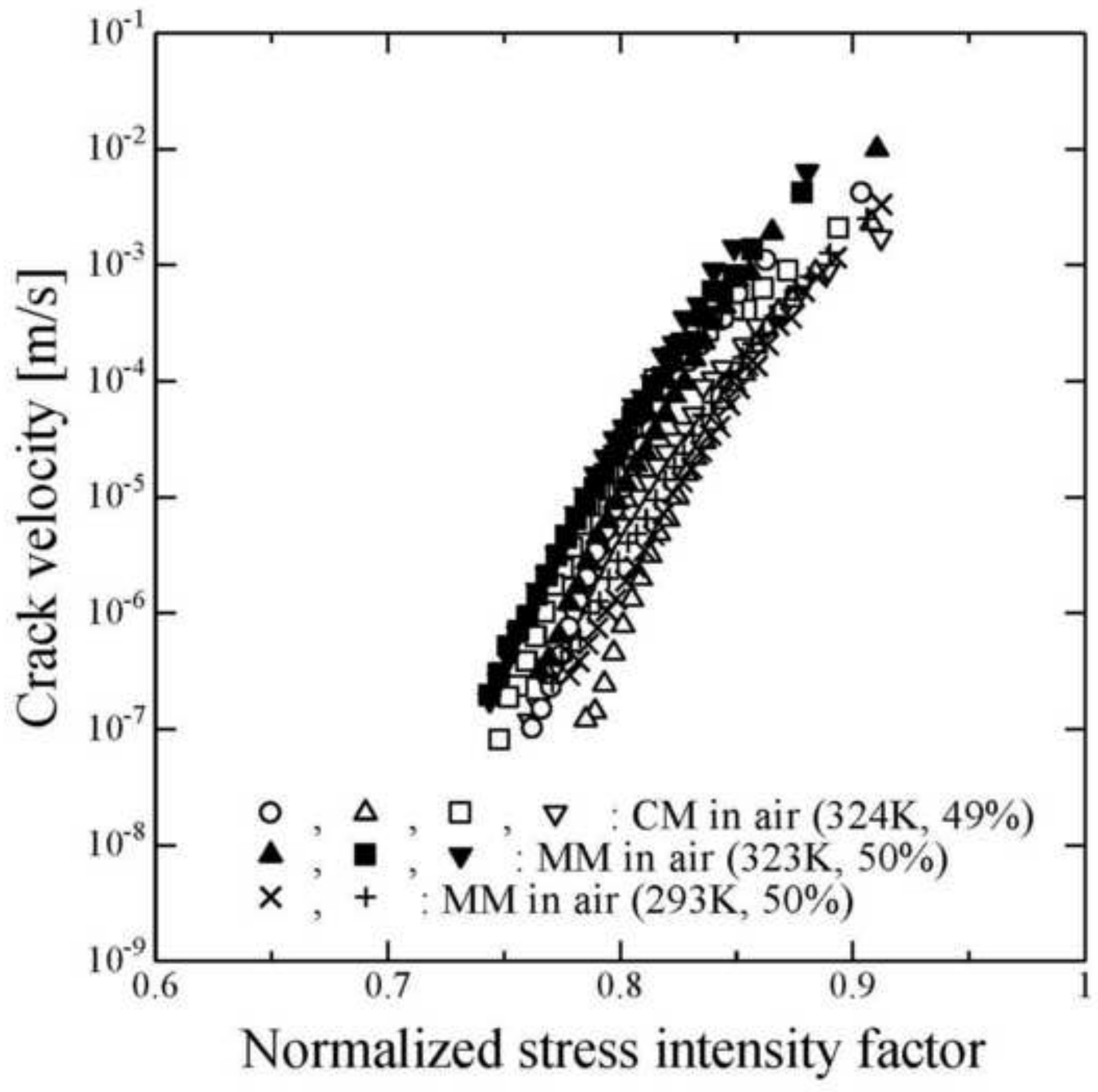




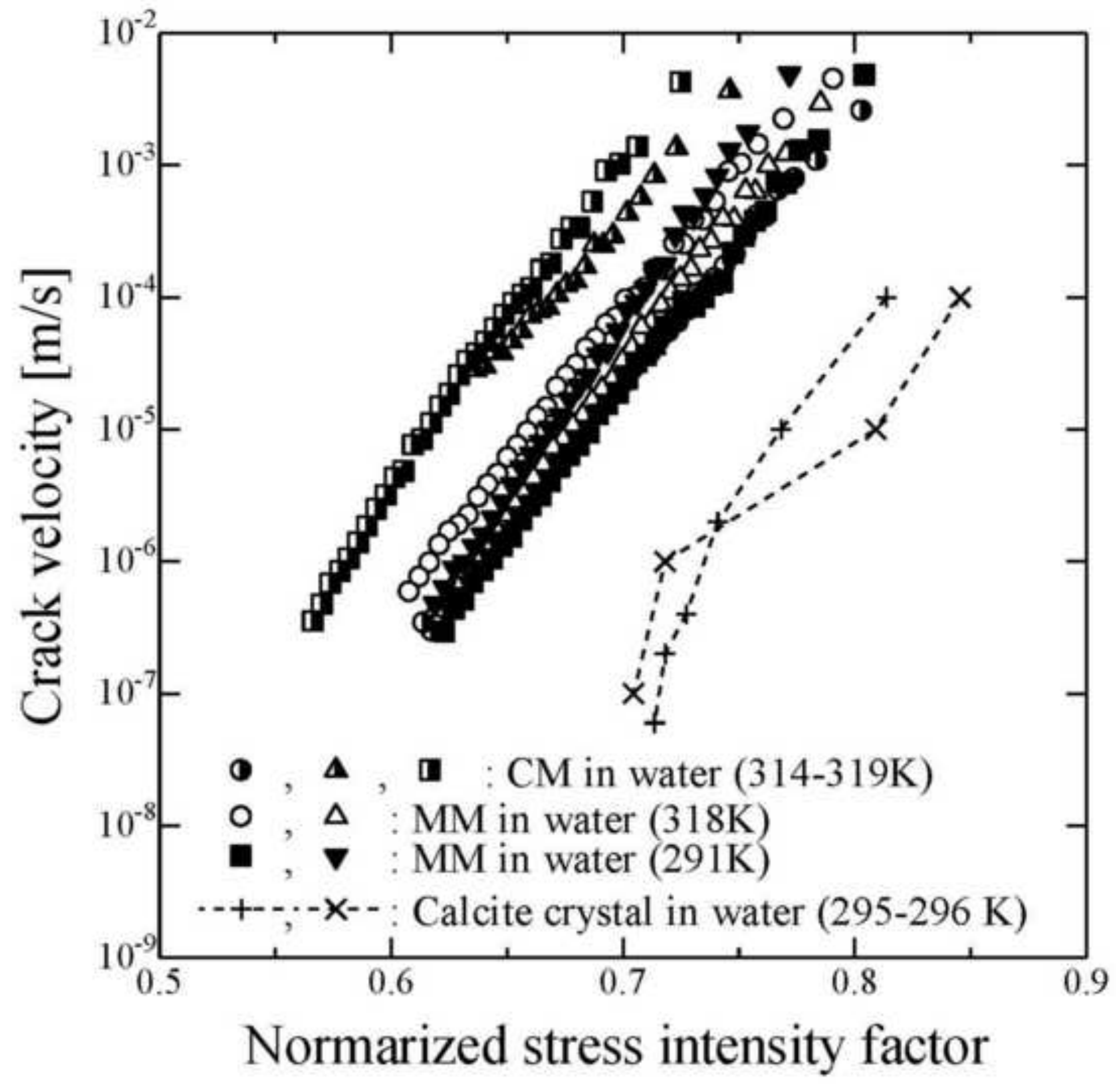


Click here to download high resolution image

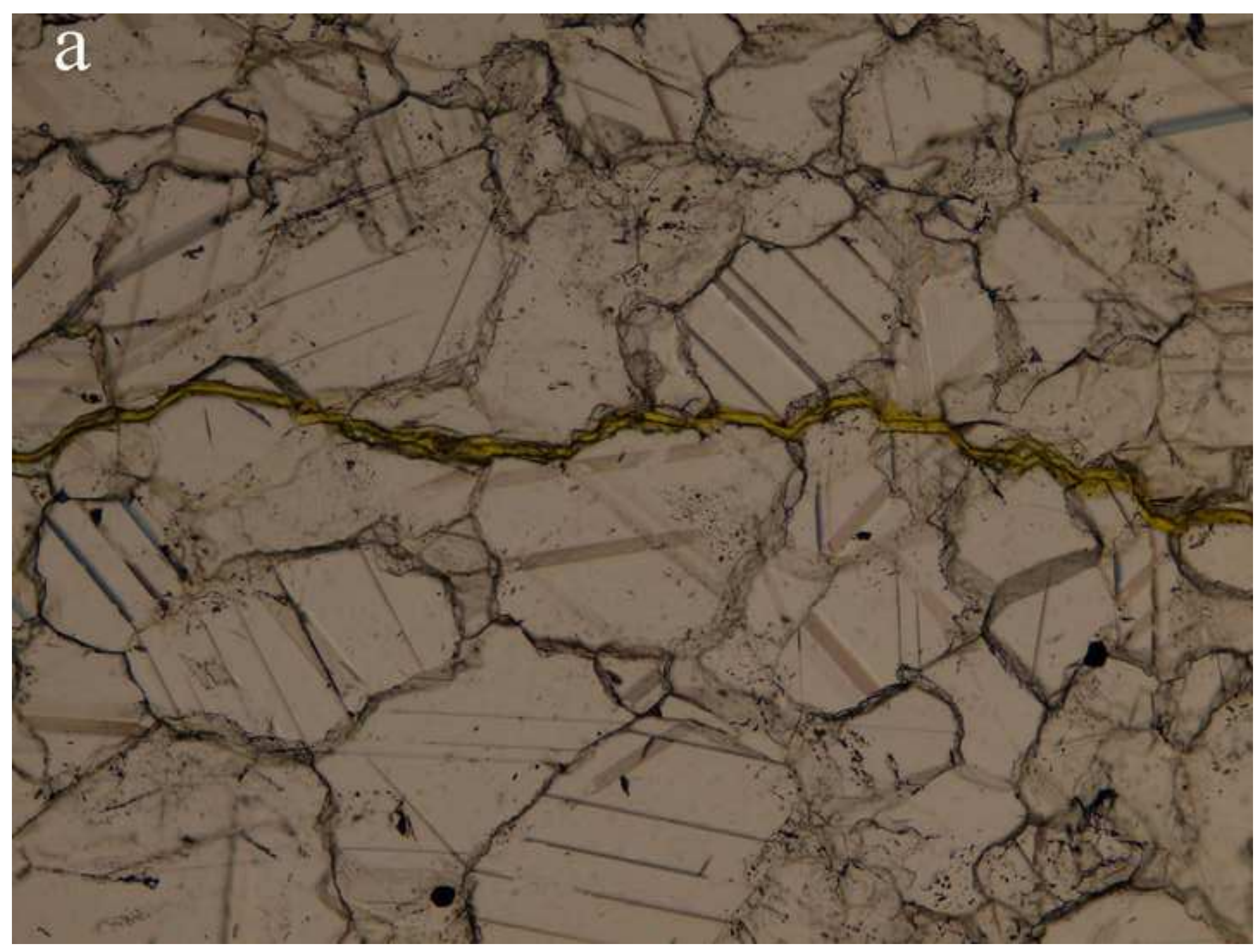


Click here to download high resolution image

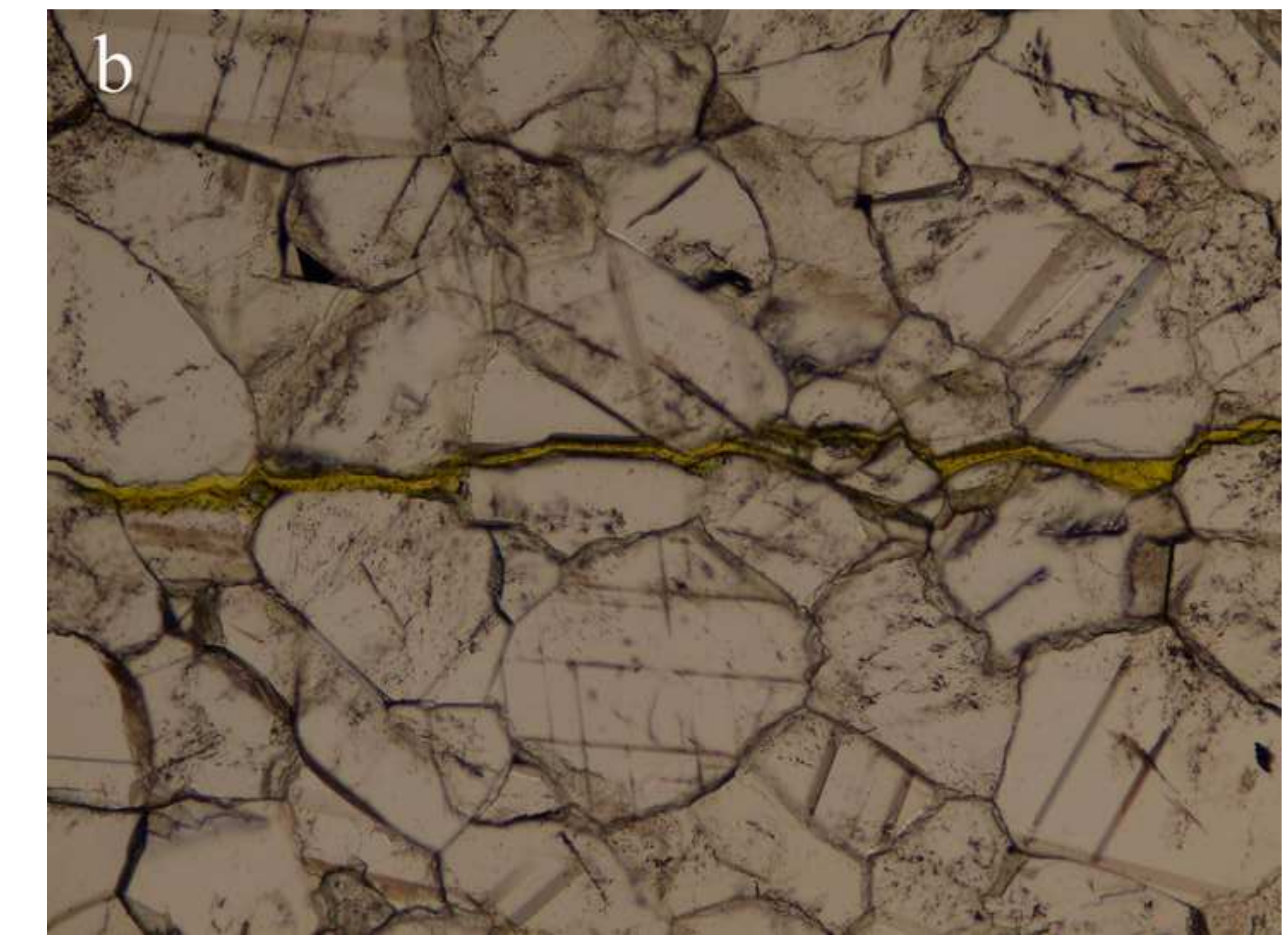




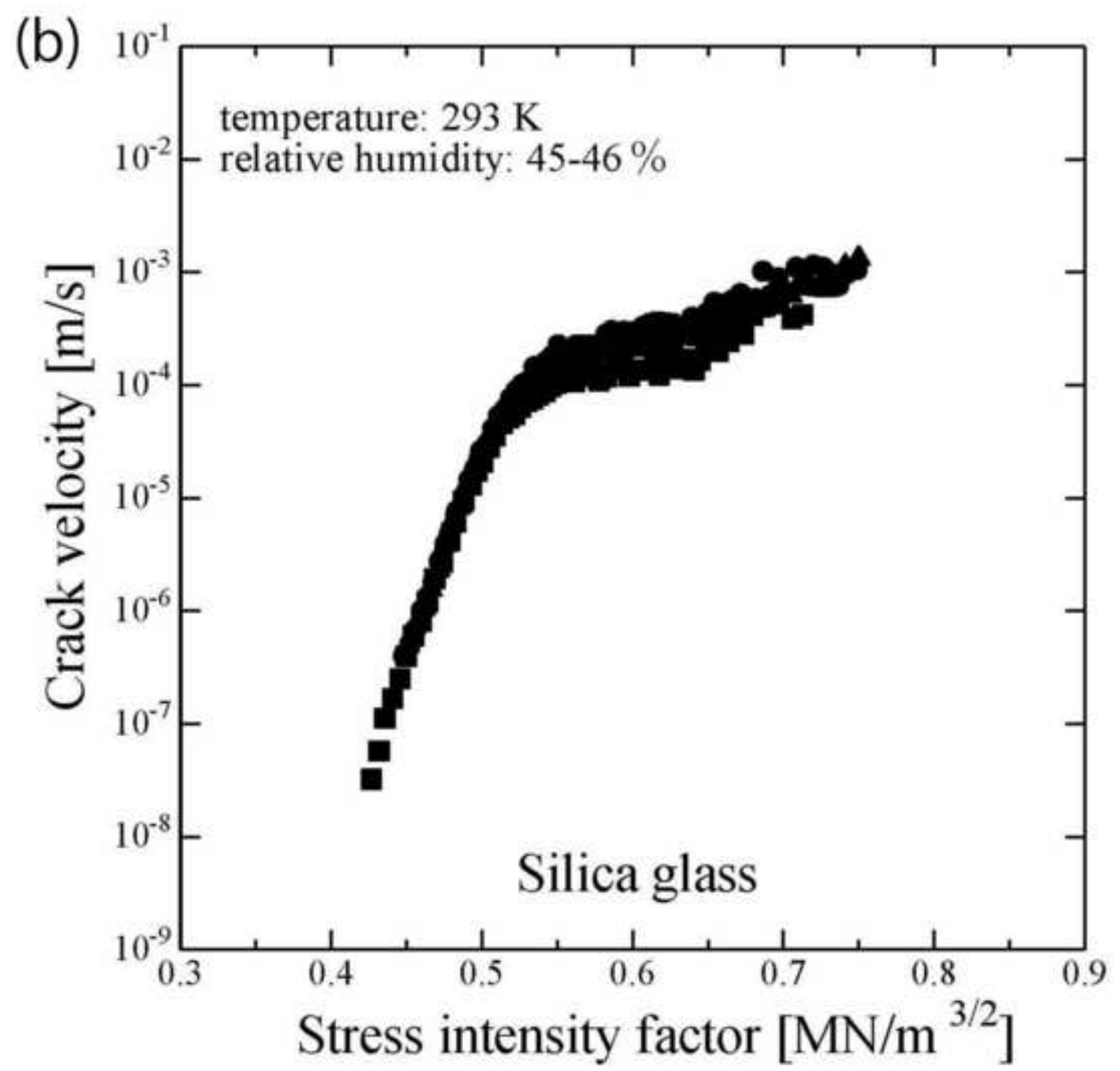


Click here to download high resolution image

\section{$M M-K I_{c}-05$}

\section{$M M-K I_{c}-05$}

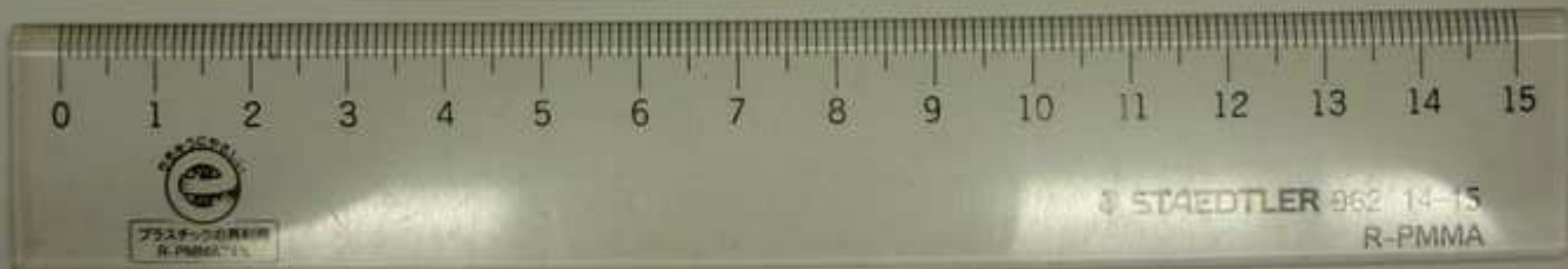




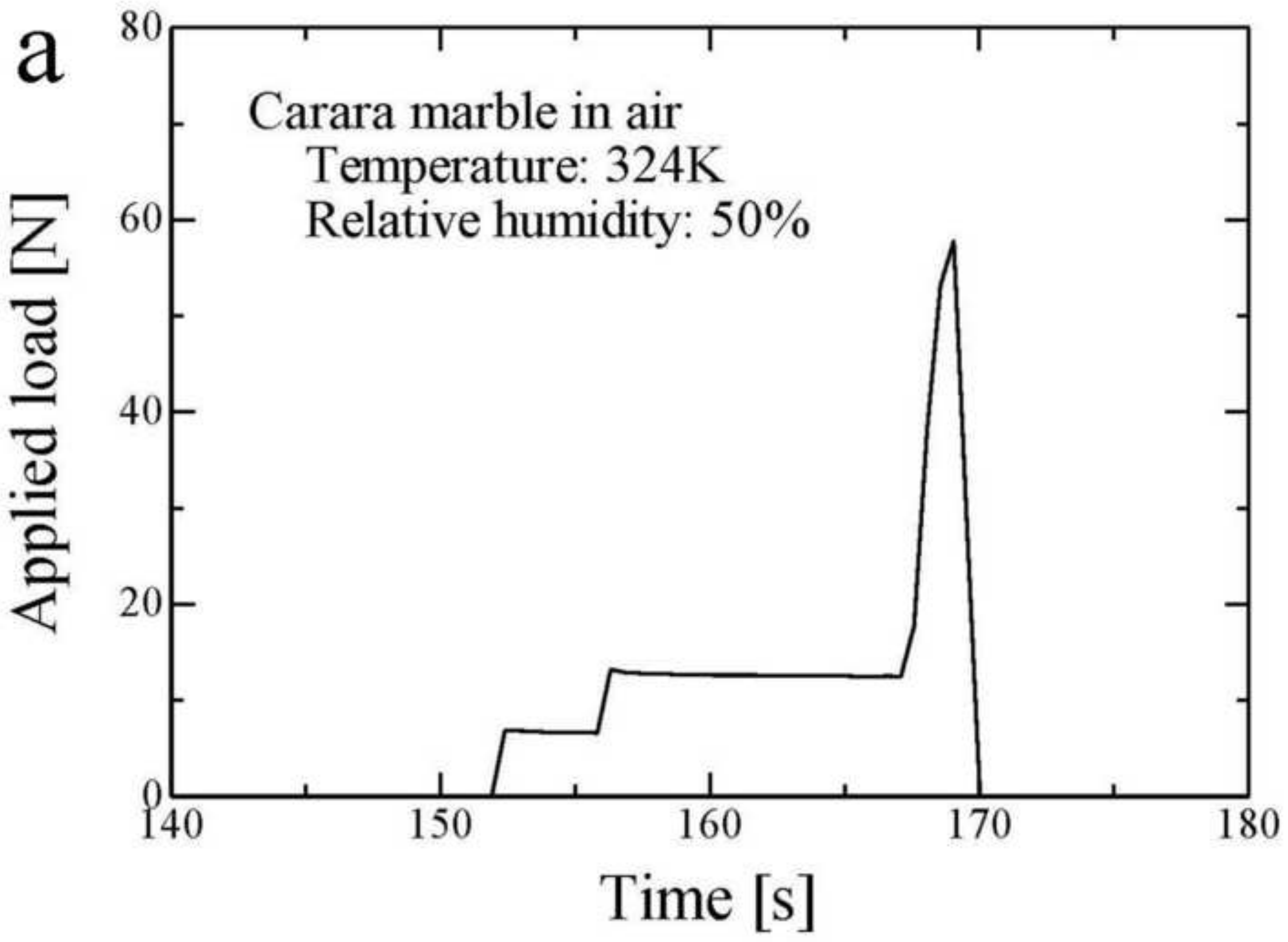




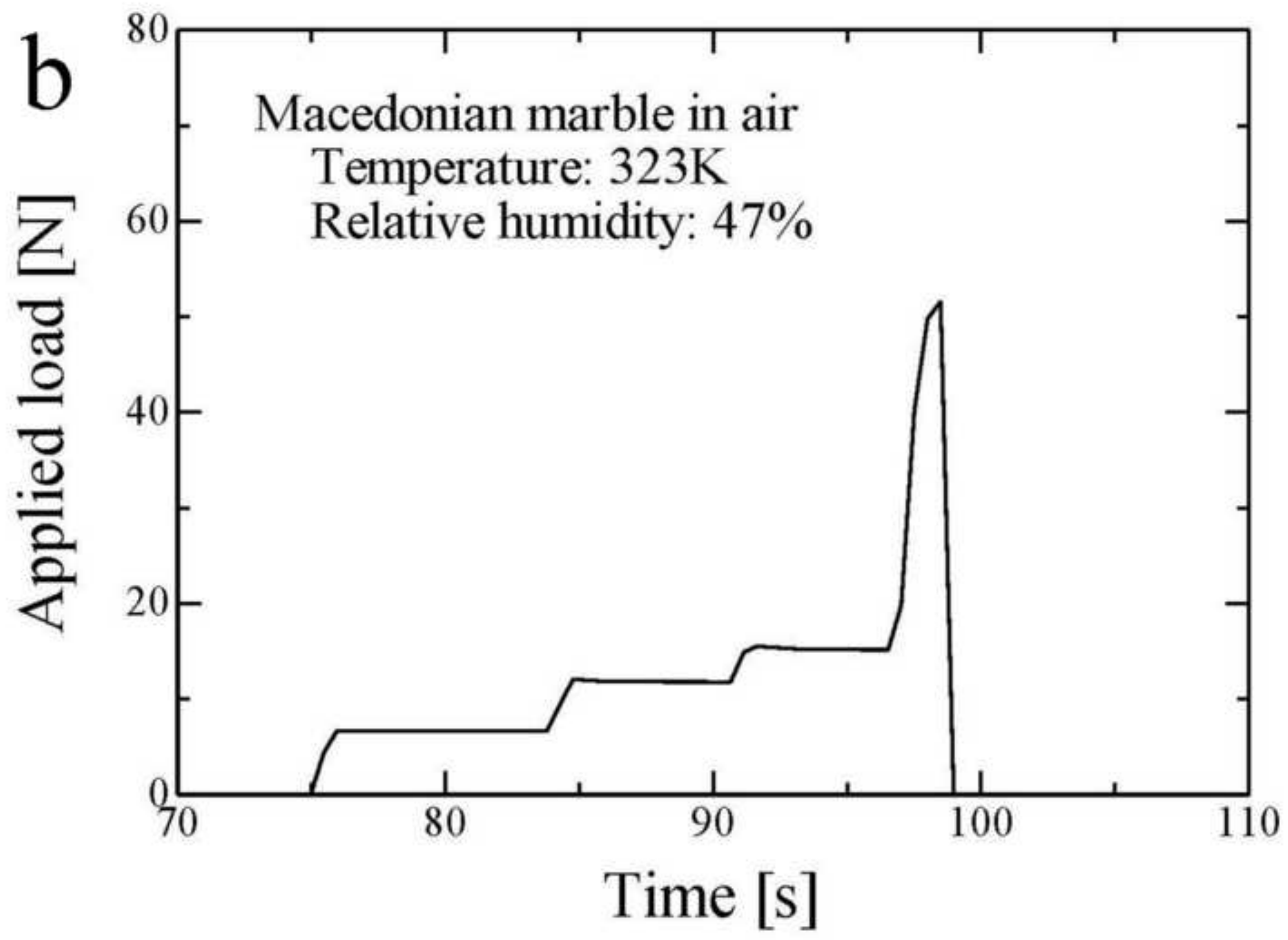




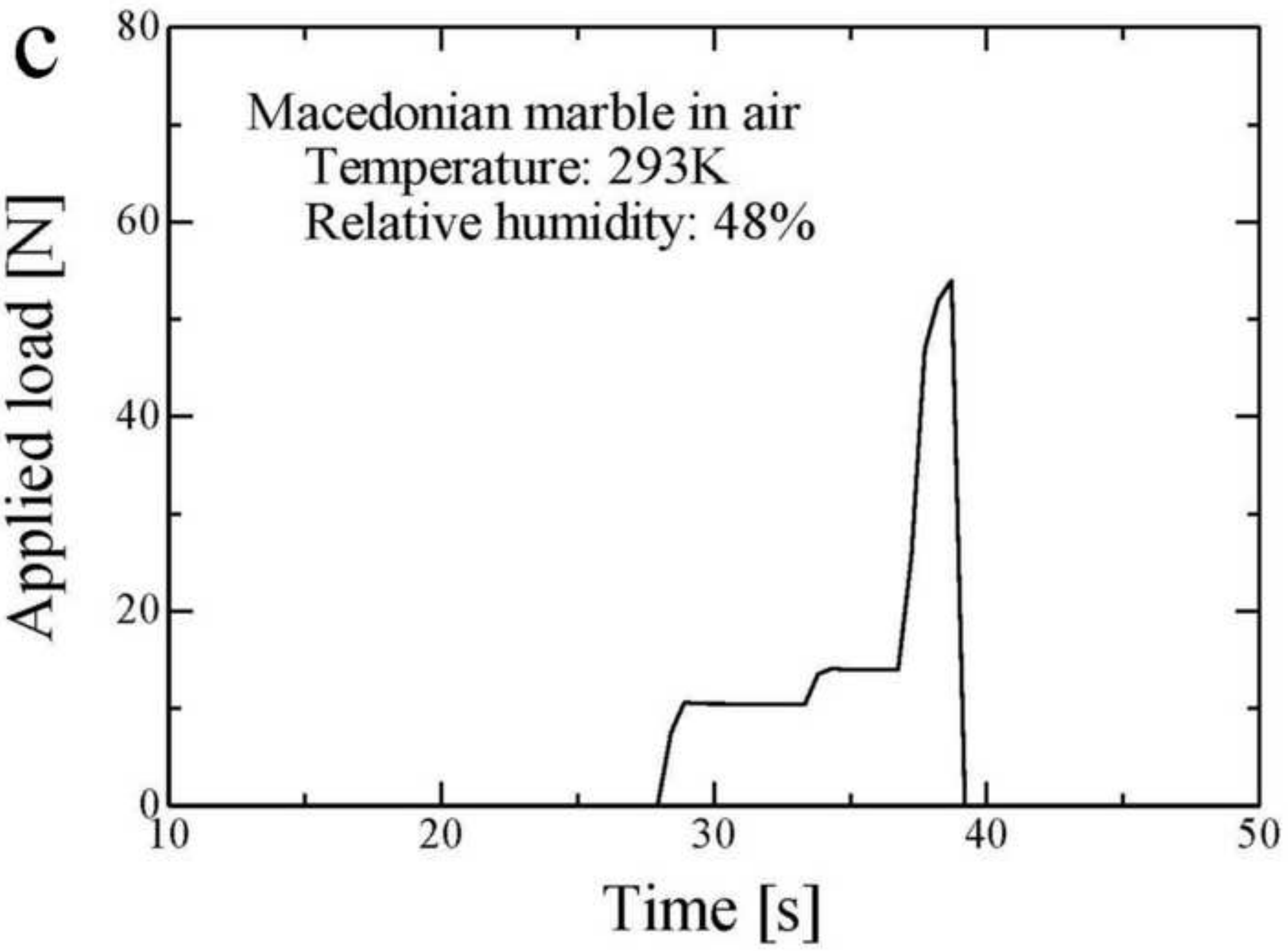

